UNIVERSIDADE DE BRASÍLIA INSTITUTO DE GEOCIÊNCIAS

\title{
ImagEM - Programa de Modelagem 2D para dados TDEM
}

\section{Umberto José Travaglia Filho}

Tese de Doutorado $\mathrm{N}^{0} 29$

Brasília - DF

2016 
UNIVERSIDADE DE BRASÍLIA INSTITUTO DE GEOCIÊNCIAS

Área de concentração:

Geofísica Aplicada

\section{ImagEM - Programa de Modelagem 2D para}

\section{dados TDEM}

\section{Umberto José Travaglia Filho}

Tese de Doutorado $\mathbf{N}^{0} 29$

Banca Examinadora:

Profa. Dra. Mônica Giannocaro Von Huelsen - Orientadora, UnB, IG

Prof. Dr. Welitom Borges - UnB, IG.

Prof. Dr. Giuliano Sant'Anna Marotta - UnB, IG.

Prof. Dr. Carlos Tadeu Carvalho do Nascimento - UnB, Planaltina.

Dr. Marcelo de Lawrence Bassay Blum - Polícia Federal.

Brasília - DF

2016 
Aos meus pais: Umberto José Travaglia e Jocineia do N.S. Travaglia; minhas irmãs: Lorena Travaglia e Mariana Travaglia; meus sobrinhos: Felipe Melo Travaglia e Manuela Travaglia "Tagarela" Campos. 


\section{Agradecimentos}

Ao fim desta etapa de trabalho vejo o quanto mudei e o quanto ainda tenho que mudar. Nenhuma caminhada se faz sozinho e no meu caso não foi diferente. Por isso agradeço a todos que me acompanharam nesta caminhada, mesmo aqueles que acompanharam somente parte dela.

Em primeiro lugar agradeço a Deus por sempre me dar forças para seguir em meus caminhos tortuosos.

Aos meus amigos de faculdade, principalmente os que seguiram comigo no nosso 226 (como diria o B2, “para sempre”), Eduardo Hermínio (Lex), Fernando Lourenço, Flávio Aguiar (d'Caprio), Hugo Dultra, as gêmeas Camila e Julina Baena, Alexandre Hung (China), Cleber Alves Costa (Clebão), Warner, Fábio, Zacarias (Zaca, in memoriam), Eduardo Xavier Seimetz (B2), Vinícius Bueno (Vini), Paulo (Goiano), Diego Nolasco, Edison Benício. Aos técnicos Cláudio Patrazana (Craucrau) e Márcio Maciel (Marção, que hoje me acompanha no doutorado). A Shirley Soares Martins que é um anjo na minha vida. Um grande abraço e agradecimento especial ao amigo/irmão Leonardo de Moura Campos Neto, que caminhou comigo em todos os trabalhos, corujões e a sua esposa Amanda Cruz e ao pequeno Luiz Henrique que esta chegando para alegrar nossas vidas. Aos amigos Pedro Colares R. Luz e sua esposa Fernanda Cruz, a Adriana Oliveira (Drica) e a Fabiana Paiva (Fabi).

A todos os professores do curso de Física da Universidade Católica de Brasília UCB, em especial aos professores Prof. Dr. Paulo Eduardo de Brito (eu vejo uma matriz) e Prof. Msc. Adolfo Dani (não seja canalha com seus alunos), meus ex orientadores Prof. Dr. Sérgio Luiz Garavelli, Prof. Dr. Bernardo Mello.

Aos professores do programa de pós-graduação do Instituto de Geociências, em especial ao prof. Dr. Augusto César Bittencourt Pires (Prof. Pires), ao Prof. Dr. Marcelo 
Peres Rocha (Marcelão) e Prof. Dr. Giuliano Marotta pela valiosa ajuda, o Prof. Dr. Welitom Borges.

Agradeço a todos do Observatório Sismológico de Brasília e do Instituto de Geociências - IG pelo suporte, em especial aos alunos Diogo Farrapo, Iago Santos, ao Prof. Dr. George Sand França (Sandiiiiiiiiii), ao Prof. Lucas Barros, aos amigos Lucas Moreira, Cristiano Chimpliganond e Sidinei pela grande ajuda e conselhos. Aos contemporâneos pós - graduação, Cintia Rocha, Paulo (Codó), Guilherme Ferreira, Pedro Vencovsky, Bruno, Jean Vinícius, Camila Prtz, Chris Busnello Fianco, Marcos Vinícius, Marta H. Jácomo (Martinha), Lavossiane Ferreira Souza, Cassia Peixoto, aos colegas estrangeiros Cristobal Condori Quispe (Perú), Magda Estrela (Portugal), Pereira Neto (Angola). A minha amiga Profa. Aline Tavares M. Coelho Silva. A Capes pela ajuda financeira com a bolsa de pesquisa.

A minha namorada Leilane Souza que mais uma vez me ajudou durante toda a caminhada e por diversas vezes deixou seu tempo livre para me ajudar com o meu trabalho, teve paciência nos meus momentos de ausência e muitas vezes abriu mão do nosso pouco tempo juntos para rever o meu trabalho. Muito obrigado cuidar de mim sem esperar nada em troca... as vezes só um sapatinho.

Ao meu amigo/irmão Sólon Povoa Neto que muito ajudou com as questões computacionais envolvendo o JAVA e o amigo do tempo de ensino médio, hoje Prof. Msc. Jones Yudi Mori Alves da Silva do Departamento de Engenharia Mecânica da UnB que também contribuiu com a parte computacional em JAVA e MatLab.

Agradeço muito a minha família, minhas irmãs Lorena Travaglia e Mariana Travaglia, seus respectivos maridos Rafael Melo e Eduardo Campos, aos meus sobrinhos Felipe Travaglia Carneiro e a Manuela Travaglia Campos que estar por vir. 
Aos meus pais Umberto José Travaglia e Jocinéia do N.S. Travaglia que sempre mantiveram a fé nas minhas decisões e são meus alicerces.

Por último e mais importante agradeço a minha orientadora Profa. Dra. Mônica Giannoccaro Von Huelsen (Moniquinha) que reforçou sua confiança em mim para continuar o trabalho que começamos no mestrado. Nestes últimos quatro anos (e um pouco mais) tivemos que tomar decisões difíceis, mas por mais que fossem difíceis eu sempre confiei no seu instinto, sabedoria e experiência. Tudo que passamos fez com que eu me torna-se um pesquisador e um ser humano melhor. Espero que possamos continuar com vários trabalhos depois deste. Mais uma vez, obrigado de coração! 


\section{Resumo}

Devido ao aumento no número de levantamentos de campo utilizando o Método Eletromagnético no Domínio do Tempo (TDEM), novos programas para processamento deste método foram desenvolvidos. Com o objetivo de contribuir com a aplicação do método, foi desenvolvido o programa ImagEM - programa de modelagem 2D para dados TDEM. O ImagEM possui sub-rotinas para realizar o pré-processamento, processamento (inversão simplificada por meio do método da secante) e imageamento dos perfis do campo secundário, das linhas de contorno da resistividade e da seção da resistividade pela profundidade para dados terrestres e aéreos, além da modelagem do alvo (mergulho, direção e profundidade). Os mapas podem ser obtidos pelo método de Krigagem, ou do Inverso da Distância Ponderada. Nesta tese são apresentados três artigos. No primeiro artigo, foram aplicados dados sintéticos para modelos de duas e três camadas, com a resistividade variando entre 10 e $100 \Omega \cdot m$ e profundidade variando entre 100 e 400m. No segundo artigo, os dados coletados com o equipamento PROTEM (Geonics) foram submetidos ao programa. A área desta coleta foi o complexo Cristalino em Carajás - PA, a inversão recuperou os valores de resistividade que variam entre $1.10^{4}$ e $2.10^{4} \Omega \cdot m$ e profundidade entre 50 e $400 \mathrm{~m}$. Também foi possível descrever as feições das regiões condutivas e a mudança em sua direção. No último artigo, foram utilizados os dados Aeroeletromagnéticos (AEM), sobre a Bacia de San Pedro (EUA), obtidos pelo GEOTEM nas três componentes (x, y e z). Aplicando a transformada de Hilbert sobre as três componentes foi possível calcular o Envelope de Energia. Por meio da razão entre a componente $B z$ e o Envelope de Energia foi possível avaliar os picos de energia e estimar o mergulho, 
a profundidade e a direção (strike) do alvo. Estes resultados foram modelados utilizando a função RDI (Resistivity Depth Image) que apresenta uma imagem da resistividade pela profundidade descrita também pelo programa. Estas informações trouxeram mais detalhes para se realizar a modelagem da subsuperfície condutiva.

\section{Abstract}

Due to the increase of field surveys using Time Domain Electromagnetic Methods (TDEM), new algorithms for data processing have been developed. In order to contribute to the use of TDEM, the program ImagEM - 2D modeling program for TDEM data was developed. The ImagEM has subroutines to execute preprocessing, processing (simplified inversion through the secant method) and imaging of secondary field profiles of resistivity contour lines and depth section resistivity for ground and air data, beyond the target modeling (dip, direction and depth). Maps can be obtained through the methods of Kriging, or Inverse Distance Square. This thesis presents three articles. The first article was applied to synthetic data models with two and three layers, with resistivity ranging from 10 to $100 \Omega . m$ and depth ranging between 100 and $400 \mathrm{~m}$. In the second article the program was submitted to data collected in Carajás using the PROTEM equipment (Geonics), the inversion routine recovered the resistivity values ranging from $1.10^{4}$ and 2.10 $\Omega . m$ and depth values from 50 to $400 \mathrm{~m}$. Also, it was possible to describe the features of conductive regions and the change in its direction. In the last article we use airborne electromagnetic data (AEM) from the Basin of San Pedro (USA), obtained by GEOTEM with three components ( $x, y$ and $z$ ). Applying a Hilbert 
transform on the three component data, it was possible to calculate the energy envelope. Through the ratio of $\mathrm{Bz}$ and the Energy Envelope component it was possible to evaluate the energy peaks and estimate the dip, depth and direction (strike) of the target, these results were confronted with section of RDI also described by the program. These data brought more information to carry out the modeling of the conductive subsurface. 


\section{Sumário}

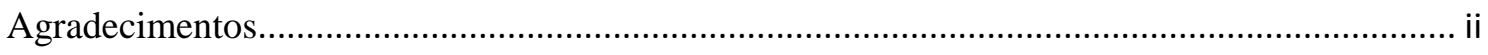

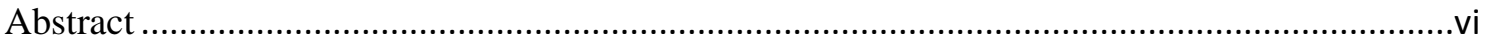

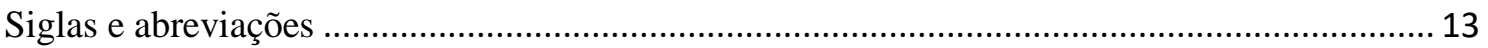

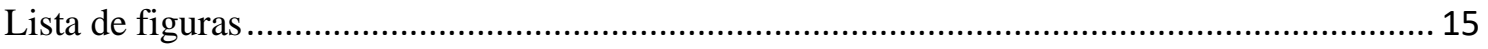

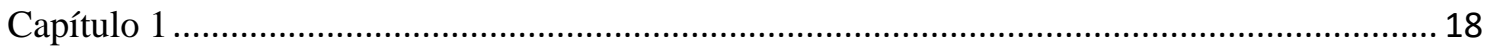

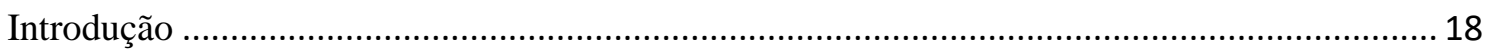

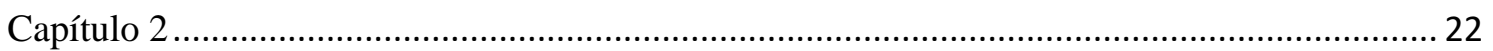

ImagEM: Programa de modelagem 2D de dados TDEM - aplicação a dados sintéticos. .......... 22

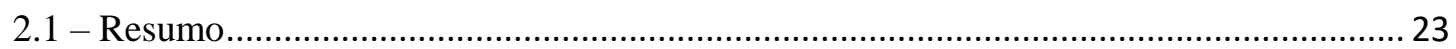

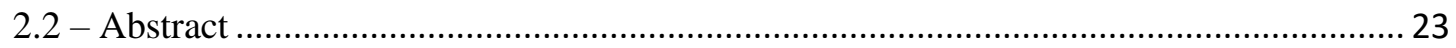

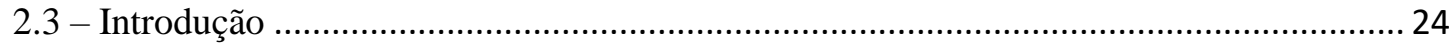

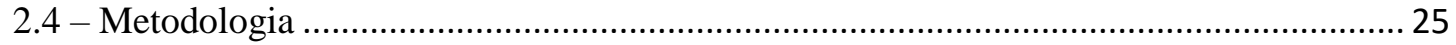

2.5 - O método matemático (Método da Secante) ….................................................................. 25

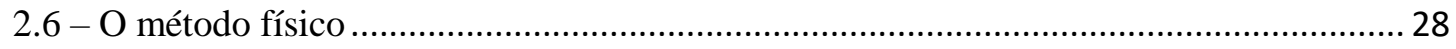

2.6.1- O método Eletromagnético Transiente no Domínio do Tempo - TDEM.................. 29

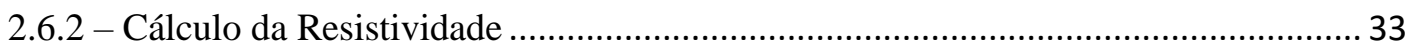

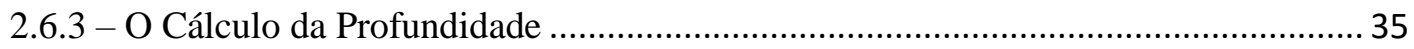

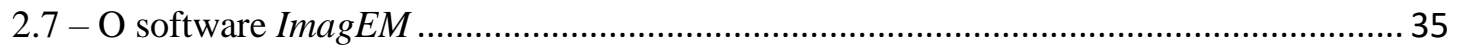

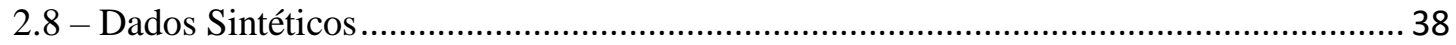

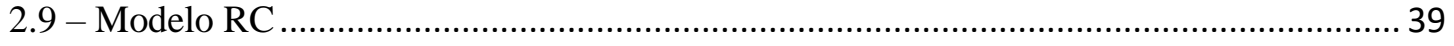

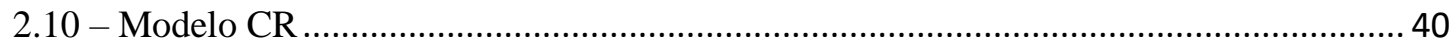

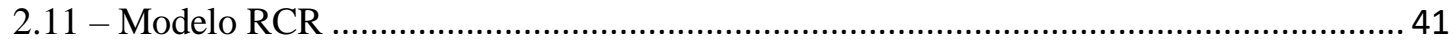

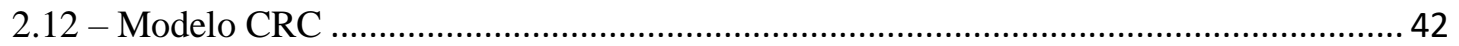

2.13 - Análise dos resultados e conclusão …………………………................................. 43

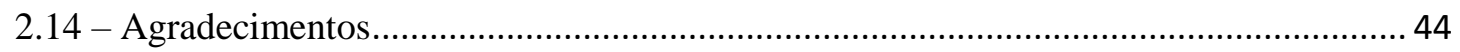

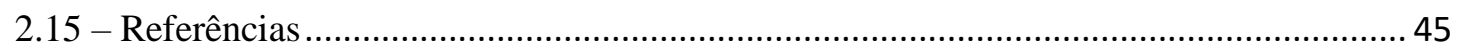

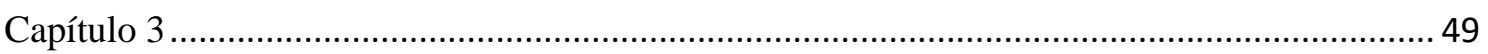

ImagEM - Programa de Modelagem 2D de Dados Eletromagnéticos no Domínio do Tempo com

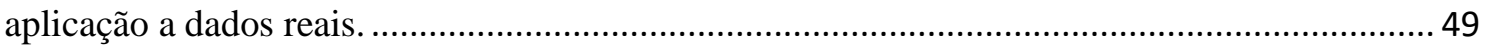

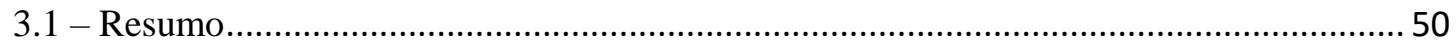

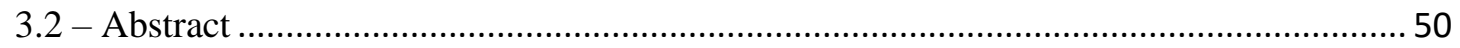

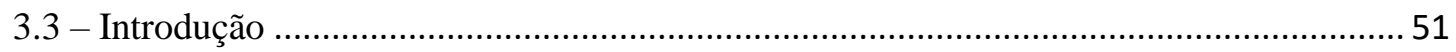


3.5 - Método de Interpolação Gráfica: krigagem..................................................................... 59

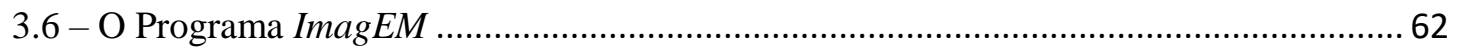

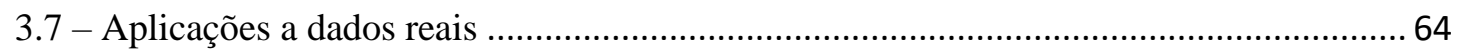

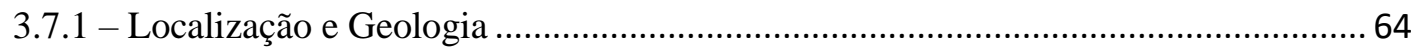

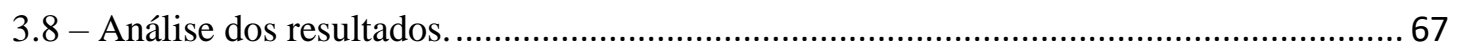

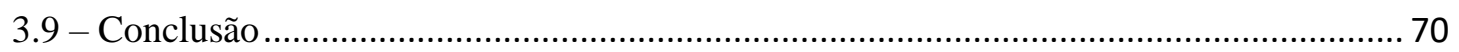

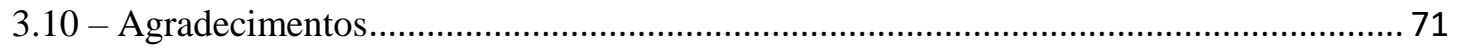

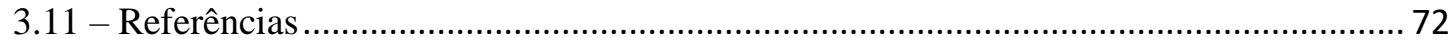

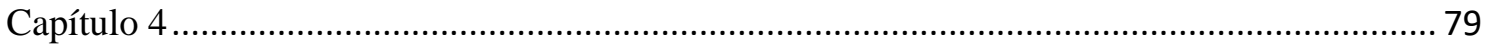

ImagEM - Programa de processamento e inversão de dados eletromagnéticos utilizando as

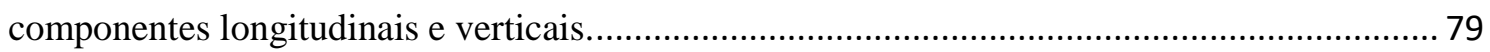

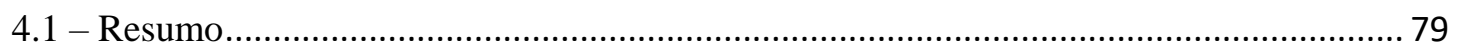

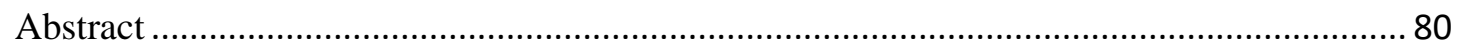

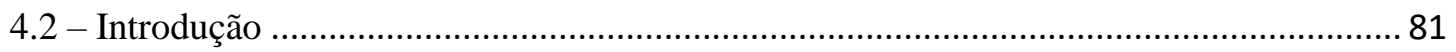

4.3 - Método do Envelope de Energia - Fundamento Teórico ................................................. 83

4.3.1 - Comportamento do Campo Secundário em Camadas ............................................... 83

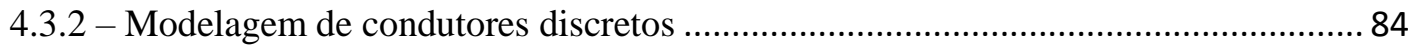

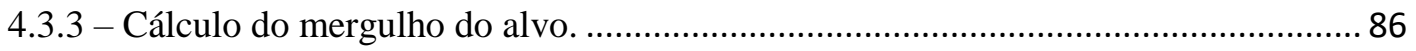

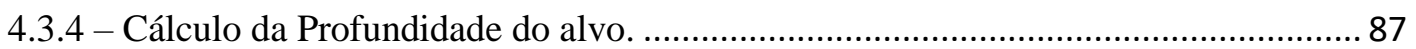

4.3.5 - Determinação da distância (Off Set) e da direção (Strike)....................................... 87

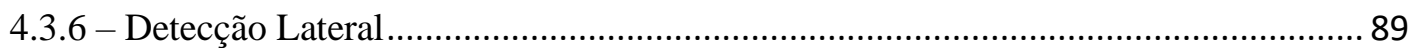

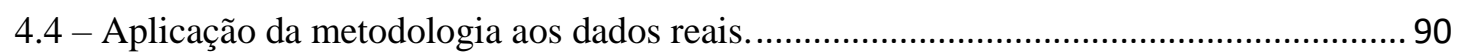

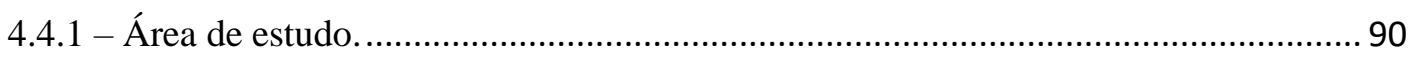

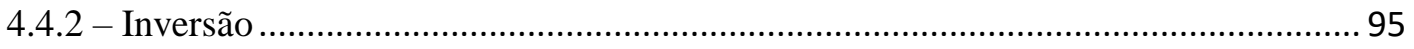

4.4.3 - Seção da resistividade pela profundidade (RDI) ………………………............... 96

4.5 - Desenvolvimento computacional ............................................................................... 99

4.5.1 - Aplicação do Envelope de Energia aos dados do GEOTEM, para o canal 12 da

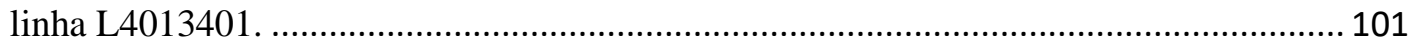

4.5.2 - Aplicação do Energy Envelope: uma modelagem com os canais selecionados.... 105

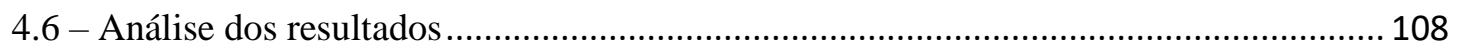

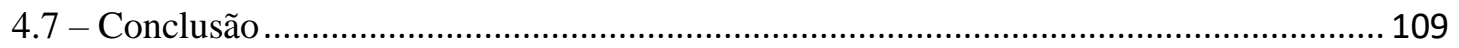

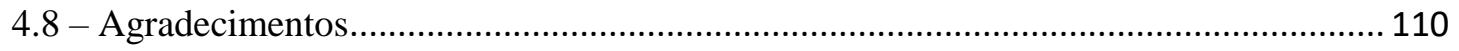

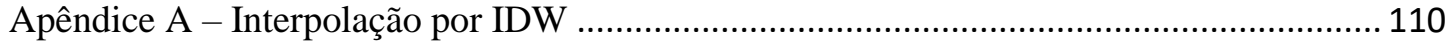

4.9 - Referências Bibliográficas ................................................................................... 112 
Conclusão da Tese. 


\section{Siglas e abreviações}

AEM - Aeroeletromagnético

CDI - Condutivity Depth Image

CPRM - Serviço Geológico do Brasil

CR - Condutivo Resistivo

CRC - Condutivo Resistivo Condutivo

EE - Envelope de Energia

EM - Eletromagnético(s)

IDW - Inverse Distance Weighted - Inverso da Distância Ponderada

LGA - Laboratório de Geofísica Aplicada

NLSTCI (Nonlinear Least-Squares Inversion of Transient Soundings for a Central Induction Loop)

$\mathrm{RC}$ - Resistivo Condutivo

RCR - Resistivo Condutivo Resistivo

RDI - Resistivity Depth Image

TDEM - Time Domain Electromagnetic

TEM - Transient Electromagnetic.

MDT - Média do Desvio do Terreno

$K$ - número de iterações;

$R$ - resto da divisão $k / 2$ (vale 0 ou 1 )

$x$ - logaritmo da $\rho$ (resistividade)

$\vec{\nabla} \cdot \vec{j}$ - vetor densidade de fluxo de corrente $\left(A / m^{2}\right)$

$K$ - número de iterações;

$B(z)$-componente no eixo $\mathrm{z}$

$\sigma-$ a condutividade elétrica $(S / m)$ e

$\vec{E}$ - campo elétrico dado em $(N / C)$

$\rho_{e t}-$ resistividade segundo o tempo inicial

$\rho_{l t}-$ resistividade segundo o tempo final

$r_{T x}-$ raio do transmissor,

$r_{R x}-$ área efetiva do receptor em $\mathrm{m}^{2}$ 
$\rho$ - resistividade

$\Omega \cdot m-$ Ohms metro

$H z-H e r t z$

$U(t)$ - tensao em volts

$M$ - área efetiva da bobina receptora

$\mu_{0}$ - permeabilidade elétrica $\left(H / m^{2}\right)$

$d B_{z} / d t$ - impedância na componente vertical $(z)$

$\mu$ - permeabilidade magnética no vácuo $\left(4 \pi \cdot 10^{-7}\right)$

Tm - momento de dipolo do transmissor

$t$ - tempo médio que cada canal registra o campo secundário em segundos.

$\delta$ - tempo para que o campo primário deixe de atuar em segundos

$a_{t}$ - área da bobina transmissora em $m^{2}$; 


\section{Lista de figuras}

Figura 2. 1 Traçado a secante entre os pontos $\mathrm{f}_{0}\left(\mathrm{x}_{0}\right)$ e $\mathrm{f}_{1}\left(\mathrm{x}_{1}\right)$, encontra-se $\mathrm{x}_{2}$, aplicando novamente o método em $\mathrm{f}_{1}\left(\mathrm{x}_{1}\right)$ e $\mathrm{f}_{2}\left(\mathrm{x}_{2}\right)$, encontra-se o valor de $\mathrm{x}_{3}$ e assim por diante até que o resultado seja dentro do erro pré-definido (Ruggiero, 1996) 27 Figura 2. 2 Comportamento do campo primário e secundário produzidos pela bobina transmissora e receptora (Ogilvy, 1983; Scrivens 2009).

Figura 2. 3 - Esboço do fluxo de corrente num condutor interagindo após desligamento do transmissor. Nos tempos iniciais as interações ocorrem na parte mais rasa e nas bordas do corpo, nos últimos canais as interações ocorrem na parte mais profunda e no interior do corpo, Modificado de Dyck \& West (1984). 32 Figura 2. 4 - a) Comportamento exponencial da tensão para um corpo condutivo e resistivo com o passar do tempo. b) $\mathrm{O}$ afastamento da curva de decaimento da origem indica o aumento da condutividade do corpo em questão. (Nabighian \& Macnae, 1987b).

Figura 2. 5 Interface ImagEM. O TDEM process realiza uma inversão simplificada por meio do método da secante e o RDI gera uma seção da resistividade pela profundidade,

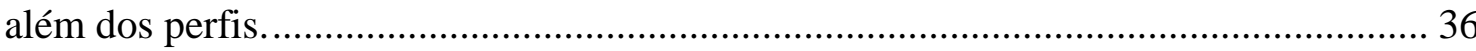
Figura 2. 6 - TDEM process Interface. Sub-rotina para processar dados TDEM. O primeiro painel são os dados do arquivo de entrada, o segundo painel são as configurações usadas no equipamento.

Figura 2.7 a) Representação do modelo sintético de duas camadas RC; 2.7b) RDI modelo com os valores da resistividade obtida pelo ImagEM. ................................... 39 Figura 2.8 a) Representação do modelo sintético de duas camadas CR; 2.8b)RDI obtida no ImagEM para o modelo condutivo(C) resistivo (R)........................................... 40 Figura 2. 9a) Representação do modelo sintético de três camadas RCR; 2.9b)RDI obtida no ImagEM, para o modelo RCR.

Figura 2. 10 a) Representação do modelo sintético de três camadas CRC.; 2.10b) RDI obtida no ImagEM para o modelo de CRC.

Figura 3. 1 - Princípios do método TEM. (a) Comportamento da corrente no circuito transmissor. (b) Força eletromotriz induzida no terreno, e (c) Campo magnético secundário captado na bobina receptora. Para levantamento com bobinas centralizadas (Christiansen et al., 2009) . 54

Figura 3. 2 - Curva de decaimento gerada pela sub-rotina Handler PROTEM Data do ImagEM, os dados são apresentados em $m V \times m s$. a) Curva de decaimento apresentada em formato $\log -\log$; b) A curva de decaimento apresentada em formato $\log Y$. 56

Figura 3. 3 - Comportamento exponencial da tensão para um corpo condutivo (curva azul) e resistivo (curva vermelha) com o passar do tempo. O decaimento da curva resistiva é mais rápido e acentuado em relação a curva condutiva (Adaptado de Nabighian \& Macnae, 1987) 57 Figura 3. 4 Interface ImagEM. A sub-rotina TDEM process realiza uma inversão simplificada por meio do método da secante e a função RDI gera perfis, linhas de contorno além de um mapa de resistividade. 
Figura 3. 5 - Interface da função RDI. Sub-rotina para gerar uma imagem da resistividade pela profundidade.

Figura 3. 6 - Localização do depósito cristalino em Carajás (Almeida Jr. et al., 2011) 64 Figura 3. 7 - Mapa geológico do Depósito Cristalino e as estações pesquisadas em cada linha do levantamento (Melo et al., 2014).

Figura 3. 8 -Linha L-300, do levantamento EM realizado com o PROTEM no Depósito de Carajás. Fig. 3.8a O sinal do perfil para os canais de 1 a 7. Fig. 3.8b perfil entre os canais 9 e 15, Fig. 3.8c perfil entre os canais 17 e 20. Fig. 3.8d Linhas de contorno da linha $L-300$. Fig. 3.8e RDI da linha $L-300$. 68

Figura 3. 9 - Linha L-1700, do levantamento EM realizado com o PROTEM no Depósito de Carajás. Fig. 3.9a O sinal do perfil da linha $L-1700$ para os canais de 1 a 7. Fig. 3.9b perfil entre os canais 9 e 15, Fig. 3.9c perfil entre os canais 17 e 20. Fig. 3.9d Linhas de contorno da linha $L-1700$. Fig. 3.9e RDI da linha $L-1700$.

Figura 4.1 - As curvas de resposta de Bz (linha preta) e $B x$ (linha azul tracejada) do canal 10 registrados pelo levantamento utilizando o GEOTEM. O nível de ruído de 30 ppm é considerado um valor típico em ambas as componentes. (adaptado de Smith \& Keating, 1996). $\quad 84$

Figura 4. 2- Sinal do canal 10 registrado pelo GEOTEM. A componente $B z$ (preto) representa os dados coletados, A componente detrend $(B z)$ (vermelho) representa o mesmo dado com a retirada da tendência. 86

Figura 4. 3 - Gráfico da amplitude do campo na componente vertical normalizado pelo $E E$. Obtendo-se a Razão (R) e a distância $|\Delta p e a k s|$ entre os picos de energia é possível calcular o mergulho e a profundidade do corpo alvo utilizando as equações 4.3 e 4.4 respectivamente (modificado de Smith \& Keating, 1996).

Figura 4. 4 - À esquerda o diagrama esquemático de uma placa condutora em plano vertical e o fluxo magnético do campo secundário. À medida que a aeronave se afasta da placa o campo magnético na componente By torna-se mais intenso (Smith \& Keating, 1996). À direita vista de cima da linha de voo e da placa condutora. .............. 88 Figura 4.5 - Diagrama esquemático mostrado a variação do ângulo de Strike $\varphi\left(45^{\circ}, 70^{\circ}\right.$ e $90^{\circ}$ ) em relação à linha do voo tomando a direção do eixo " $x$ " como referencial....... 89 Figura 4. 6 - Localização da área. O retângulo vermelho delimita a área do levantamento aeroeletromagnético (Von Huelsen, 2007). ........................................... 91

Figura 4. 7- Formação esperada da Bacia de San Pedro (Von Huelsen, 2007). ............ 92 Figura 4. 8- Linhas de voo do levantamento aéreo realizado pelo GEOTEM, com destaque para as linhas L40112901, L4013001, L4013101, L4013201, L4013301, L4013401 e L4013501. 93

Figura 4. 9 - Mapa da componente $\mathrm{Z}$ do campo secundário do canal 12, no quadrado em branco está a região condutiva cortada pelas linhas L4012901, L4013001, L4013101, L4013201, L4013301, L4013401 e L4013501 dentro da Bacia de San Pedro. 94 Figura 4. 10 - Mapa da componente $X$ do campo secundário do canal 12, no quadrado em branco está a região condutiva cortada pelas linhas L4012901, L4013001, L4013101, L4013201, L4013301, L4013401 e L4013501 dentro da Bacia de San Pedro 
Figura 4. 11 - Mapa da componente Y do campo secundário do canal 12, no quadrado em branco está a região condutiva cortada pelas linhas L4012901, L4013001, L4013101, L4013201, L4013301, L4013401 e L4013501 dentro da Bacia de San Pedro

Figura 4. 12 - Interface da função $R D I$ aplicando o interpolador $I D W$, acima os parâmetros de entrada e abaixo os histogramas bruto à esquerda e equalizado à direita.

Figura 4. 13 - Resultados da Linha L4013401, (13a) perfis dos canais de 1 a 15 dados em $m V$. (13b) Seção da $R D I$ interpolada pelo método $I D W$ com célula de $25 \mathrm{~m}$. (13c) Superfície com as linhas de contorno de resistividade aparente.

Figura 4. 14- Interface do ImagEM. O painel TDEM, refere-se ao processamento no domínio do tempo. O Envelope de Energia é uma das funções deste método. 100 Figura 4. 15- Interface do Energy Envelope. Considerando o banco de dados de entrada, o usuário coloca os números das colunas que constam: o número da linha do levantamento, a distância, as coordenadas (x e y) e as componentes dos campos magnéticos medidos ( $B x$, By e $B z)$.

Figura 4. 16 - Campo secundário $B x$, $B y$ e $B z$, de cima para baixo respectivamente, pela distância em metros. 101

Figura 4. 17- Perfis do Envelope de Energia (EE) para a linha L4013401. 102 Figura 4.18 - (18a) Perfis $B z / E E$ (Vermelho em linha sólida) e $B x / E E$ (Azul em linha tracejada), os quadrados em azul demonstram a marcação dos picos de energia. Tomando como base a marcação destes picos de energia foi possível calcular o mergulho e profundidade. (18b) $B x, B y, B z$ e o EE do canal 12 da linha L4013401... 102 Figura 4. 19 - Gráfico da razão dos picos das amplitudes pelo ângulo de mergulho calculado para o canal 12, linha L4013401. 103 Figura 4. 20 - Gráfico da distância entre os picos das amplitudes pela profundidade do topo do corpo para o canal 12, linha L4013401. 104 Figura 4. 21 - (21a) Perfil do campo secundário By e By pela distância; em azul os dados reais e em vermelho os valores calculados (eq. 4.5). (21b) Curva representativa da função trigonométrica da equação 4.8. O eixo das ordenadas é o ângulo da direção do alvo (Strike) e o círculo azul é o strike calculado para o canal 12. 105 


\section{Capítulo 1}

\section{Introdução}

O estudo do Método Eletromagnético aplicado à geologia teve seu início no começo dos anos 50 com o artigo de Wait (1951) e descreve uma aproximação do campo secundário em fase e quadratura para uma esfera condutora em subsuperfície. A partir deste ano muitos investimentos foram feitos no que se refere a equipamentos como o PROTEM, o GTEM e o TEM57-MK2 da Geonics, os equipamentos da Geophysical Survey Systems, Inc. (GSSI) como o StructureScan Standard, o Profiler e o UtilityScan Pro, ou mesmo os T3, T4 e MTU da Phoenix entre outros.

Também foram desenvolvidos programas por estas empresas como o DAT, o GSPX7 da Geonics e o IX1D, distribuído gratuitamente pela INTERPEX e indicado pela Geonics. O REFLEX da GSSI para processamentos de GPR, o SSMT2000 e da Phoenix destinado a levantamento magnetotelúricos, além é claro do WinGlink, que hoje pertence a Schlumberger e em sua licença completa tem a capacidade de reconhecer um leque extenso de formatos de arquivos para diversos equipamentos e métodos geofísicos.

Tendo em vista o crescente investimento computacional aplicado à geofísica, este trabalho tem como objetivo apresentar o programa ImagEM - Programa de Inversão $2 D$ de dados TDEM, bem como os resultados obtidos e as adaptações do método utilizando a lógica computacional. Todo o código foi desenvolvido na plataforma MATLAB da MathWorks devido a sua vasta biblioteca matemática e gráfica.

Neste trabalho foram apresentados três artigos em que os dados foram submetidos a quatro etapas. A primeira etapa é o pré-processamento, a segunda o processamento, a terceira o imageamento de resultados e última etapa consiste em 
modelar o corpo alvo. A função de pré-processamento Handler Protem Data foi formatada aos moldes da extensão do arquivo .TMP do PROTEM, esta função separa os dados de uma, ou três componentes, quando houver, realiza a média dos valores do campo secundário e correlaciona os valores de tensão com a localização da medida bem como a sua distância com relação à origem da linha do levantamento; estes dois últimos constam em outro arquivo. Para finalizar a função confecciona as curvas de decaimento de cada estação.

O TEM process e o GeoTEM process são funções responsáveis pela segunda etapa. O processamento dos dados é realizado por meio de uma inversão utilizando o método da secante, este método calcula a resistividade aparente e profundidade, sendo a primeira função para dados terrestres e a segunda destinada a dados aéreos.

A terceira etapa fica a cargo da função gráfica Resistivity Depth Image - RDI, que é responsável pelo imageamento dos dados, e é capaz de gerar perfis do campo secundário, o mapa com linhas de contorno da resistividade e uma seção da resistividade pela profundidade com dois métodos de interpolação, a krigagem e o Inverso da Distância Ponderada (Inverse Distance Weighted - IDW).

A quarta etapa, que proporciona uma modelagem do alvo, o ImagEM fornece a função Energy Envelope que é destinada ao processamento de dados com três componentes e por meio destas componentes calcula o Envelope de Energia (EE). Com estas informações é possível estimar a profundidade, o mergulho e a direção (strike) da região condutiva.

O segundo capítulo desta tese foi destinado a apresentação do ImagEM e seu teste de validação utilizando dados sintéticos. Para a validação do TDEM process foram utilizados dados sintéticos gerados pelo programa Nonlinear Least-Squares Inversion of Transient Soundings for a Central Induction Loop (NLSTCI). Foram modelados 
ambientes geológicos de duas e três camadas de forma alternada, Resistiva - Condutiva (RC), Condutiva - Resistiva (CR), Resistiva - Condutiva - Resistiva (RCR) e Condutiva - Resistiva - Condutiva (CRC). Os dados foram processados utilizando a função TDEM process. Os resultados foram apresentados em seções da resistividade pela profundidade gerada pela função gráfica RDI. Assim foram utilizadas a primeira, segunda e terceira etapas descritas.

O terceiro capítulo trata da pesquisa de campo em Carajás - PA, no complexo Cristalino realizado pela Vale S.A.. Os mesmos procedimentos submetidos aos dados sintéticos foram também submetidos aos dados adquiridos neste levantamento. Os dados do levantamento foram processados por meio do TDEM process e a resposta do levantamento foi imageada pela função gráfica RDI. Além da seção da imagem da resistividade pela profundidade foram incluídos os perfis, do campo secundário, separados de acordo com a ordem de grandeza para melhor visualização e por fim o mapa de contorno da resistividade. O levantamento TDEM foi adquirido pelo EM57 transmiter e o PROTEM da Geonics. Esta região possui potencial econômico de interesse na exploração de cobre $(\mathrm{Cu})$, níquel $(\mathrm{Ni})$, ouro $(\mathrm{Au})$ e metais nobres.

O quarto capítulo aborda o levantamento aeroeletromagnético (AEM) sobre a Bacia de San Pedro (EUA). Este levantamento foi realizado pela Fugro utilizando a plataforma GEOTEM da empresa Geoterrex que ao realizar a pesquisa registrou o campo magnético secundário das três componentes $(B x, B y$ e $B z)$. Estas componentes foram submetidas à função Energy Envelope do ImagEM, esta função aplica sobre os dados a transformada de Hilbert e calcula o Envelope de Energia (EE). Por meio da razão da componente $B z / E E$ o programa plota os picos de energia e a partir da distância entre estes picos de energia e a razão entre os mesmos é possível estimar a profundidade 
e o mergulho do corpo alvo, além da angulação entre a linha de voo e a posição do corpo. 


\section{Capítulo 2}

\section{ImagEM: Programa de modelagem 2D de dados TDEM -}

\section{aplicação a dados sintéticos.}

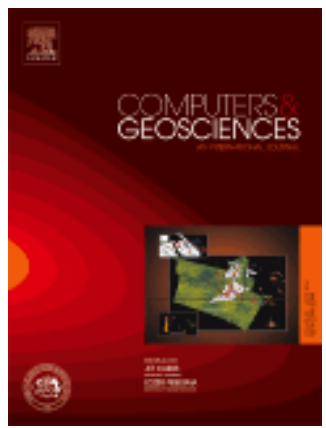

\begin{tabular}{|r|l|}
\hline Jornal: & Computers \& Geosciences \\
\hline Manuscript ID: & CAGEO-D-16-00158 \\
\hline Date submitted by author: & $25 / 02 / 2016$ \\
\hline Complete Listo f Authors: & Umberto José Travaglia Filho, Mônica G. Von Huelsen \\
\hline Keywords: & $\begin{array}{l}\text { electromagnetic modeling, inversion, development } \\
\text { program }\end{array}$ \\
\hline Area of Expertise: & \\
\hline
\end{tabular}

Ms. Ref. No.: CAGEO-D-16-00158

Title: ImagEM: 2D modeling program TEM data - application to synthetic data.

Computers \& Geosciences

Dear Mr. Travaglia Filho,

Your submission entitled "ImagEM: 2D modeling program TEM data - application to synthetic data." has been assigned the following manuscript number: CAGEO-D-16-00158.

You may check on the progress of your paper by logging on to the Elsevier Editorial System as an author. The URL ishttp://ees.elsevier.com/cageo/.

Your username is: umberto.travaglia@gmail.com

If you need to retrieve password details, please go

to: $\underline{\text { htp: }: / / e e s . e l s e v i e r . c o m / C A G E O / a u t o m a i l ~ q u e r y . a s p ~}$

Please contact us if you have not received a report within 4 months of the date on this letter.

Thank you for submitting your work to this journal.

Kind regards,

Computers \& Geosciences 


\title{
ImagEM: Programa de modelagem 2D de dados TDEM -
}

\section{aplicação a dados sintéticos.}

\author{
Umberto José Travaglia Filho $^{1}$, Mônica G. Von Huelsen ${ }^{1}$ \\ 1 - Universidade de Brasília - UnB, Instituto de Geociências - IG
}

\section{1 - Resumo}

Este trabalho tem como objetivo apresentar o software ImagEM, que foi desenvolvido com a finalidade de processar dados eletromagnéticos no domínio do tempo para levantamentos com bobinas centralizadas. O software utiliza uma inversão simplificada aplicando o método da secante. Este método tem se demonstrado confiável para uma análise qualitativa dos resultados e por ser ágio em seu processamento. Com base no estudo do campo magnético secundário obtém-se, como resultado, uma estimativa da profundidade do alvo, sua forma espacial em 2D, além dos resultados de resistividade aparente. Assim o ImagEM permite obter uma imagem da resistividade pela profundidade. Foram aplicados ao ImagEM dados sintéticos simulando o PROTEM57 (Geonics). Neste artigo foram apresentados os resultados obtidos para dados em duas e três camadas.

\section{2 - Abstract}

This paper aims in presenting the ImagEM software that was developed with the purpose of processing electromagnetic data in the time domain on field surveys using in loop coils. The software uses a simplified inversion and it the applies the secant method. This method has proven reliable for a qualitative analysis of the results and very agile in its processing. Based on the study of the secondary magnetic field is obtained as a result an estimate of the depth of resistive targets, 
besides its 2D spatial form, an apparent resistivity results. So the ImagEM allows obtaining the Resistivity Depth Image - RDI. The synthetic PROTEM (Geonics) data were tested. In this first article we present the results for synthetic data for two and three layers.

\section{3 - Introdução}

Nos anos 2000, com o grande salto na capacidade de processamento computacional, ocorreu também um avanço na arquitetura de programação de softwares aplicados a geologia e geofísica, principalmente, no que se refere ao tratamento de dados eletromagnéticos transientes (TEM). Formulações matemáticas sobre o comportamento do campo transiente em subsuperfície utilizando o conceito de corrente alternadas foi descrita por Talwani (1965), Nabighian (1979) e Hoversten \& Morrison (1982), que explicam a interação do campo com a subsuperfície. Utilizando estes estudos como base, foi possível implementar computacionalmente a teoria do campo eletromagnético no domínio do tempo de forma rápida e apropriada.

A profundidade atingida pelo campo eletromagnético transiente na subsuperfície foi descrita com a concepção da variação da corrente elétrica (Frischknecht \& Raab, 1984; Eaton \& Hohmann, 1989; Macnae \& Lamontagne, 1987; Nabighian \& Macnae, 2005). A profundidade atingida pelo sinal eletromagnético juntamente com a resistividade do subsolo, servem de base para uma Imagem da Resistividade pela Profundidade ( $R D I$ ). Com o avanço gráfico computacional, as RDI's podem ser confeccionadas em 2D e 3D, entretanto, o número de softwares que processa os dados de equipamentos eletromagnéticos e retornam estas informações é reduzido e não são de livre acesso. 
Para abordar este problema, é apresentado, o software ImagEM, que é capaz de processar dados eletromagnéticos no domínio do tempo e apresenta em seu arquivo de saída as informações necessárias para a construção de uma $R D I$. O programa aplica o método da secante, encontrando assim as raízes de uma função polinomial, de forma rápida e confiável (Travaglia Filho, 2012).

O ImagEM foi aplicado a dados sintéticos, numa primeira fase onde existe o controle da fonte geradora da anomalia. Nos dados sintéticos, foram modelados subsolos de duas e três camadas de formas alternadas com resistividades entre $\rho=0.1$ $\Omega \cdot m$ a $\rho=1000 \Omega \cdot m$.

\section{4 - Metodologia}

Parte da metodologia aplicada na arquitetura do programa baseou-se no software RAMPRES (Sandberg, 1988; Von Huelsen, 2007; Von Huelsen et al., 2008), o qual calcula a resistividade aparente utilizando da diferença de potencial induzida em uma bobina receptora, estando esta concêntrica a outra bobina transmissora.

O ImagEM vincula dois métodos para processar seus dados, um matemático e outro físico. O método matemático, descrito a seguir (item 2.5), é conhecido como método da secante, muito utilizado para achar as raízes de equações polinomiais. O método físico está apoiado nos princípios das leis de Maxwell e será descrito no item 2.6 .

\section{5 - O método matemático (Método da Secante)}

O programa ImagEM adota como modelo de convergência uma variação do método de Newton-Raphson (Press et al., 1992), também conhecido Método da Secante. Na solução de equações polinomiais é comum a aplicação do cálculo da derivada na 
função, sendo este tipo de cálculo, tarefa não tão simples nas funções da inversão eletromagnética. Para casos como este, a derivada pode ser substituída por um quociente da diferença entre os resultados das aproximações das raízes sobre as próprias raízes das funções polinomiais (Chapra \& Canale, 2002) como descrita pela equação (2.1):

$$
f^{\prime}(x) \approx \frac{f\left(x_{n}\right)-f\left(x_{n-1}\right)}{x_{n}-x_{n-1}}
$$

Onde: $x_{n-1}$ e $x_{n}$ são as aproximações das raízes da equação; $f\left(x_{n-1}\right)$ e $f\left(x_{n}\right)$ são os resultados correspondentes a $x_{n-1}$ e $x_{n}$; e $f^{\prime}(x)$ é a solução que substitui a derivada.

O método da secante contorna a necessidade de se aplicar a derivada, contudo, alguns procedimentos devem ser estabelecidos como definir a função a ser estudada e a quantidade de raízes possíveis. A partir da equação 2.1 pode-se deduzir a equação 2.2 abaixo para se encontrar as raízes (Chapra \& Canale, 2002).

$$
x_{n+1}=\frac{x_{n-1} \cdot f\left(x_{n}\right)-x_{n} \cdot f\left(x_{n-1}\right)}{f\left(x_{n}\right)-f\left(x_{n-1}\right)} \text { para } n=1,2,3 \ldots
$$

Onde: $n$ é o número de iterações para se encontrar a raiz.

Para este método ser bem sucedido, alguns cuidados devem ser tomados. Primeiro, o número de raízes da função aplicada deve ser estimado. Em seguida, devese delimitar um intervalo na abscissa onde uma das raízes deve estar contida. Este intervalo não deve conter mais de uma raiz (Chapra \& Canale, 2002).

A raiz da função estará dentro da margem de erro definido entre dois pontos na abscissa, se distância entre estes pontos for maior que esta margem, um novo cálculo será feito, caso a distância entre eles seja menor, se obtêm a raiz da função (Press et al., 1992). A Figura 2.1 ilustra a aproximação para se encontrar a raiz da equação.

Contudo, do ponto de vista computacional é possível que a distância entre a nova e antiga raiz aumente, desta forma a distância entre as raízes nunca atingirá um 
valor igual, ou menor que a margem de erro. Neste caso, ocorre uma divergência e o cálculo entrará em um ciclo interminável de iterações (Ruggiero, 1996).

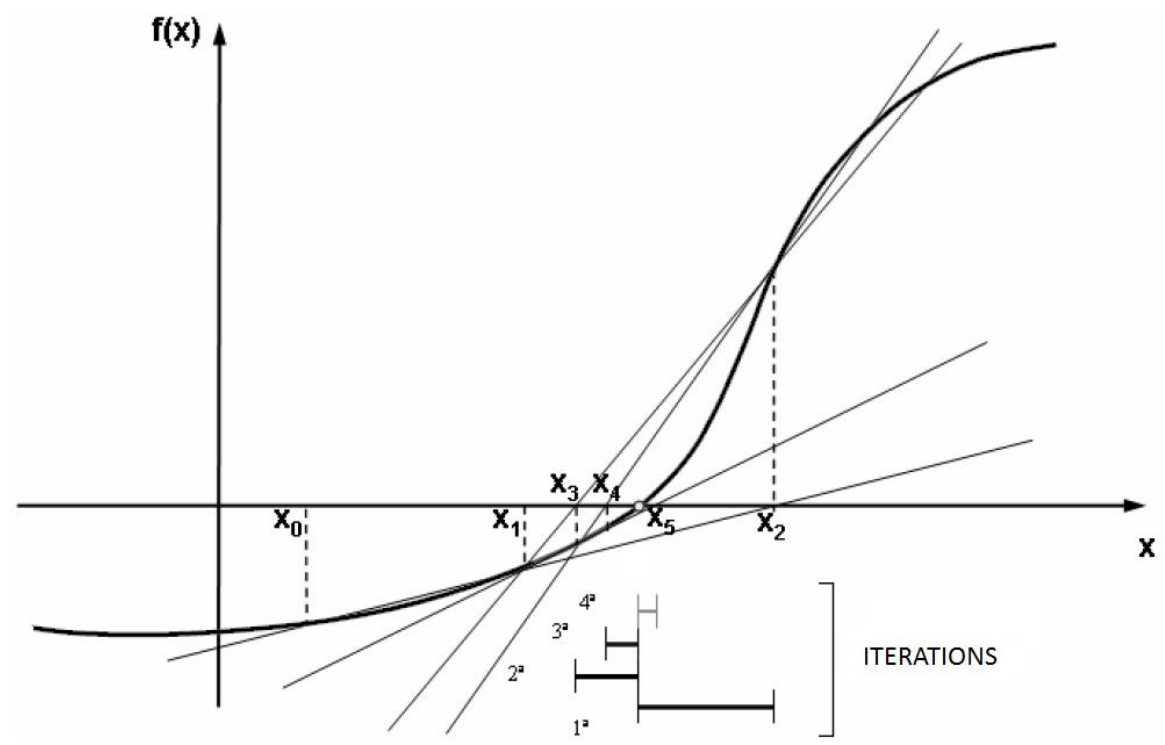

Figura 2. 1 Traçado a secante entre os pontos $\mathrm{f}_{0}\left(\mathrm{x}_{0}\right)$ e $\mathrm{f}_{1}\left(\mathrm{x}_{1}\right)$, encontra-se $\mathrm{x}_{2}$, aplicando novamente o método em $\mathrm{f}_{1}\left(\mathrm{x}_{1}\right)$ e $\mathrm{f}_{2}\left(\mathrm{x}_{2}\right)$, encontra-se $\mathrm{o}$ valor de $\mathrm{x}_{3}$ e assim por diante até que $\mathrm{o}$ resultado seja dentro do erro pré-definido (Ruggiero, 1996).

O ImagEM limita este ciclo em 70 iterações na tentativa de se encontrar a solução dentro da barra de erro. Este número de iterações é satisfatório devido as raízes serem encontradas nas dez primeiras iterações. O limite de iterações deve ser estabelecido devido a possibilidade da não convergência, o que acarretaria em um loop infinito, na situação em que o programa ultrapassar o limite de 70 iterações, o programa assume o último valor como o melhor encontrado e prossegue o script sinalizando que não houve uma convergência. 


\section{6 - O método físico}

Para a solução dos problemas eletromagnéticos considera-se a Terra como um meio isotrópico, homogêneo, e os parâmetros elétricos independentes do tempo, da pressão e da temperatura. Na prática, o modelo geoelétrico é constituído pela justaposição de várias regiões isotrópicas, onde uma equação de onda é postulada para cada região, cuja solução baseia-se nas equações de Maxwell (Von Huelsen, 2007).

As equações de Maxwell são generalizadas e simétricas, onde é possível trabalhar na forma de vetores potenciais. As funções vetoriais são polarizadas em duas partes (elétrica e magnética) e a soma algébrica destas funções representam a indução do alvo a modelar. Para facilitar a descrição física do problema, estas funções comumente são estudadas separadamente.

O software ImagEM aborda o método eletromagnético no domínio do tempo, ou método transiente. O campo eletromagnético é representado pela componente do campo elétrico e do campo magnético, e é uma manifestação da distribuição de carga regida pela Lei de Coulomb (Nabighian \& Macnae, 1987a):

$$
\vec{\nabla} \cdot \varepsilon_{0} \vec{E}=q
$$

Onde $q$ é a distribuição de carga $\left(C / m^{3}\right), \varepsilon_{0}$ é a permeabilidade dielétrica e $\vec{E}$ é o campo elétrico $(N / C)$.

De acordo com a distribuição de carga dentro do condutor poderá se estabelecer uma corrente elétrica e consequentemente uma densidade de corrente $\vec{j}$ (Nabighian \& Macnae, 1987a):

$$
\vec{\nabla} \cdot \vec{j}=-\frac{\delta q}{\delta t}
$$

Onde é $\vec{j}$ o vetor densidade de fluxo de corrente $\left(A / m^{2}\right)$ e $t$ é o tempo em segundos. 
A densidade de corrente que flui num meio é um resultado do campo elétrico e varia linearmente com o mesmo, de acordo com a Lei de Ohm (Nabighian \& Macnae, 1987b):

$$
\vec{j}=\sigma \vec{E}
$$

Onde é $\sigma$ a condutividade elétrica $(S / m)$ e $\vec{E}$ é o campo elétrico dado em $(N / C)$.

De acordo com a equação 2.5, existe uma dependência da densidade de corrente com o campo elétrico, que é a mais relevante propriedade física no estudo do método EM (Von Huelsen, 2007).

Em busca desta propriedade, será explicitada a seguir a interação do campo eletromagnético com o alvo e a resposta eletromagnética obtida no receptor no domínio do tempo.

\subsection{1- O método Eletromagnético Transiente no Domínio do Tempo - TDEM}

O método Eletromagnético no Domínio do Tempo baseia-se na resposta, detectada pelo receptor, do campo eletromagnético secundário gerado pela variação da condutividade no subsolo (campo secundário), quando este foi submetido também a um campo eletromagnético primário proveniente do transmissor. No caso de equipamentos que trabalham off time, o campo secundário só é captado quando a corrente no transmissor é desligada, registrando somente a resposta do alvo (Telford et al., 1990).

Os equipamentos EM comumente são compostos de um transmissor e um receptor. O transmissor é uma bobina confeccionada com fio condutor. No transmissor é injetada uma corrente elétrica, esta corrente elétrica variante no tempo gera um campo magnético que se intensifica de acordo com o número de voltas do fio. Este campo produzido pelo transmissor é denominado de campo magnético primário. A Figura 2.2 ilustra o comportamento deste campo (Scrivens, 2009; Ogilvy, 1983). 


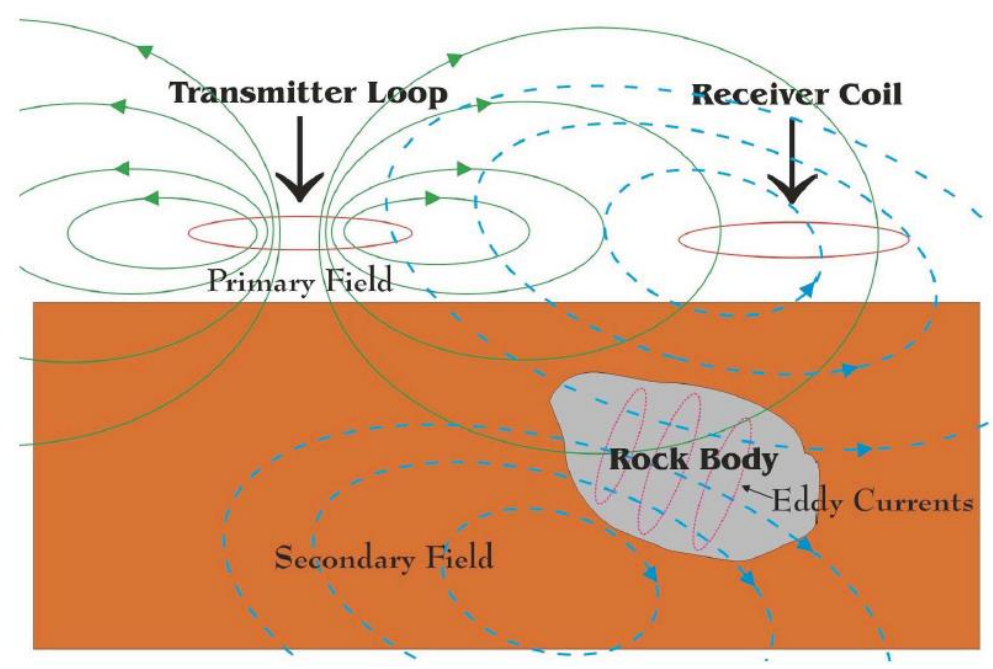

Figura 2. 2 Comportamento do campo primário e secundário produzidos pela bobina transmissora e receptora (Ogilvy, 1983; Scrivens 2009)

O campo magnético primário propaga-se até o subsolo e interage com corpos de maior, ou menor condutividade. A interação deste campo induz uma corrente elétrica no solo em subsuperfície, estas correntes no interior do corpo alvo são conhecidas como correntes parasitas, sendo mais intensas para os corpos condutores, e menos intensas para os corpos resistivos (Nekut, 1987; Telford et al., 1990; Kearey et al., 2009).

Nos corpos resistivos, devido a pouca diferença de potencial, o campo primário se propaga sem sofrer atenuação. Entretanto, quando o campo primário encontra um corpo condutor (ex: fluído salino, sulfetos maciços, grafita etc), o deslocamento das correntes parasitas é mais intenso. Estas correntes movimentam-se de forma alternada no corpo condutor, gerando um campo eletromagnético secundário que se propaga até o receptor (Nabighian \& Macnae, 1987; Fullagar, 1989; Kearey et al., 2009) O campo secundário, ao encontrar o receptor, gera uma corrente alternada em sua bobina. O pulso elétrico no receptor é convertido em sinais eletrônicos e registrado pelo equipamento durante o levantamento. 
Com relação à interação do campo eletromagnético com o meio, Hoversten \& Morrison (1982) avaliaram o modelo de 1, 2 e 3 camadas horizontais baseados na corrente máxima e em um semi-espaço infinito para bobinas concêntricas. O comportamento do campo eletromagnético, gerado pela bobina transmissora, decai à medida que interage com as camadas da terra devido à penetração do sinal (Nabighian, 1979; Fullagar \& Oldenburg, 1984). As medidas da tensão $U(t)$ captadas pelo receptor são obtidas pela derivada do campo magnético em relação ao tempo $\partial h / \partial t$, e foi formulado por Newman et al. (1987):

$$
U(t)=-\mu_{0}\left(\frac{\partial h}{\partial t}\right) M
$$

Onde: $M$ é a área efetiva da bobina receptora $\left(m^{2}\right)$ e $\mu_{0}$ é permeabilidade elétrica $\left(H / \mathrm{m}^{2}\right)$.

Esta tensão captada pela bobina receptora, para cada intervalo de tempo, pode ser relacionada com modelos de camadas em diferentes profundidades (Wait, 1951; Eaton, 1989; Wait \& Hill, 1973). Frischknecht \& Raab (1984), com base na teoria da lei de Faraday, demonstraram que, na interação corrente/meio, a corrente elétrica fica confinada à superfície do condutor durante os tempos iniciais (early time) e é normal ao campo que a gerou. Quando esta corrente começa a ser dissipada (late time), ocasiona uma diminuição do campo magnético que gera corrente na vizinhança, este comportamento é descrito na Figura 2.3. 


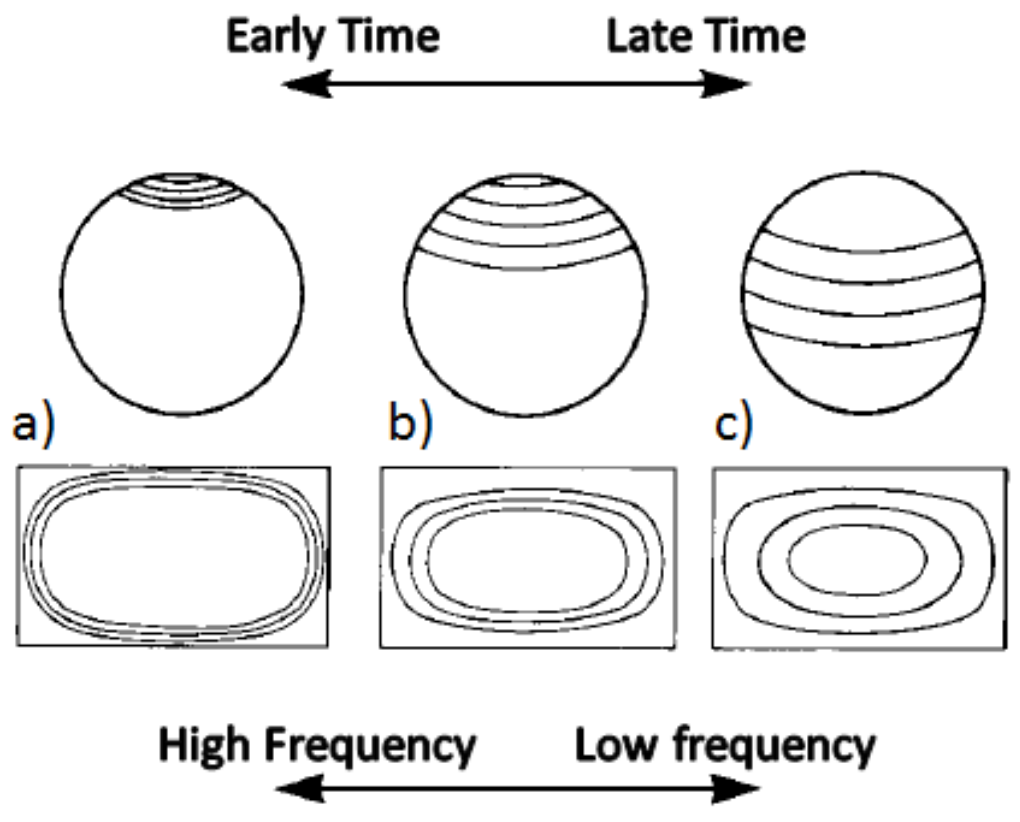

Figura 2. 3 - Esboço do fluxo de corrente num condutor interagindo após desligamento do transmissor. Nos tempos iniciais as interações ocorrem na parte mais rasa e nas bordas do corpo, nos últimos canais as interações ocorrem na parte mais profunda e no interior do corpo,

Modificado de Dyck \& West (1984).

Como foi mencionado anteriormente, o decaimento do campo eletromagnético descreve as características físicas da rocha, quando este decaimento é mais lento, sua curvatura tende a ser menos acentuada e o corpo apresenta uma resposta condutiva. De forma contrária, quando o tempo do decaimento é rápido e sua curvatura é mais acentuada (Nabighian \& Macnae, 1987b).

Devido a forte interação entre o condutor e o sinal as tensões registradas são maiores (Figura 2.4a), desta forma foi possível comparar a diferença de condutividade de dois corpos condutores pelo afastamento da exponencial em relação a origem (Figura 2.4b). Quanto mais afastado a curva estiver da origem dos eixos, maior será a condutividade do corpo. 

a) fem
b) fem
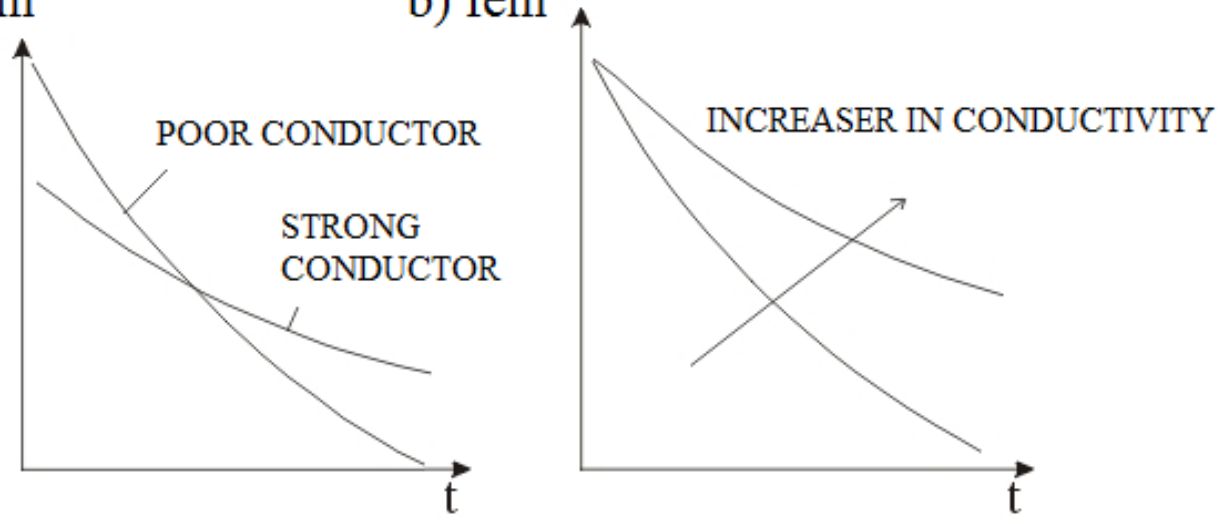

Figura 2. 4 - a) Comportamento exponencial da tensão para um corpo condutivo e resistivo com

o passar do tempo. b) $\mathrm{O}$ afastamento da curva de decaimento da origem indica o aumento da condutividade do corpo em questão. (Nabighian \& Macnae, 1987b).

Assim, utilizando-se o acoplamento eletromagnético entre o transmissor, o alvo e o receptor é possível medir a resposta do campo magnético secundário. Quanto mais condutor for o corpo, mais intenso o campo magnético emitido por ele, e maior será o tempo de interação eletromagnético captado pela bobina receptora (Frischknecht \& Raab, 1984).

\subsection{2 - Cálculo da Resistividade}

A descrição matemática da resistividade para os canais inicial $\left(\rho_{e t}\right)$, também conhecidos como early times implementada no software é dada por (Frischknecht \& Raab, 1984):

$$
\rho_{e t}=\frac{r_{T x}^{3} \cdot d B_{z} / d t}{3 r_{R x}}
$$

Onde $r_{T x}$ é o raio do transmissor, $r_{R x}$ é a área efetiva do receptor em $\mathrm{m}^{2} \mathrm{e} d B_{z} / d t$ é a impedância na componente vertical (z) obtida pela bobina receptora em (V/A). 
Quando este processo é completado, a configuração da distribuição de corrente induzida será mais ou menos invariante no tempo, também chamado de tempo tardio. Neste último estágio ocorre a diminuição da amplitude do campo secundário e a resistividade $\left(\rho_{l t}\right)$ é descrito por Frischknecht \& Raab (1984).

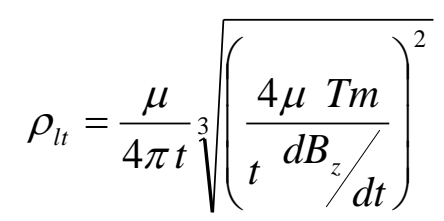

Onde $\mu$ é a permeabilidade magnética no vácuo $\left(4 \pi \cdot 10^{-7}\right), T m$ é o momento de dipolo do transmissor que é dado pelo produto da corrente pela área do transmissor, $t$ é o tempo médio que cada canal registra o campo secundário em segundos.

Com os dados da resistividade calculados pelas equações de $\rho_{e t}, \rho_{l t}$ e o método da secante, é possível obter a função de decaimento da resistividade pelo tempo de interação $f(t, \rho)$ :

$$
f(t, \rho)=\frac{\left(\frac{\mu r a_{r} 0,886226}{\delta a_{t}}\right)(1-2 R)\left[\left(\frac{\mu r_{t}^{2}}{t x}\right)^{k+1,5}-\left(\frac{\mu r^{2}}{(t+\delta x)}\right)^{k+1,5}\right]}{4^{k} k !(2 k+5)(2 k+3)}
$$

Onde $\delta$ é o tempo para que o campo primário deixe de atuar em segundos, $a_{t}$ é a área da bobina transmissora em $m^{2} ; K$ é número de iterações; $R$ é o resto da divisão $k / 2$ (vale 0 ou 1); e $x$ é logaritmo da $\rho$ (resistividade) em que $\rho$ é dado pelas equações 2.7 e 2.8 .

De forma interativa a resistividade é encontrada assumindo que a função é aproximadamente linear na região do levantamento, utilizado na solução das raízes da equação:

$$
f(t, \rho)-z(t)=0
$$

onde $\mathrm{z}(\mathrm{t})$ é a impedância (tensão do receptor dividida pela corrente transmitida). 
O incremento de resistividade não deve exceder $10 \%$ do valor da resistividade atual em espaço logaritmo, evitando um salto na curva de decaimento e valores negativos (Von Huelsen, 2007). A saída fornece a resistividade aparente (equações 2.7 e 2.8) e a profundidade da camada (equação 2.11).

\subsection{3 - O Cálculo da Profundidade}

Existem várias formas de se calcular a profundidade $(d)$ com o campo eletromagnético secundário. No ImagEM, utiliza-se a resistividade do corpo alvo e tempo médio de decaimento de cada canal. A equação de profundidade proposta para bobinas dispostas sobre o mesmo eixo vertical

$$
d=750 \sqrt{t \cdot \rho}
$$

Onde $t$ é o tempo médio de cada canal em segundos e $\rho$ é a resistividade $(\Omega \cdot \mathrm{m})$.

\section{7 - O software ImagEM}

O ImagEM (Fig. 2.5) foi desenvolvido com o objetivo de se obter uma ferramenta computacional capaz de processar dados TEM de forma interativa e amigável ao usuário, com boa agilidade de processamento e reproduzir dados qualitativos. A teoria do método eletromagnético apresentada anteriormente foi aplicada levando em conta a adaptação computacional para as funções matemáticas descritas.

Devido as bibliotecas matemáticas e gráficas o ImagEM foi desenvolvido em MatLab, para que seus cálculos, sua lógica e a depuração do programa fossem testados com maior simplicidade e cuidado. O software pode ser utilizado tanto em Linux quanto em Windows.

Como foi mencionado, o ImagEM calcula a profundidade (eq. 2.11) e a resistividade aproximada (eq. 2.7 e 2.8) para cada sondagem eletromagnética observada 
em campo, estes parâmetros servirão de modelo geoelétrico inicial da subsuperfície. Os parâmetros de entrada são: latitude, longitude, os canais desligados, a distância, a Média do Desvio de Terreno (MDT), linha e estação. A saída do ImagEM é um arquivo de dados do tipo xyz contendo os parâmetros de entrada: linha, estação, latitude, longitude e distância. Além dos dados calculados após a inversão: tensão (V), profundidade (m), resistividade $(\Omega \cdot \mathrm{m})$, decaimento $(\mathrm{V} / \mathrm{A})$, tempo de decaimento $(m s)$.

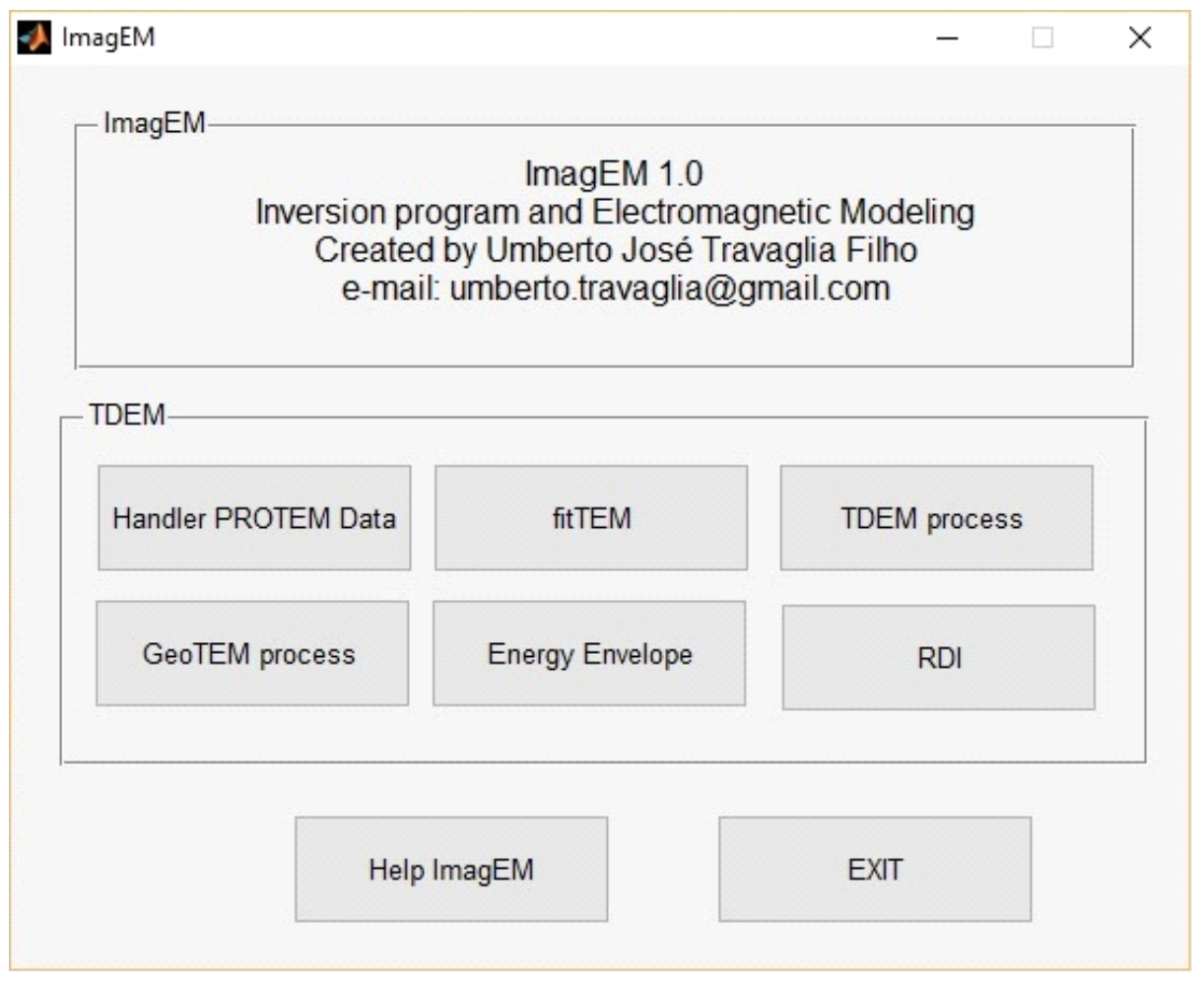

Figura 2. 5 Interface ImagEM. O TDEM process realiza uma inversão simplificada por meio do método da secante e o RDI gera uma seção da resistividade pela profundidade, além dos perfis.

Para se processar os dados foi utilizado o TDEM process (Fig. 2.6), que é uma sub-rotina do ImagEM. Para isso é necessário informar ao programa a disposição dos dados dentro do seu arquivo de entrada, ou seja, informar o significado de cada coluna. Nesta primeira versão do programa, o usuário fornece a posição das colunas de latitude, longitude, estações, distância, modelo digital do terreno (MDT) se houver e a linha do 
levantamento. Na Figura 2.6, por exemplo, tem-se Latitude $=3$, isso indica que na terceira coluna do arquivo de dados estão registrados os valores das Latitudes.

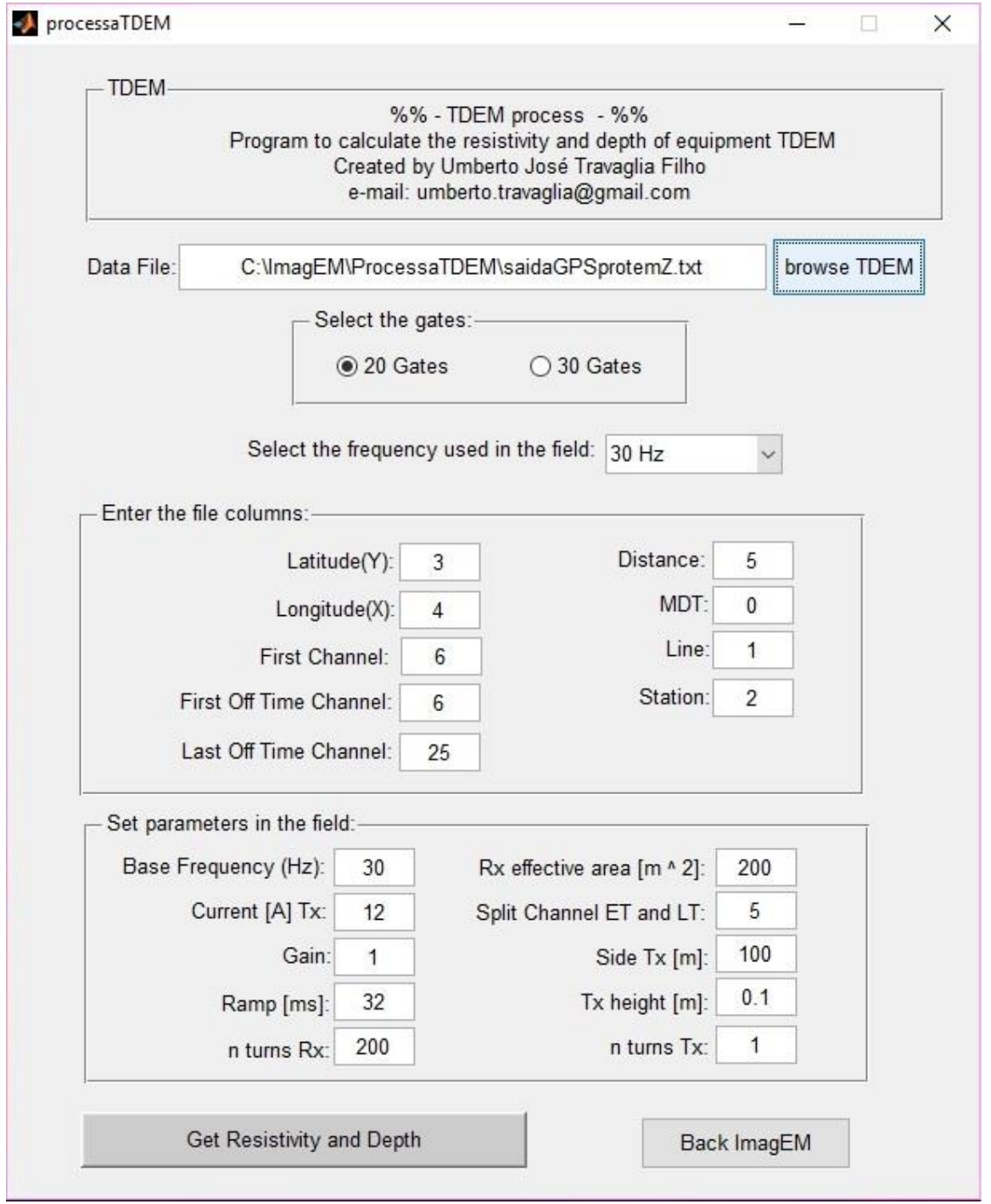

Figura 2. 6 - TDEM process Interface. Sub-rotina para processar dados TDEM. O primeiro painel são os dados do arquivo de entrada, o segundo painel são as configurações usadas no equipamento.

As colunas do primeiro ao último canal off time indicam os valores do campo magnético secundário que serão processados. Para o processamento dos dados é necessário que todos os canais off time estejam em sequência de ordem crescente.

O segundo painel da Figura 2.6 consta os dados de entrada da configuração usada no equipamento TDEM em campo. Neste é indagado ao usuário a configuração 
feita no receptor, tais como a frequência base utilizada no levantamento $(\mathrm{Hz})$, o tempo de desligamento (ramp $-m s$ ), a corrente elétrica em Ampère, o Ganho, o número de voltas da bobina receptora e a área efetiva da bobina. Quanto ao transmissor é fornecido pelo usuário o comprimento do lado da bobina, na prática é comum montar loops quadrados e o número de voltas.

Uma característica do TDEM process é que não é necessário inserir informações a priori da região estudada, com isso é possível processar os dados sem conhecimentos da geologia da área.

\section{8 - Dados Sintéticos}

Os modelos sintéticos foram gerados pelo algoritmo computacional NLSTCI (Nonlinear Least-Squares Inversion of Transient Soundings for a Central Induction Loop) utilizando o seu modelador direto (Anderson, 1982; Von Huelsen \& Moraes, 2008). Foram geradas respostas eletromagnéticas para modelos de duas e de três camadas com estações dispostas a cada $100 m$ de distância, da seguinte forma:

Modelo de duas camadas: 1 - A primeira camada resistiva e segunda condutiva (modelo RC, Figura 2.7); 2 - A primeira camada condutiva e a segunda resistiva (modelo CR, Figura 2.8).

Modelo de três camadas: 1 - A primeira camada resistiva, a camada intermediária condutiva e a terceira camada resistiva (modelo RCR, Figura 2.9); 2 - A primeira camada condutiva, a camada intermediária resistiva e a terceira camada condutiva (modelo CRC, Figura 2.10). 


\section{9 - Modelo RC}

O modelo sintético RC (Fig. 2.7a) foi confeccionado para uma camada de $380 m$ de profundidade onde a resistividade foi de $1000 \Omega \cdot m$ e um semi espaço infinito com a resistividade de $10 \Omega \cdot m$, respectivamente, para as camadas resistiva (R) e condutiva (C).

A seção do modelo RC (Fig. 2.7b) foi confeccionada a partir da função RDI (Fig. 2.5). A sub-rotina RDI aplicou o método de interpolação por krigagem, para este modelo foi utilizada uma célula de $25 \mathrm{~m}$.

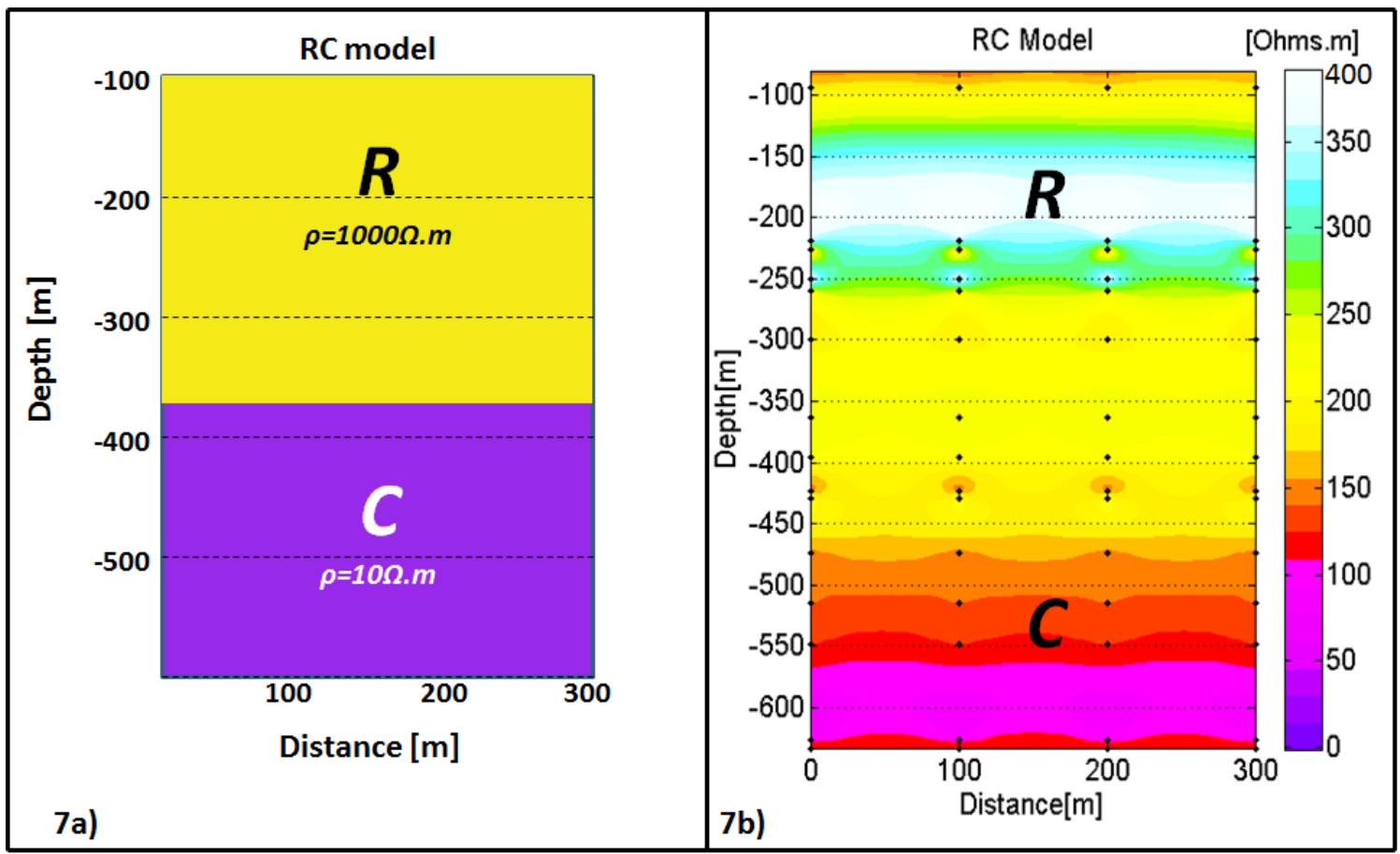

Figura 2.7 a) Representação do modelo sintético de duas camadas RC; 2.7b) RDI modelo com os valores da resistividade obtida pelo ImagEM.

A resposta do modelo RC (Fig. 2.7b) obtida com o ImagEM apresenta uma camada resistiva com profundidade média de 400m. Abaixo desta camada, o resultado mostra uma camada condutiva com resistividade menor que $100 \Omega \cdot m$ (Tabela 2.1 ). 


\subsection{0 - Modelo CR}

O modelo sintético (Fig. 2.8a) foi confeccionado para uma camada de $380 \mathrm{~m}$ de profundidade onde o a resistividade foi de $10 \Omega \cdot m$ e um semi-espaço infinito com a resistividade $1000 \Omega \cdot m$ respectivamente para as camadas condutiva (C) e resistiva (R). Da mesma forma do modelo anterior, a RDI do modelo CR (Fig. 2.8b) foi confeccionada utilizando a função RDI com tamanho de célula de $25 \mathrm{~m}$.

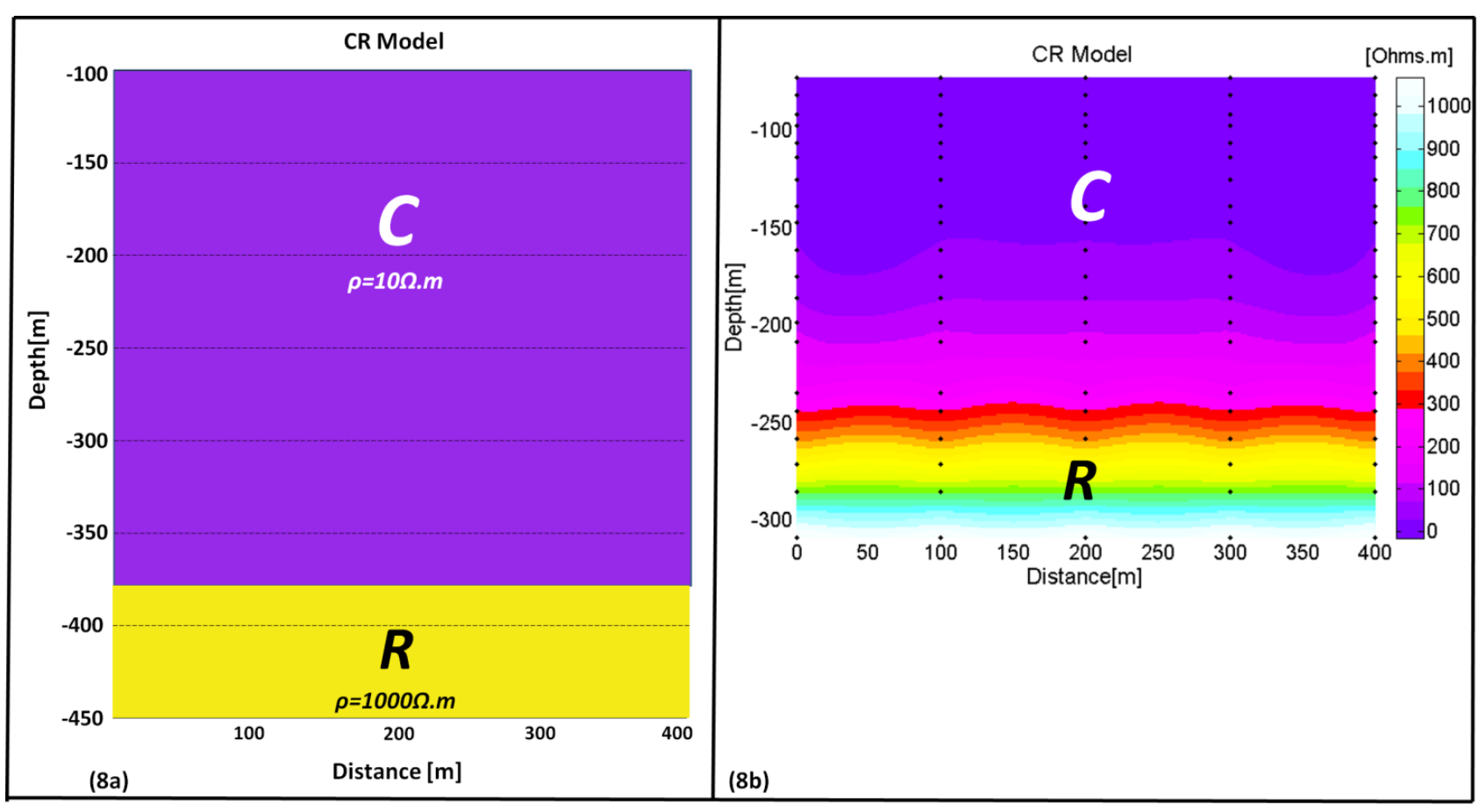

Figura 2. 8 a) Representação do modelo sintético de duas camadas CR; 2.8b)RDI obtida no ImagEM para o modelo condutivo(C) resistivo (R).

A RDI do modelo CR (Fig. 2.8b) apresenta para a primeira camada uma resistividade média de $300 \Omega \cdot m$ com profundidade entorno de $250 \mathrm{~m}$, o semi-espaço apresenta uma resistividade entre 300 e $1200 \Omega \cdot m$. 


\subsection{1 - Modelo RCR}

O modelo RCR (Fig. 2.9a) foi dividido de acordo com as seguintes profundidades: de 0 à $180 m$ a primeira camada apresenta resistividade de $100 \Omega \cdot m$, de 180 a $240 m$ uma segunda camada com resistividade de $10 \Omega \cdot m$ e abaixo de $240 m$ o semi-espaço infinito com resistividade de $100 \Omega \cdot m$. A Figura 2.9 apresenta um comparativo entre o modelo sintético e a recuperação do mesmo utilizando o ImagEM.

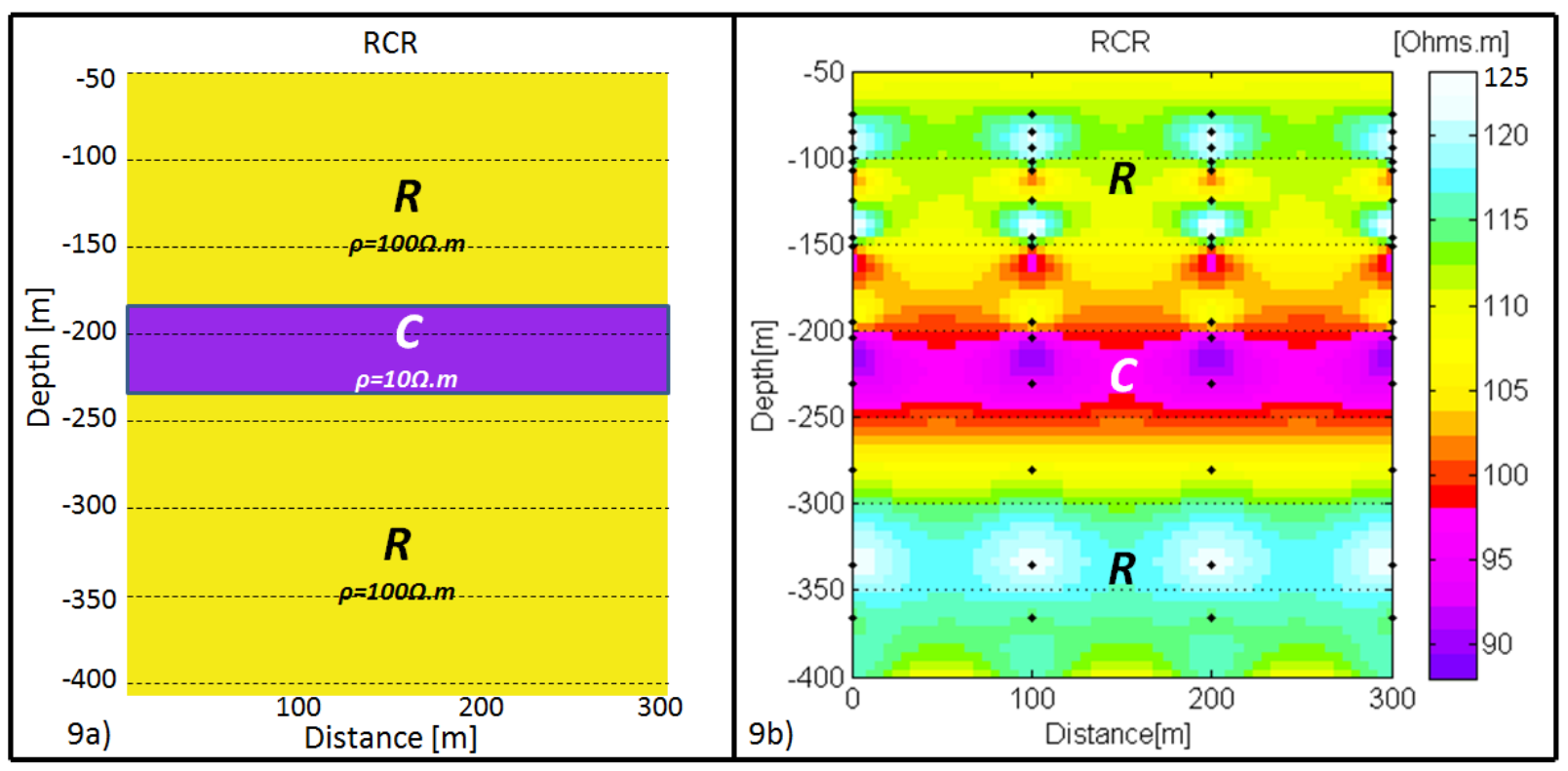

Figura 2. 9a) Representação do modelo sintético de três camadas RCR; 2.9b)RDI obtida no ImagEM, para o modelo RCR.

A RDI obtida do modelo RCR (Fig. 2.9b) apresenta uma primeira camada resistiva com cerca de $200 \mathrm{~m}$ de profundidade, e uma resistividade entre 105 e $115 \Omega \cdot m$, a segunda camada mais condutiva com valores de resistividade abaixo de $100 \Omega \cdot m$, e profundidade entre 200 e $260 \mathrm{~m}$. O semi-espaço abaixo de $260 \mathrm{~m}$ de profundidade apresenta uma resistividade máxima de $125 \Omega \cdot m$ em sua maior parte. 


\subsection{2 - Modelo CRC}

O modelo CRC (Fig. 2.10a) foi dividido de acordo com as seguintes profundidades: de 0 à $120 \mathrm{~m}$ a primeira camada aparente com resistividade média de 0.7 $\Omega \cdot m$, de 120 à $280 m$ uma segunda camada com resistividade média de $200 \Omega \cdot m$ e abaixo de $280 m$ o semi-espaço infinito com resistividade média de $0,7 \Omega \cdot m$. A Figura 2.10 apresenta os resultados do modelo sintético (Fig. 2.10a) e da modelagem obtida pelo $\operatorname{ImagEM}$ (Fig 2.10b), (Tabela 2.1).

A RDI do modelo CRC (Fig. 2.10b) apresenta uma camada com profundidade próximo a $50 \mathrm{~m}$ e a resistividade variando entre 0 e $45 \Omega \cdot m$. A segunda camada ficou perceptível entre 50 e $180 \mathrm{~m}$ de profundidade e a resistividade ficou entorno de $48 \Omega \cdot m$, a última camada tem seu início após $180 \mathrm{~m}$ de profundidade e a resistividade ficou abaixo de $45 \Omega \cdot m$, semelhante a primeira camada (Tabela 2.1 ).

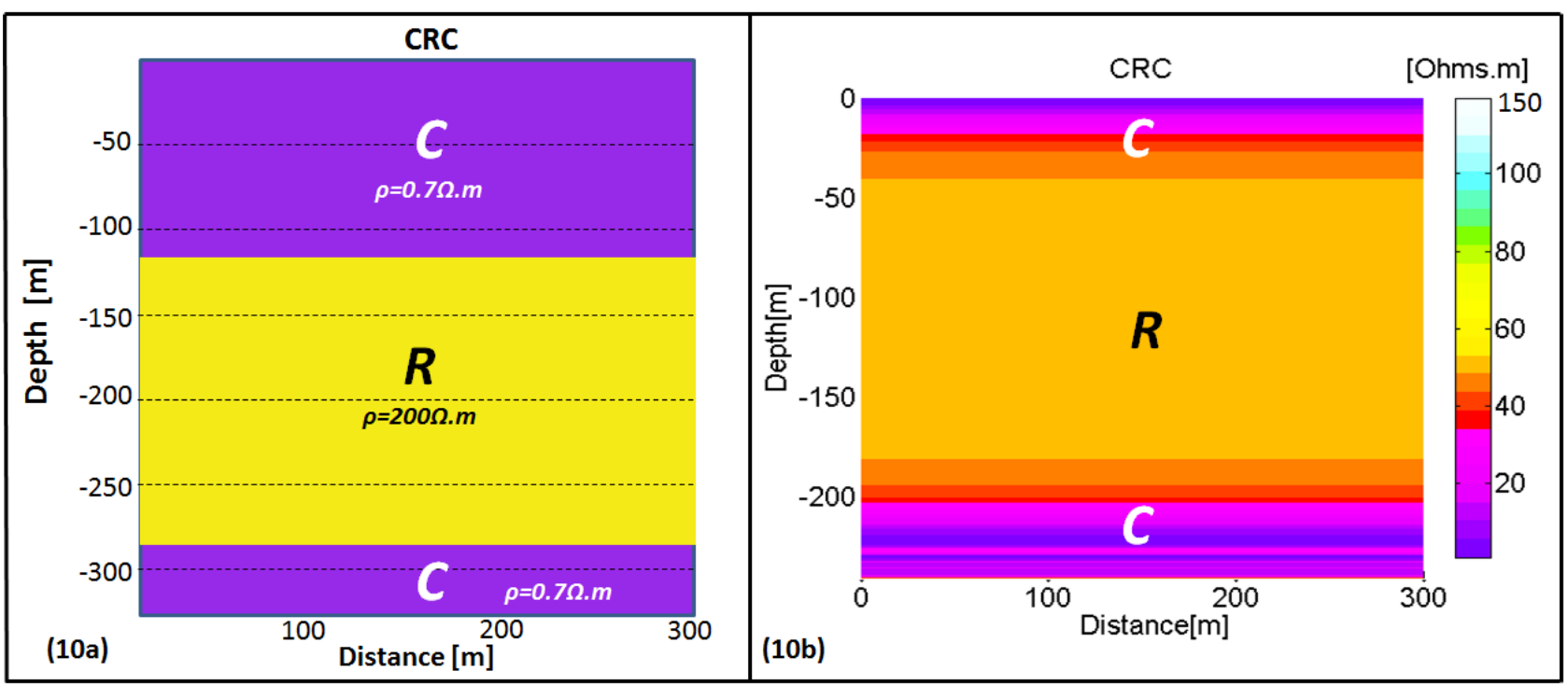

Figura 2. 10 a) Representação do modelo sintético de três camadas CRC.; 2.10b) RDI obtida no ImagEM para o modelo de CRC. 


\subsection{3 - Análise dos resultados e conclusão}

A Tabela 2.1 sumariza os modelos de duas e três camadas juntamente com seus valores sintéticos e a resposta obtida do ImagEM para as profundidades e resistividade de cada camada.

\begin{tabular}{|c|c|c|c|c|}
\hline & $\begin{array}{l}\text { Modelo } \\
\text { sintético }\end{array}$ & $\begin{array}{c}\text { Resultado } \\
\text { RDI }\end{array}$ & $\begin{array}{l}\text { Modelo } \\
\text { sintético }\end{array}$ & Resultado $R D I$ \\
\hline & $\overline{\mathrm{RC}(\mathrm{I}}$ & 7 ab) & $\overline{\mathbf{C R}}$ & g. 8ab) \\
\hline & 380 & 400 & 380 & $<250$ \\
\hline & Semi-espaço & $>450$ & Semi-espaço & $>250$ \\
\hline Resistividade & 1000 & 350 & 10 & 300 \\
\hline$[\Omega \cdot m]$ & 10 & $<100$ & 1000 & $300-1200$ \\
\hline & $\overline{R C R}$ & $.9 a b)$ & $\overline{C R C}$ & g. 10ab) \\
\hline & $0-180$ & 200 & $0-120$ & 50 \\
\hline Profundidade[m] & $180-240$ & $200-260$ & $120-280$ & $50-180$ \\
\hline & Semi-espaço & $260-400$ & Semi-espaço & $180-250$ \\
\hline & 100 & $105-115$ & 0.7 & $0-40$ \\
\hline Resistividade & 10 & $<100$ & 200 & $\sim 48$ \\
\hline & 100 & $105-125$ & 0.7 & $<45$ \\
\hline
\end{tabular}

Tabela 2.1: Resposta dos modelos sintáticos obtidos pelo ImagEM para duas e três camadas

As RDIs dos modelos sintéticos RC e CR apresentam uma separação entre as duas camadas. A profundidade nestes modelos também foi compatível com o esperado, principalmente para o modelo RC. A resistividade encontrada nas duas situações também descrevem de forma satisfatória os modelos (Tabela 2.1).

Para os modelos RCR e CRC foi possível recuperar as três camadas. O modelo RCR apresentou profundidades compatíveis ao esperado e boa percepção na separação 
das camadas. Seus valores de resistividade também retornaram valores compatíveis ao modelo proposto. O modelo de três camadas CRC apresentou bons valores de resistividade, principalmente para os valores de resistividade mais baixos. A variação dos valores de resistividade para este modelo é explicada devido a forte interação com a camada superficial mais condutiva, dificultando a penetração do sinal para regiões mais profundas (Tabela 2.1). Interações como estas foram descritas por Santos \& Flexor (2008).

Foi possível demostrar neste artigo que o software ImagEM apresenta bons resultados qualitativos no processamento de dado eletromagnético no domínio do tempo. A sub-rotina TDEM process que realiza o método da secante é capaz de interagir de forma rápida e eficiente sobre as equações de resistividade, proporcionando uma inversão simplificada para construção de perfis 2D. Devido sua agilidade o ImagEM pode ser bastante eficaz para o processamento dos dados e mostrou neste trabalho uma resposta confiável.

\subsection{4 - Agradecimentos}

Os autores deste trabalho agradecem aos dirigentes e pesquisadores do Observatório Sismológico e do Instituto de Geociências da Universidade de Brasília (UnB) pela liberação de suas instalações e da licença do MatLab. Agradeço a CAPES pelo suporte financeiro da bolsa de pesquisa. O primeiro autor encaminha os agradecimentos ao Sólon Povoa Neto que aprimorou a estrutura do programa e melhorou sua funcionalidade. 


\subsection{5 - Referências}

Anderson, W. L.1982. Adaptative nonlinear least-squares solution for constrained or unconstrained minimization problems (Subprogram NLSOL). USGS Open-File Rept. 82-68, 66p.

Chapra, Steven C., Canale, Raymond P. 2002 Numerical methods for engineers: international edition. 4. Ed. New York: McGraw-Hill.

Dyck, A.V. \& West. G.F. 1984. The role of simple computer models in interpretation of wide-band, drill-hole electromagnetic survey in mineral exploration. Geophysicis, Vol. 49. Nº 7. P. 957-980.

Eaton, P. A. \& Hohmann, G. W. 1989. A rapid inversion technique for transient electromagnetic soundings. Physics of the Earth Planetary Interiors, 53: 384404.

Frischknecht, F. C. \& Raab, P. V. 1984.Time domain electromagnetic soundings at the Nevada test site. Geophysics. 49: 981-992.

Fullagar, P. K. \& Oldenburg, D. W. 1984. Inversion of horizontal electromagnetic frequency soundings. Geophysics, 49: 150-164.

Fullagar, P. K. 1989. Generation of conductivity-deph pseudo sections from coincident loop and in-loop TEM data. Expl. Geophys., 20: 43-53

Hoversten,G. M. \& Morrison, H. F. 1982. Transient Fields Of A Current Loop Source Above A Layered Earth. Geophysics, 47: 1068-1077. International Conference On Mineral Exploration, P. 489 -496.

Kearey, P. Brooks, M., Hill, I. 2009. Geofísica de Exploração. Ed. Oficina de Textos, São Paulo. 
Macnae, J. C. \& Lamontagne, Y. 1987. Imaging quasi-layered conductive structures by simple processing of transient electromagnetic data. Geophysics, 52: 545554.

Nabighian M.N. \& Macnae J.M. 2005. Eletrical and EM methods, 1980- 2005. SEG@75, pag 42-45.

Nabighian, M. N. \& Macnae C. J. 1987a., Eletromagnetic Theory for geophysical applications. In Nabighian, M.N. Ed, Eletromagnetic methods in applied geophysics, v. 1, Theory, Investigations in geophysics, SEG, 203-252.

Nabighian, M. N. \& Macnae C. J. 1987b. Time domain eletromagnetic prospecting methods. In Nabighian, M.N. Ed, Eletromagnetic methods in applied geophysics, v. 1, Theory, Investigations in geophysics, SEG, 427-520.

Nabighian, N. Misac. 1979. Quasi-static transient response of a conductivity half-space - an approximate representation. Geophysics, 44: 1700 - 1705.

Nekut, A. G. 1987. Direct inversin of time-domain eletromagnetic data. Geophysics, 52: 1432-1435.

Newman, G. A., Anderson, W. L. \& Holmann, G. W. 1987. Interpretation of transient electromagnetic soundings over three-dimensional structures for the centralloop configuration. Geophys. J. R. astr. Soc. 89: 889-914.

Ogilvy R.D. 1983. A model study of the transient electromagnetic concident loop technique. Geoexploration, $n^{\circ} 21$, pgs. 231-264.

Press, W. H., Teukolsky, S.A., Vetterling, W. T. \& Flannery, B. P. 1992. Numerical Recipes the art of scientific computing. Cambridge University Press. New York. 
Raab, P. V. \& Frischknecht, F. C. 1983. Desktop computer processing of coincident and central loop time-domain electromagnetic data . U.S. Geol. Surv. Open File Rep. 83-240.

Ruggiero, M. A. G. 1996. Cálculo numérico: aspectos teóricos e computacionais. 2. ed. São Paulo: Pearson Education do Brasil.

Sandberg, S. K. 1988, Microcomputer software for the processing and forward modeling of transient electromagnetic data taken in the central loop sounding configuration: New Jersey Geological Survey Open-File Report 88-1.

Santos, H.S., Flexor, J.M. 2008. O Método Transiente Eletromagnético (TEM) Aplicado ao Imageamento Geoelétrico da Bacia de Resende (RJ, Brasil). Revista Brasileira de Geofísica, volume 26(4), pgs 543-553.

Talwani, M. 1965. "Computation with the help of a digital computer of magnetic anomalies caused by bodies of arbitrary shape”. Geophysics 30: 797-817.

Telford, W.M., Geldart, L.P., Sheriff, R.E., “Applied Geophysics”, Cambridge University, 1990.

Von Huelsen, M. G. V., Moraes, R. A. V, Carvalho, T.. 2008. “CDI Versus inversão - aplicação a dados reais”. Rev. Bras. Geof., vol.26, n³, São Paulo.

Von Huelsen, M. G. V., Moraes, R. A. V. 2008. "Imageamento da subsuperfície baseado na condutividade: obtenção de CDIs para o Sistema Geotem”. Rev. Bras. Geof., vol.26, n⿳3 3, São Paulo.

Von Huelsen, M. G. V.. 2007. "Interpretação de Dados de Eletromagnetometria Aeroeletrotransportada (AEM) do Sistema GEOTEM (Domínio do Tempo)". Tese de Doutorado n 080 , Instituto de Geociências - Universidade de Brasília - UnB, 202 pp. 
Wait, J. R. 1951. A conducting sphere in a time varying magnetic field. Geophysics,16, 666-672.

Wait, J. R. \& Hill, D. A. 1973. Excitation of a homogeneous conductive cylinder of finite length by a prescribed axial current distribution. Radio Science, 8(12), 1169-1176. 


\title{
Capítulo 3
}

\section{ImagEM - Programa de Modelagem 2D de Dados}

\section{Eletromagnéticos no Domínio do Tempo com aplicação a}

\author{
dados reais.
}

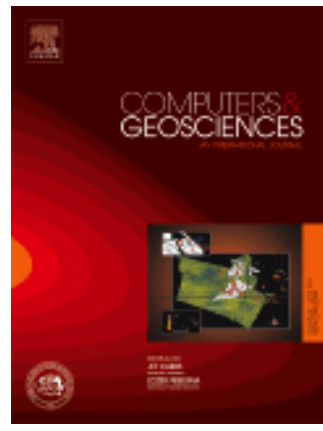

\begin{tabular}{|r|l|}
\hline Jornal: & Computers \& Geosciences \\
\hline Manuscript ID: & \\
\hline Date submitted by author: & $01 / 03 / 2016$ \\
\hline Complete Listo f Authors: & $\begin{array}{l}\text { Umberto José Travaglia Filho, Mônica G. Von Huelsen } \\
\text { e Aline Tavares Maciel Coelho Silva }\end{array}$ \\
\hline Keywords: & electromagnetic modeling, RDI, Carajás \\
\hline Area of Expertise: & \\
\hline
\end{tabular}

Re: ImagEM - 2D modeling program TEM data - Application to Crystalline deposit in Carajás, Pará State, Brazil Case study

Dear Mr. Travaglia Filho,

Your submission entitled "ImagEM - 2D modeling program TEM data - Application to Crystalline deposit in Carajás, Pará State, Brazil" has been received by Computers \& Geosciences

You may check on the progress of your paper by logging on to the Elsevier Editorial System as an author. The URL is http://ees.elsevier.com/cageo/.

Your username is: umberto.travaglia@gmail.com If you need to retrieve password details, please go to: http://ees.elsevier.com/CAGEO/automail query.asp

Your manuscript will be given a reference number once an Editor has been assigned.

Thank you for submitting your work to this journal.

Kind regards,

Elsevier Editorial System

Computers \& Geosciences 


\title{
ImagEM - Programa de Modelagem 2D de Dados
}

\section{Eletromagnéticos no Domínio do Tempo com aplicação a}

\section{dados reais.}

\author{
Umberto José Travaglia Filho $^{1}$, Mônica G. Von Huelsen ${ }^{1}$ e Aline Tavares Melo ${ }^{2}$ \\ 1 - Universidade de Brasília - UnB, Instituto de Geociências - IG \\ 2 - Universidade federal de Minas Gerais
}

\section{1 - Resumo}

Este trabalho tem como objetivo aplicar a função RDI (Resistivity Depth Image) do programa ImagEM em dados reais. Esta função gera uma imagem da resistividade pela profundidade em uma seção $2 \mathrm{D}$. A função $R D I$ interpola os dados pelo método de krigagem e gera uma tabela com a distribuição estatística dos dados relacionando a resistividade da geologia em subsuperfície. Estas informações ajudam o pesquisador na interpretação geológica da área investigada. Para este artigo foram utilizados os dados do levantamento no depósito Cristalino em Carajás, no estado do Pará, Brasil. Os dados foram processados utilizando a função TDEM process (Time Domain Electromagnetic), sub-rotina do ImagEM responsável pela inversão de dados eletromagnéticos no domínio do tempo para levantamento com bobinas centralizadas.

\section{2 - Abstract}

This paper aims to present the image software and its function Resistivity Depth Image - RDI that generates a $2 \mathrm{D}$ resistivity section of the depth, the contour lines and the profile of the voltage generated by the secondary field. This feature also generates a map with the coordinates. The RDI function interpolates the data by 
kriging method and generates a table with the statistical distribution of data relating the resistivity of the material. This information helps the researcher in geological interpretation of the investigated area. For this article we used the survey data in Crystalline deposit in Carajás, Pará State, Brazil, assigned by Vale S.A. The data were processed using the function TDEM process, another subroutine image responsible for the inversion of electromagnetic data in the time domain to survey in loop.

\section{3 - Introdução}

O imageamento de dados eletromagnéticos (EM) é uma técnica muito utilizada para interpretação em geociências. A representação destes dados em forma de imagem da seção de condutividade pela profundidade (Condutivity Depth Image - CDI) é interessante para interpretação em exploração mineral, e distribuição da condutividade em mapeamento geológico na identificação de alvos condutivos (Huang \& Rudd, 2008). O estudo destas pseudo-seções começa no comportamento da propagação do campo eletromagnético no interior da terra e na interação com suas camadas, tendo início no trabalho de Wait (1951) e em vários artigos depois deste (Ryu et al., 1970; Wait \& Hill, 1971; Wait \& Ott, 1971; Nabighian, 1972; Rijo et al., 1977; Reynolds, 1977).

Uma das referências mais importantes sobre a propagação do campo secundário no interior da terra e a profundidade atingida foi apresentada por Nabighian (1979), onde foram descritas as relações matemáticas dos campos secundários, apelidados por de smoke rings e a demonstração da resposta transiente para uma bobina circular. Os trabalhos de Mahmoud et al. (1979), Spies (1978), entre outros descreveram a interação do campo eletromagnético para modelos de duas camadas, assim foi possível descrever o comportamento do campo secundário para os tempos tardios (late times) e realizar a 
inversão de dados eletromagnéticos obtendo-se a resistividade aparente. Em 1980, McNeill (1980a, 1980b, 1980c) apresenta uma série de notas técnicas explicando o funcionamento eletrônico dos equipamentos eletromagnético, as aplicações em campo para o semi-espaço e as respostas do decaimento do sinal em função do tempo para alvos confinados de tamanhos diferentes.

Macnae \& Lamontagne (1987), publicaram um trabalho relacionando a condutividade com a profundidade, chamada inicialmente de "depth-image processing" e mais conhecido hoje como "Condutivity Depth Image - CDI". Estas imagens foram construídas por camadas horizontalizadas e apresentaram uma profundidade aparente. Este mesmo processo de camadas horizontalizadas foi descrito por Nekut (1987).

Em 1989 foi apresentado um método para calcular a resistividade aproximada baseado no comportamento das correntes transientes por meio de uma fonte controlada, proposto por Eaton \& Hohmann (1989), que descreveu as pseudo seções em forma de imagem da resistividade pela profundidade "Resistivity Depth Image - RDI". Fullagar (1989) apresentou resultados em forma de Conductivity Depth Image - CDI para dados sintéticos e reais com bobinas coincidentes e centralizadas. Estes métodos de se representar a resposta em subsuperfície demostrou ser bastante eficiente e foram aplicados em muitos trabalhos, tais como: Macnae et al. (1991), aplicado a dados aéreos; Fullagar \& Reid (1992), Wolfgram (1995), Zhdanov et al. (1995), Von Huelsen (2007), Von Huelsen et al. (2008), Von Huelsen \& Moraes (2008), Travaglia Filho (2012), Melo et al. (2014).

Ferramentas computacionais destinadas ao processamento de dados EM não são novidades, Talwani (1965), Anderson (1982), Raab \& Frischknecht (1983) e Sandberg (1988) já aplicaram seus conhecimentos em códigos para processar dados geofísicos. Entre os trabalhos mais recente, é possível destacar os artigos de Irving \& Knight 
(2006), para GPR, o programa CRIDmod de Ingeman-Nielsen \& Baumgartner (2006), para métodos elétricos e eletromagnéticos, o CRlDinv, que realiza inversão 1D utilizando o método Cole-Cole (Ghorbani et al., 2009). Rao \& Babu (2009) normaliza o campo magnético para bobinas quadradas e calcula a profundidade para n-camadas, além do ModEM para inversão de dados Magnetotelúricos (Kelbert et al., 2014).

Com o desenvolvimento de ferramentas matemáticas aplicadas a bibliotecas computacionais, os gráficos e mapas se tornaram mais precisos e dinâmicos. Os computadores atuais são capazes de processar mega byte de informação em poucos minutos. Seguindo esta linha de pesquisa em desenvolvimento de programas e com o objetivo de proporcionar uma ferramenta para o processamento de dados eletromagnéticos transiente no domínio do tempo, foi desenvolvido o ImagEM Programa de Modelagem 2D de Dados Eletromagnéticos no Domínio do Tempo, para auxiliar os geocientistas no processamento e interpretação de dados de campo. Neste artigo destaca-se a função gráfica $R D I$, capaz de gerar seções da resistividade pela profundidade, perfis do sinal captado pelo equipamento e linhas de contorno na aplicação a dados reais.

\section{4 - O método Eletromagnético Transiente no Domínio do Tempo - TDEM}

O princípio do TDEM pode ser compreendido da seguinte forma: a bobina transmissora é ligada gerando um campo magnético primário, esta fase é conhecida com “on time”, este campo se propaga na subsuperfície e ao interagir com corpos condutivos gera uma corrente elétrica em seu interior chamada de corrente de Foucault. Esta corrente gera um campo magnético secundário que é captado pela bobina receptora, contudo esta captação só ocorre após o desligamento do transmissor e da interrupção do campo primário, sendo que apenas o campo secundário é captado pelo receptor, esta 
fase é conhecida como "off time”. (Nabighian \& Macnae, 1987a; Telford et al., 1990; Kearey et al., 2009). A Figura 3.1 resume o comportamento dos campos.

(a)

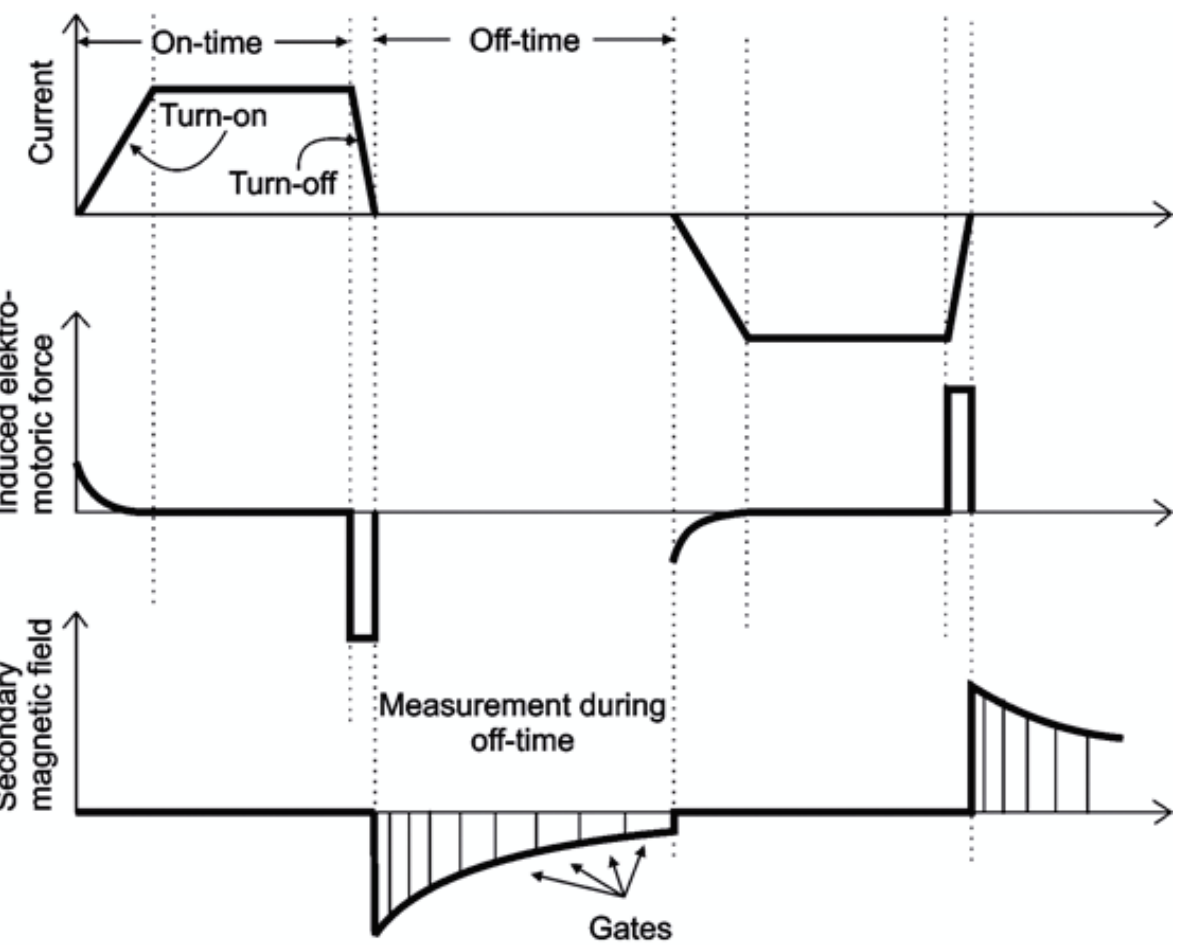

Figura 3. 1 - Princípios do método TEM. (a) Comportamento da corrente no circuito transmissor. (b) Força eletromotriz induzida no terreno, e (c) Campo magnético secundário captado na bobina receptora. Para levantamento com bobinas centralizadas (Christiansen et al., 2009) .

Nabighian (1979) descreve a perda de energia do campo primário devido à interação com as camadas da terra e Hoversten \& Morrison (1982) relacionaram a interação deste campo com o meio geologico para diferentes camadas horizontais baseados na corrente máxima e em um semi-espaço infinito para bobinas concêntricas. A tensão $U(t)$ gravada pelo receptor são obtidas pela derivada do campo magnético em relação ao tempo $(\partial h / \partial t)$, dado por Newman et al. (1987):

$$
U(t)=-\varepsilon_{0}\left(\frac{\partial h}{\partial t}\right) M
$$


Onde: $M$ é a área efetiva da bobina receptora $\left(m^{2}\right)$ e $\varepsilon_{0}$ é permeabilidade magnética $\left(H / m^{2}\right)$

A relação entre as tensões e a janelas de tempo estão diretamente relacionadas às profundidades alcançadas pela propagação do sinal (Wait, 1951; Wait \& Hill, 1971; Eaton \& Hohmann, 1989). De acordo com Frischknecht \& Raab (1984), a lei de Faraday demonstra que na interação da corrente elétrica com o meio, a corrente elétrica fica confinada à superfície do condutor durante os tempos iniciais (early time) e dissipada nos tempos finais (late time). (Frischknecht \& Raab, 1984).

Os dados são gravados pelo receptor e seu registro normalmente é feito em milivolts $(m V)$, ou picovolts $(p V)$, e são transferidos para um computador $\mathrm{e}$ posteriormente ser processado por um programa como o ImagEM. A sub-rotina Handler PROTEM Data foi desenvolvida para o PROTEM57 - Geonics, e é capaz de construir um gráfico do decaimento do sinal de cada medida realizada. As janelas de tempo são dispostas de forma crescente e a curva de decaimento geralmente é apresentada em forma semi - logarítmica, log ou logarítmica para uma melhor resolução da curva, em especial nos tempos finais (Christiansen et al., 2009). Outra forma de representar a curva de decaimento é pela relação da derivada do campo magnético secundário pelo tempo $(\partial B / \partial t)$. A sub-rotina TDEM process, também do ImagEM, é capaz de realizar uma inversão utilizando o método da secante e gera como saída dados de resistividade e profundidade (Travaglia Filho, 2012). 

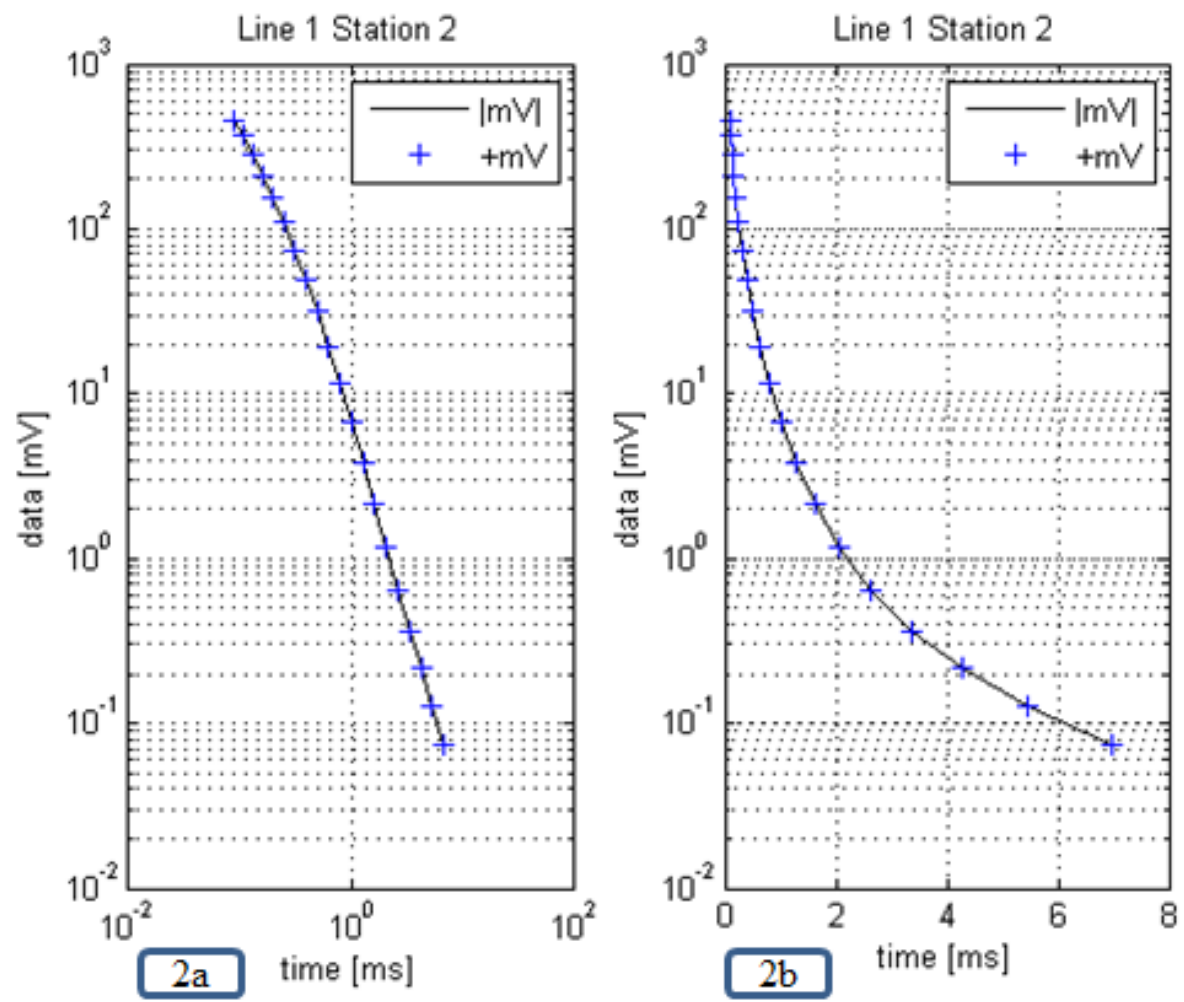

Figura 3. 2 - Curva de decaimento gerada pela sub-rotina Handler PROTEM Data do ImagEM, os dados são apresentados em $m V \times m s$. a) Curva de decaimento apresentada em formato log$\log$; b) A curva de decaimento apresentada em formato $\log \mathrm{Y}$.

O decaimento do campo EM descreve as características físicas das rochas. Quando este decaimento é mais lento, sua curvatura tende a ser menos acentuada e o corpo apresenta uma resposta condutiva. De forma contrária, quando decaimento é rápido sua curvatura é mais acentuada, sendo esta uma resposta menos condutiva (Nabighian \& Macnae, 1987b) (Fig. 3.3). 


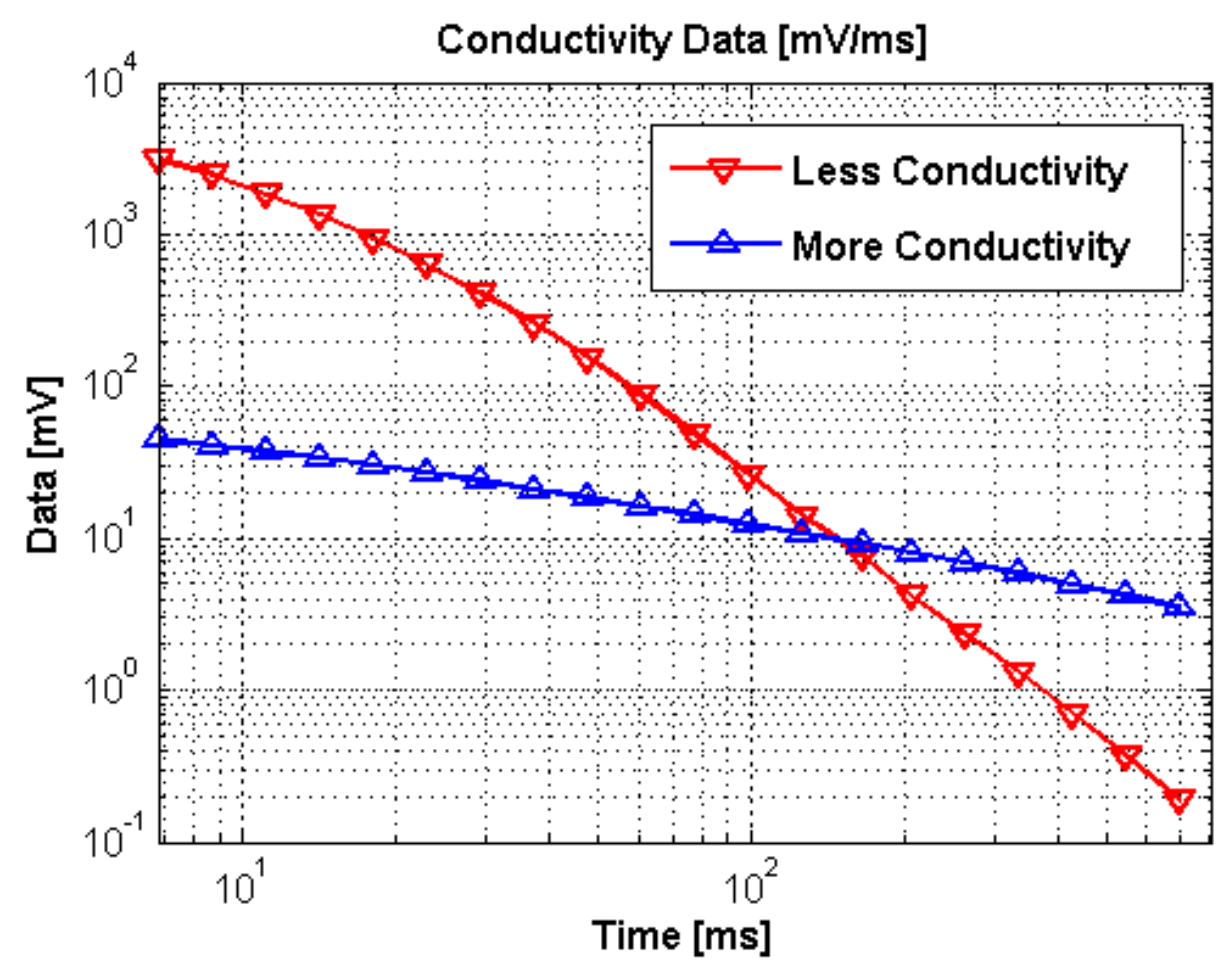

Figura 3. 3 - Comportamento exponencial da tensão para um corpo condutivo (curva azul) e resistivo (curva vermelha) com o passar do tempo. O decaimento da curva resistiva é mais rápido e acentuado em relação a curva condutiva (Adaptado de Nabighian \& Macnae, 1987)

Devido a sua forte interação entre o condutor e o campo, as tensões registradas são de maior valor, desta forma podemos comparar a diferença de condutividade de dois corpos condutores pelo afastamento da exponencial em relação a origem (Fig. 3.3) (Nabighian \& Macnae, 1987).

Desta forma, utilizando-se o acoplamento entre o transmissor, o alvo e o receptor, é possível medir a resposta do campo magnético secundário. Quanto mais condutor for o corpo em subsuperfície, mais intenso é o campo magnético emitido por ele, e maior será o tempo de interação eletromagnética captada pela bobina receptora (Frischknecht \& Raab, 1984). 
A descrição matemática da resistividade para os tempos iniciais $\rho_{T I}$ que foi implementada na sub-rotina TDEM process do ImagEM é dada por (Frischknecht \& Raab, 1984):

$$
\rho_{\mathrm{IT}}=\frac{\mathrm{r}_{\mathrm{T}}^{3} \mathrm{~dB}_{\mathrm{z}} / \mathrm{dt}}{3 \mathrm{a}_{\mathrm{r}}}
$$

Onde $\mathrm{r}_{\mathrm{T}}$ é o raio do transmissor, $a_{r}$ é a área efetiva do receptor em $\mathrm{m}^{2}$ e $d B_{z} / d t$ é a impedância obtida pela bobina receptora em (V/A).

Quando este processo é completado, a configuração da distribuição de corrente induzida no alvo será mais ou menos, invariante no tempo, também chamado de tempo tardio $\rho_{T D}$. Este último estágio temos diminuição da amplitude do campo secundário e a resistividade é descrito por Frischknecht \& Raab (1984), como mostra a equação 3.3.

$$
\rho_{T D}=\frac{\mu}{4 \pi t}\left(\frac{4 \mu T m}{t}\right)^{2 / 3}
$$

Onde $\mu$ é a permeabilidade magnética no vácuo $\left(4 \pi \cdot 10^{-7} \mathrm{H} / \mathrm{m}\right), \mathrm{Tm}$ é o momento de dipolo do transmissor que é dado pelo produto da corrente $(A)$ pela área do transmissor $\left(m^{2}\right), t$ é o tempo em segundos.

Partindo da resistividade é possível calcular a profundidade. No ImagEM, utiliza-se a resistividade do corpo alvo e tempo médio de decaimento de cada canal. A fórmula da profundidade para bobinas centralizada sob o mesmo eixo vertical foi implementada ao TDEM process considerando o PROTEM - Geonics e é dada por,

$$
d=750 \sqrt{t \cdot \rho}
$$

Onde $d$ é a profundidade dada em metros, $t$ é o tempo médio de cada canal em segundos e $\rho$ é a resistividade $(\Omega \cdot \mathrm{m})$. 
A partir dos dados de resistividade, profundidade e da distância da linha de levantamento, a sub-rotina RDI do ImagEM é capaz realizar uma interpolação destas informações usando o método de krigagem descrito a seguir.

\section{5 - Método de Interpolação Gráfica: krigagem}

A geoestatística descreve a autocorrelação de uma, ou mais variáveis em dimensões 1D, 2D, 3D, ou (4D) no espaço-tempo e faz previsões em locais não observados, para dar informações sobre locais conhecidos e atribuir valores. A forma, o intervalo e a direção da autocorrelação espacial são descritos pelo variograma, que é a principal ferramenta em geoestatística linear. (Davis, 2002).

A idéia fundamental é usar o variograma para interpolar e determinar a influência de observações vizinhas e sua magnitude em locais desconhecidos. A geoestatística linear básica inclui dois procedimentos principais: variograma e krigagem para a interpolação (Sandwell, 1987; The MathWork, 2011). A krigagem utiliza uma média ponderada dos vizinhos para estimar o valor não observado $\hat{z}_{x 0}$ em relação aos dados observados $z_{x 0}$ (Kitanidis, 1997):

$$
\hat{z}_{x 0}=\sum_{i}^{N} \lambda_{i} \cdot z_{x i}
$$

onde $\lambda_{\mathrm{i}}$ são os pesos estimados. A soma dos pesos resulta em um para garantir que as estimativas serão imparciais, ou seja:

$$
\sum_{i}^{N} \lambda_{i}=1
$$

O erro estimado (média) deve ser o mais próximo de zero, logo:

$$
E\left(\hat{z}_{x 0}-z_{x 0}\right)=0
$$


onde $\mathrm{z}_{\mathrm{x} 0}$ é o valor verdadeiro, mas desconhecido. Usando as equações 3.5 e 3.7, é possível calcular o erro quadrático-médio em termos de variograma:

$$
E\left[\left(\hat{z}_{x 0}-z_{x 0}\right)^{2}\right]=2 \sum_{i=1}^{N} \lambda_{i} \gamma\left(x_{i}, x_{0}\right)-\sum_{i=1}^{N} \sum_{j=1}^{N} \lambda_{i} \lambda_{j} \gamma\left(x_{i}, x_{j}\right)
$$

Onde:

$E$ é a variância de kriging (kriging variance), que tem que ser minimizado;

$\gamma\left(x_{i}, x_{0}\right)$ é o variograma (semivariância) entre os dados e os dados não observados;

$\gamma\left(x_{i}, x_{j}\right)$ é o variograma entre os pontos de dados $x_{i}$ e $x_{j}$.

$\lambda_{i} e \lambda_{j}$ são os pesos por i e j-ésimo dado.

Para krigagem é necessário minimizar a eq. 3.8 satisfazendo a condição de que a soma dos pesos deve ser um. Este problema de otimização pode ser resolvido usando um multiplicador de Lagrange $v$ resultando no sistema de krigagem linear de $\mathrm{N}+1$ equações e $\mathrm{N}+1$ incógnitas:

$$
\sum_{i=1}^{N} \lambda_{i} \gamma\left(x_{i}, x_{0}\right)+v=\gamma\left(x_{i}, x_{j}\right)
$$

Após calcular os pesos $\lambda_{\mathrm{i}}$, a variância é dada por:

$$
\sigma^{2}\left(x_{0}\right)=\sum_{i=1}^{N} \lambda_{i} \gamma\left(x_{i}, x_{0}\right)+v\left(x_{0}\right)
$$

O sistema de equações do método de krigagem pode ser apresentado por uma notação matricial, onder:

$$
\text { Mkrig }=\left[\begin{array}{ccccc}
0 & \gamma\left(x_{1}, x_{2}\right) & \cdots & \gamma\left(x_{1}, x_{N}\right) & 1 \\
\gamma\left(x_{2}, x_{1}\right) & 0 & \cdots & \gamma\left(x_{2}, x_{N}\right) & 1 \\
\vdots & \vdots & \vdots & \vdots & \vdots \\
\gamma\left(x_{N}, x_{1}\right) & \gamma\left(x_{N}, x_{2}\right) & \cdots & 0 & 1 \\
1 & 1 & \cdots & 1 & 0
\end{array}\right]
$$


Mkrig é a matriz dos coeficientes, estes são os valores dos variogramas modelados para os pares observados. A diagonal principal da matriz é zero, ou seja, a distância entre os pontos observados e os pontos estimados é zero, o valor de $\gamma$ desaparece.

$$
E=\left[\begin{array}{c}
\lambda_{1} \\
\lambda_{2} \\
\vdots \\
\lambda_{N} \\
v
\end{array}\right]
$$

$E$ é o vetor dos pesos desconhecidos e o multiplicador de Lagrange.

$$
\text { LDvet }=\left[\begin{array}{c}
\gamma\left(x_{1}, x_{0}\right) \\
\gamma\left(x_{2}, x_{0}\right) \\
\vdots \\
\gamma\left(x_{N}, x_{0}\right) \\
1
\end{array}\right]
$$

LDvet é o lado direito do vetor. Para obter os pesos e os multiplicadores de Lagrange, a matriz Mkrig é invertida.

$$
E=M_{k i r g}^{-1} \cdot \text { LDvet }
$$

e a variancia da krigagem é dado por:

$$
\sigma^{2}=L D e v^{-1} \cdot E
$$

A krigagem depende da distância entre os dados observados e dos seus valores. A krigagem reproduz a média da população quando as observações estão fora do alcance do variograma. A variância pode ser utilizada como um critério para melhorar a concepção da amostragem, e é necessária para transformação de volta no modelo $\log$ Normal que é dado por:

$$
y\left(x_{0}\right)=e^{z\left(x_{0}\right)+0.5 \cdot \sigma^{2}\left(x_{0}\right)-v}
$$




\section{6 - O Programa ImagEM}

O ImagEM (Fig. 3.4) foi desenvolvido em MATLAB ${ }^{\circledR}$ como o objetivo de obter uma ferramenta capaz de processar os dados TDEM e apresentá-los. Para o processamento utilizamos o TDEM process, que realiza uma inversão pelo método da secante para dados em bobinas centralizadas. Para gerar os perfis e mapas utilizamos a função RDI (Fig. 3.5), esta função apresenta os perfis do sinal, uma seção de linhas de contorno e uma imagem da resistividade pela profundidade.

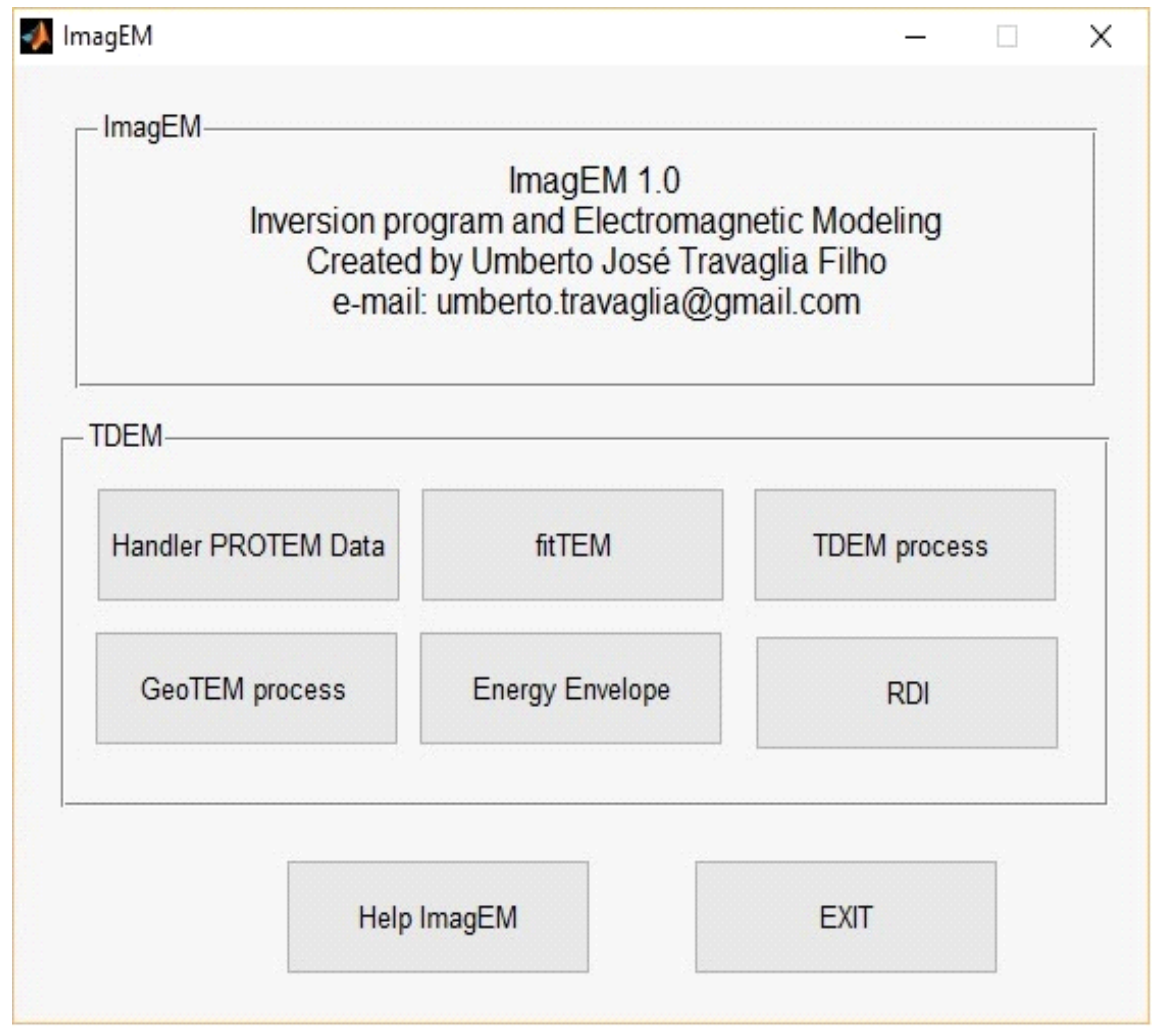

Figura 3. 4 Interface ImagEM. A sub-rotina TDEM process realiza uma inversão simplificada por meio do método da secante e a função RDI gera perfis, linhas de contorno além de um mapa de resistividade.

Para gerar as RDIs foi utilizada a função de mesmo nome (Fig. 3.5), que é uma sub-rotina do ImagEM. Nesta função o usuário carrega os dados que foram processados pelo TDEM process, ou qualquer outro programa que realize um método de inversão e tenha como saída os valores de resistividade, profundidade e coordenada de localização $X, Y$. 


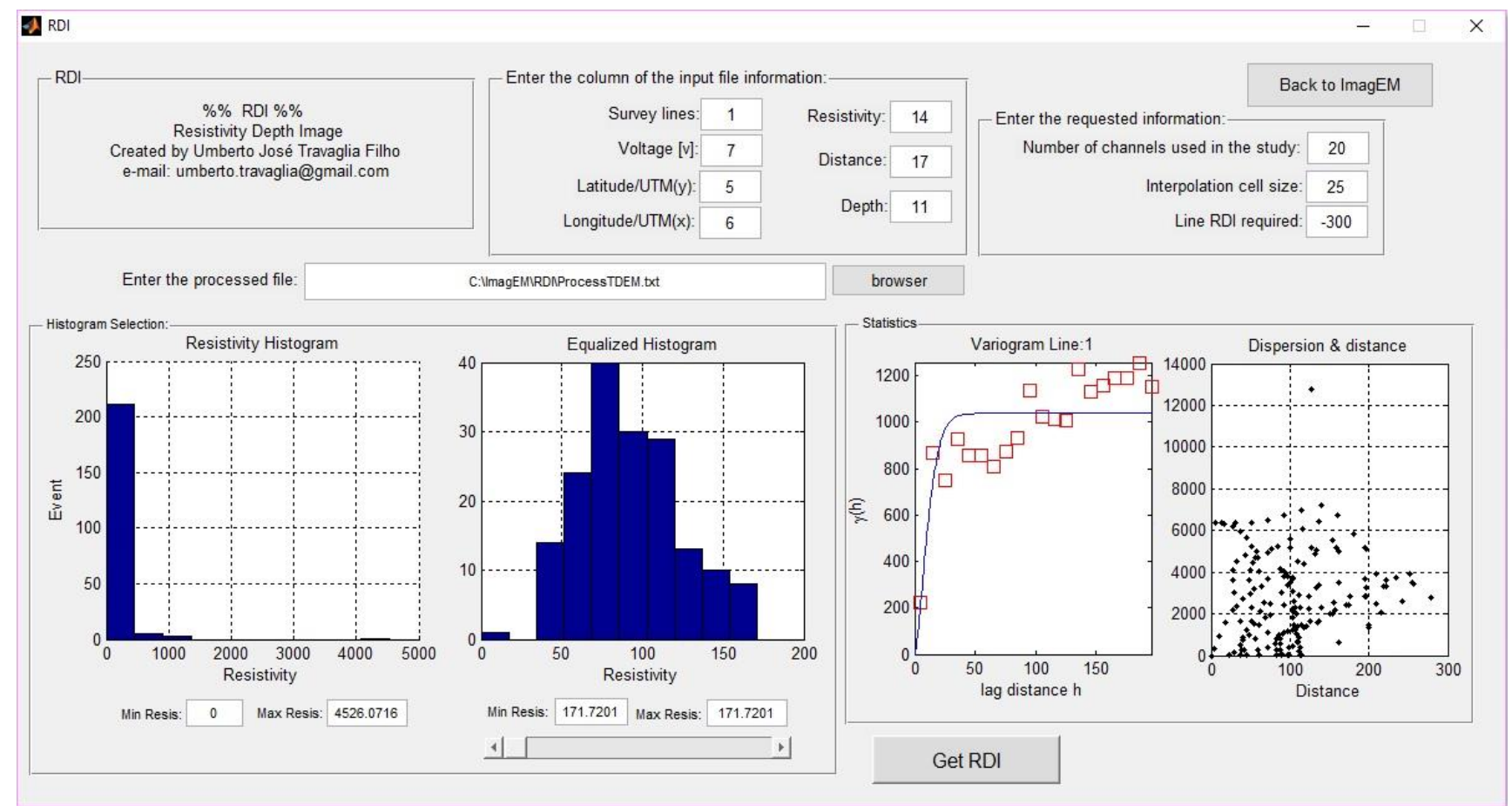

Figura 3. 5 - Interface da função RDI. Sub-rotina para gerar uma imagem da resistividade pela profundidade.

Na interface RDI é possível notar no painel "Resistivity Histogram” (Fig. 3.5), que o usuário pode monitorar o histograma de resistividade de cada linha de levantamento e em "Resistivity Histogram" selecionar por meio do "slider" a faixa do histograma que deseja usar em cada RDI. O "slider" ajuda o geocientista selecionar a faixa de dados que mais se adeque a realidade e relaciona com a uma tabela de resistividade de materiais, deixando o investigador livre para construir as RDIs. No painel "Statistics" é possível notar a curva do variograma da linha selecionada e a nuvem de dispersão dos dados.

A função $R D I$ também é capaz de gerar perfis separados em três gráficos considerando os tempos iniciais "early time", tempos intermediários "intermediate time" e tempos finais "late time". Os perfis são a resposta do campo secundário captado pelo equipamento em $m V$. 


\section{7 - Aplicações a dados reais}

\subsection{1 - Localização e Geologia}

Os dados são do depósito cristalino que fica na região Norte do Brasil na Província Mineral de Carajás (PMC) a qual metalogeneticamente é altamente mineralizada e fica a sudeste do Cráton Amazônico (Fig. 3.6), (Docegeo, 1988; Araújo et al., 1988; Meirelles et al., 1991; Teixeira \& Eggler, 1994; Tassinari \& Macaimbra, 2004; Lobato et al., 2006).

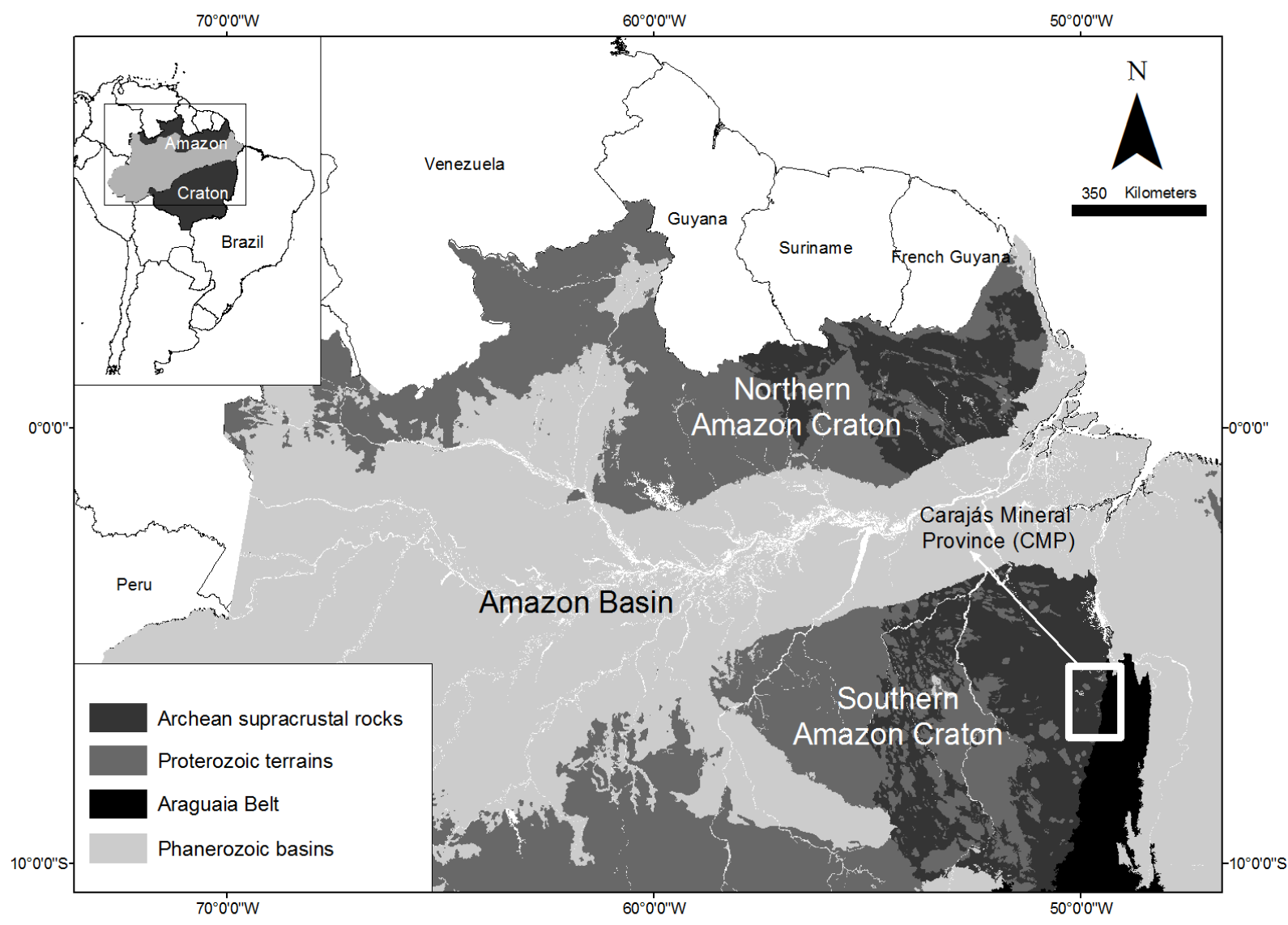

Figura 3. 6 - Localização do depósito cristalino em Carajás (Almeida Jr. et al., 2011)

O Depósito Cristalino situa-se na montanha Serra do Rabo, na parte sudeste do domínio Carajás contendo mineralização de $\mathrm{Cu}-\mathrm{Au}$, a qual é hospedada por rochas vulcânicas máficas a félsicas com alteração hidrotermal e intercalada com formação 
ferrífera do Grupo Grão Pará (2,74 Ga) e foi classificado como um depósito do tipo FeCu-Au-U-REE (Huhn et al., 1999).

A mineralização de $\mathrm{Cu}-\mathrm{Au}$ do Depósito Cristalino está hospedada em rochas vulcânicas intermediárias a félsicas hidrotermalmente alteradas e intercaladas com BIFs do Grupo Grão Pará. A mineralização ocorre em brechas e como stockworks, disseminações e preenchimento de fraturas e o recurso está estimado em mais de 500Mt com teor de $1.0 \% \mathrm{Cu}$ e $0.3 \mathrm{~g} / \mathrm{t} \mathrm{Au}$ (Huhn et al., 1999; Silva et al., 2006).

O método TDEM é muito importante para a exploração de grandes depósitos de sulfeto maciço. Os dados foram adquiridos com o equipamento PROTEM 57, com frequência de $30 \mathrm{~Hz}$, nas componentes $\mathrm{X}$, Y e Z, medindo $d B / d t$, a corrente empregada foi de $8 A$, a resposta do campo magnético secundário foi obtida em 20 canais de tempo, e a configuração da bobina transmissora foi de $200 \times 200 m$. A linha de direção do levantamento foi NE-SW, e o espaçamento entre linhas de $200 m$, a distância entre os pontos de medição variou entre 100 e $200 m$ (Fig. 3.7). 


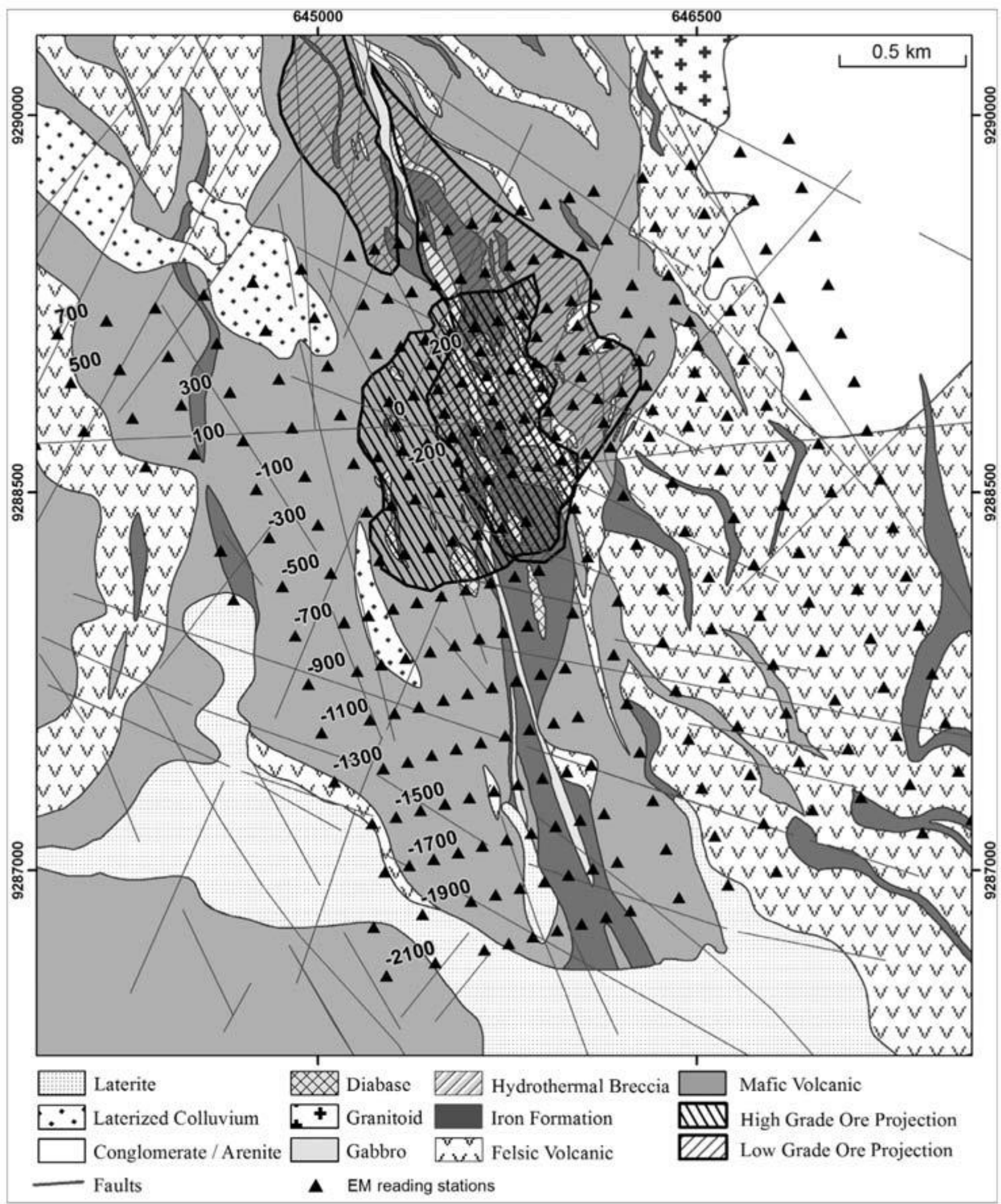

Figura 3. 7 - Mapa geológico do Depósito Cristalino e as estações pesquisadas em cada linha do levantamento (Melo et al., 2014). 


\section{8 - Análise dos resultados.}

O ImagEM foi aplicado a todos os dados do levantamento, contudo somente o resultado de duas linhas estão sendo apresentadas neste trabalho. As linhas $L-300$ e $L$ 1700 foram selecionadas devido à boa resposta do campo magnético secundário indicando possíveis condutores EM. Os perfis e os resultados das RDIs estão apresentados nas Figuras 3.8 e 3.9 respectivamente.

O perfil da linha L-300 (Fig. 3.8a, b e c) apresenta a resposta em $m V$ de cada canal pela distância da linha. O sinal é mais forte até $1300 m$ de distância para os primeiros canais, chegando até a $4 \cdot 10^{5} \mathrm{mV}$ na distância de $400 \mathrm{~m}$. Entre os canais 9 e 15 é possível notar uma resposta mais intensa entre 1000 e 1200m com a tensão próxima a $15000 \mathrm{mV}$ e um comportamento similar entre os canais 17 e 20 com picos de $80 \mathrm{mV}$.

A RDI da linha L-300 (Fig 3.8e) foi interpolada com célula de 25m e apresenta um aumento da condutividade entre 200 e 1200m de distância sendo a resistividade menor que $10^{4} \Omega \cdot \mathrm{m}$, as linhas de contorno (Fig. 3.8d) delimitam esta mesma região com resistividade próxima de $1000 \Omega \cdot \mathrm{m}$. A profundidade deste corpo atinge entorno de 400m podendo chegar aos 600m entre 1000 e 1200m de distância e um mergulho na direção SW-NE de forma gradual.

O sinal do perfil da linha $L-1700$ (Fig. 3.9a) é mais forte entre 500 e $1000 m$ de distância para os canais de 1 a 7 , chegando até a $20 \cdot 10^{4} \mathrm{mV}$ próximo de $750 \mathrm{~m}$. Entre os canais 9 e 15 (Fig. 3.9b) é possível notar uma resposta mais intensa entre 400 e 650m e a tensão correspondente próxima a $2500 \mathrm{mV}$, um pouco mais próximo do início da linha podemos constatar um pico de $40 \mathrm{mV}$ entre os canais 17 e 20 (Fig. 3.9c). 

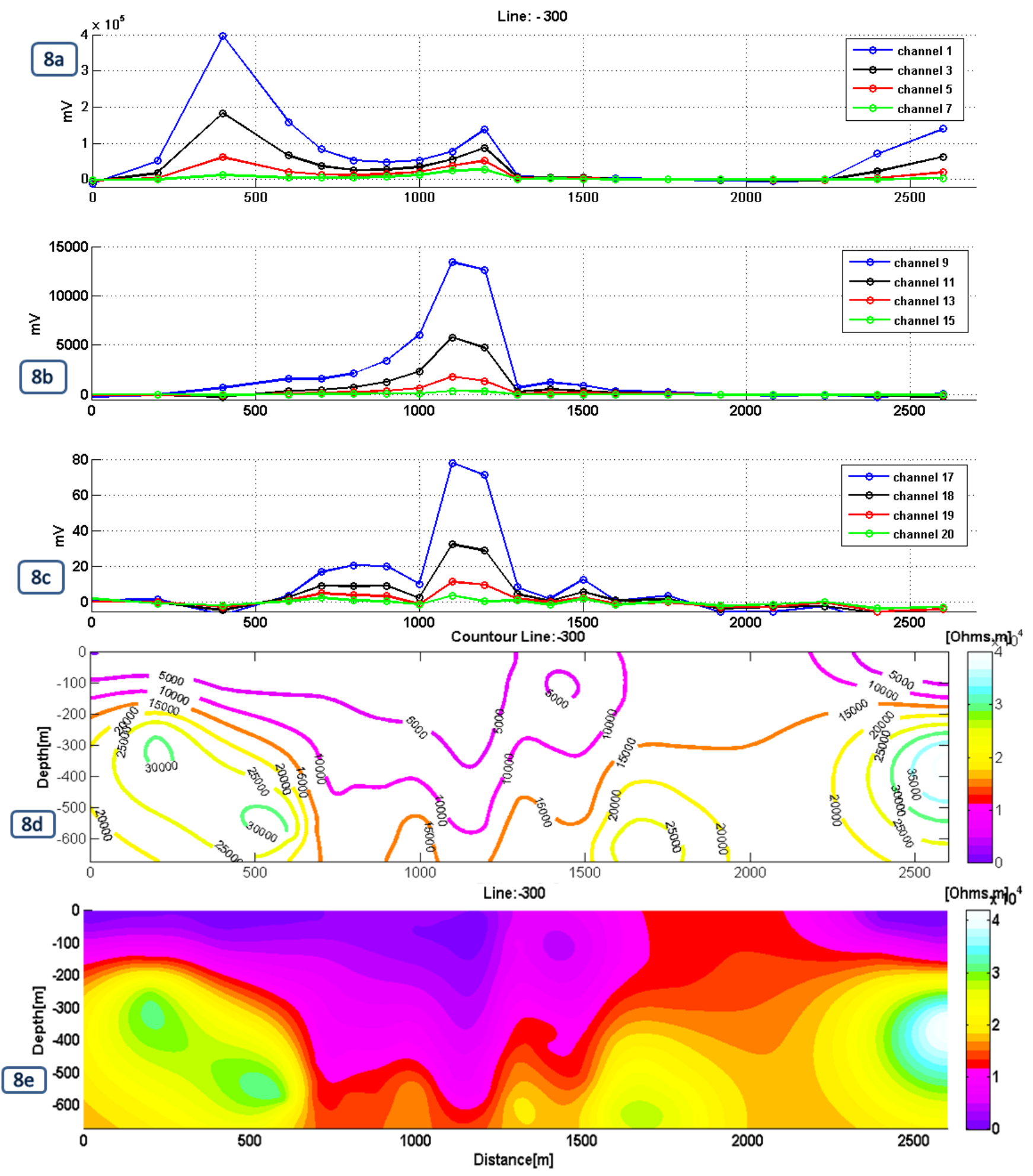

Figura 3. 8 -Linha $L-300$, do levantamento EM realizado com o PROTEM no

Depósito de Carajás. Fig. 3.8a O sinal do perfil para os canais de 1 a 7. Fig. 3.8b perfil entre os canais 9 e 15, Fig. 3.8c perfil entre os canais 17 e 20. Fig. 3.8d Linhas de contorno da linha $L-300$. Fig. 3.8 e RDI da linha $L-300$. 

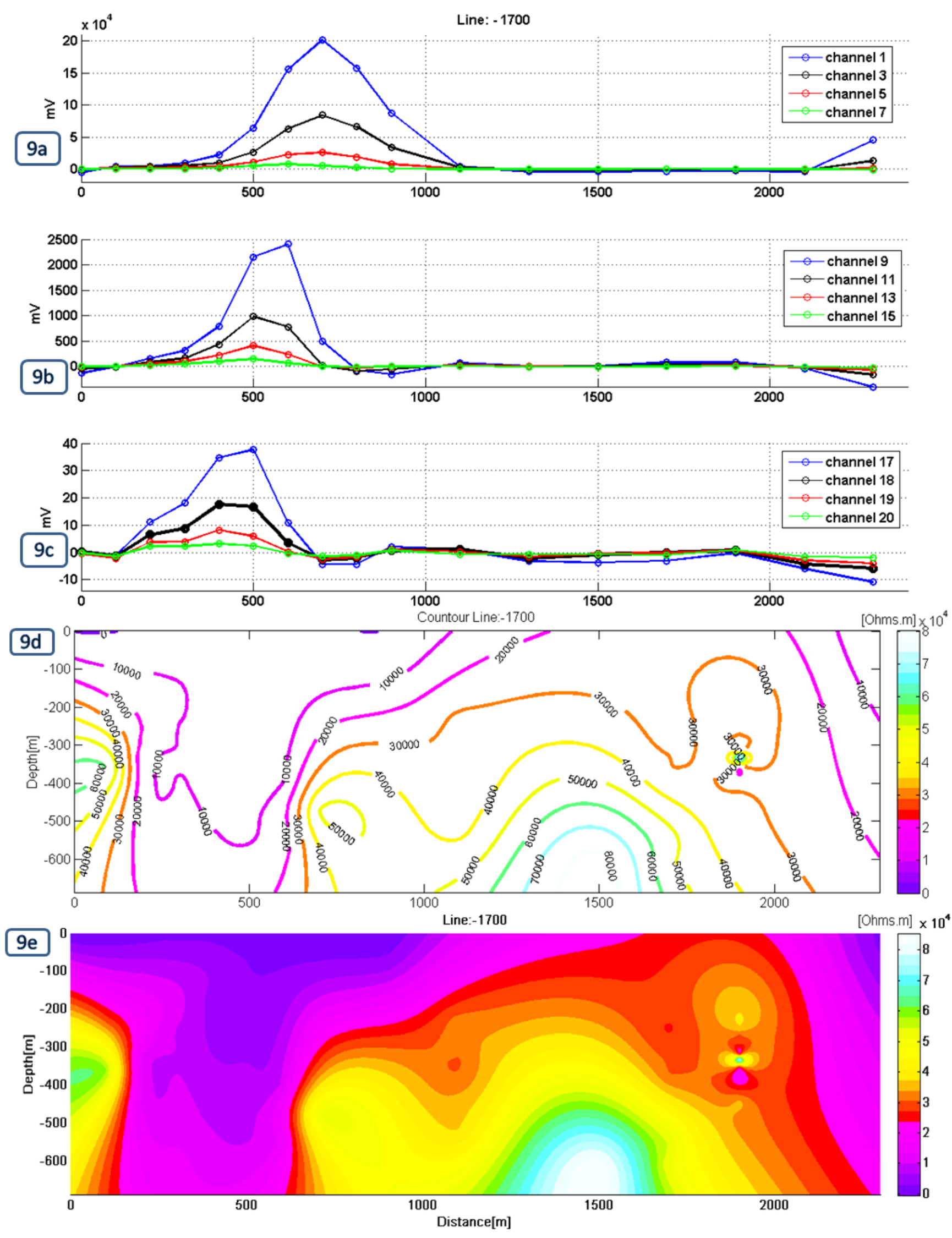

Figura 3. 9 - Linha L-1700, do levantamento EM realizado com o PROTEM no

Depósito de Carajás. Fig. 3.9a O sinal do perfil da linha L-1700 para os canais de 1 a 7. 
Fig. 3.9b perfil entre os canais 9 e 15, Fig. 3.9c perfil entre os canais 17 e 20. Fig. 3.9d Linhas de contorno da linha $L-1700$. Fig. 3.9e RDI da linha $L-1700$.

Na linha L-1700 constata-se um alvo condutivo com ângulo de mergulho elevado no sentido NE-SW (Fig. 3.9c). Este depósito encontra-se entre o início da linha do levantamento até próximo a $1200 m$ de distância. A resistividade é inferior a $2 \cdot 10^{4} \Omega \cdot m$. A maior parte deste alvo se encontra entre 200 e $600 m$ de distância (Fig. 3.9d e 3.9e).

\section{9 - Conclusão}

Pode-se demonstrar neste artigo que o software ImagEM apresenta bons resultados qualitativos no processamento de dado eletromagnéticos no domínio do tempo. O método da secante é capaz de interagir de forma rápida e eficiente sobre as equações de resistividades, proporcionando uma inversão simplificada para construção de perfis 2D. Devido sua agilidade o ImagEM pode ser bastante eficaz para o processamento dos dados, já que é possível obter uma resposta confiável durante o levantamento.

Os dados levantados do Depósito Cristalino de Carajás apresentam uma resposta compatível com a resistividade da região, além da localização e direção do mergulho dos corpos condutivos descrevendo com boa precisão a subsuperfície da região. Teste preliminares realizados por Melo et al. (2014) utilizando outro modelador, coincide com os resultados obtidos pelo ImagEM. O software ImagEM é conciso e pode ser instalado nas plataformas Windowns e Linux. 


\subsection{0 - Agradecimentos}

Os autores deste trabalho agradecem aos dirigentes e pesquisadores do Observatório Sismológico e do Instituto de Geociências da Universidade de Brasília (UnB) pela liberação de suas instalações e das licenças dos softwares MATLAB ${ }^{\circledR}$. Agradecem também à Vale S.A, pela permissão para trabalhar com estes dados e publicar os resultados. Agradeço a CAPES pelo suporte financeiro da bolsa de pesquisa e ao amigo Geólogo Mario Paes de Almeida pelo suporte nos gráficos da região de Carajás. O primeiro autor agradece o irmão/amigo Sólon Povoa Neto que aprimorou a estrutura do programa e melhorou sua funcionalidade. 


\subsection{1 - Referências}

Almeida Júnior, M.P.,Von Huelsen, M.G., Takenaka, G., Coelho-Silva, A.T.M, Rocha, A.A, Travaglia Filho, U.J., Freitas, C., Aires, B., 2011. Modeling of airbone data (magnetic and electromagnetic) of Cristalino $\mathrm{Cu}-\mathrm{Au}$ Deposit, Carajás, Pará, Brazil, In: 12th International Congress of the Brazilian Geophysical Society held in Rio de Janeiro, Brazil, August 15-18.

Anderson, W. L.1982. Adaptative nonlinear least-squares solution for constrained or unconstrained minimization problems (Subprogram NLSOL). USGS Open-File Rept. 82-68, 66p.

Araújo, O.J.B., Maia, R.G.N., Xafi, J.J.S., Costa, J.B.S., 1988. A megaestruturação arqueana da folha Serra dos Carafás. VII Congresso Latino Americano de Geologia, pp. 324 - 333.

Christiansen, A.V., Auken, E., Sorensen, K. 2009. In Reinhard Kirsch. Groundwater Geophysics A Tool for Hydrogeology. Ed. Spring, second edition. P. 179 $-226$.

Melo, A. T. C., Von Huelsen M.G., Travaglia Filho, U.J., Fuck R. 2014. A Comparison Between 1d Electromagnetic Modeling Programs: A Case History For Cristalino Iron Oxide Copper Gold Deposit, Carajás Mineral Province, Brazil. Revista Brasileira de Geofísica, vol. 32(3). P. 433-443

Davis, J.C. 2002. Statistics and Data Analysis in Geology, third edition. John Wiley and Sons, New York.

Docegeo (Rio Doce Geologia e Mineracao - Distrito Amazonia) 1988. Revisao litoestratigrafica da Provincia Mineral de Carajás, Para. In: SBG, Congresso Brasileiro de Geologia, 35, Belem. Anexos, vol. Provincia Mineral de Carajás - Litoestratigrafia e Principais Depositos Minerais. p. 11-54. 
Eaton, P. A. \& Hohmann, G. W. 1989. A rapid inversion technique for transient electromagnetic soundings. Physics of the Earth Planetary Interiors, 53: 384-404.

Frischknecht, F. C. \& Raab, P. V. 1984.Time domain electromagnetic soundings at the Nevada test site. Geophysics. 49: 981-992.

Fullagar, P. K. 1989. Generation of conductivity-deph pseudo sections from coincident loop and in-loop TEM data. Expl. Geophys., 20: 43-53

Fullagar, P.K. \& Reid, J.E. 1992. Condutivity - Depth Transformation of Fixed Loop TEM Data. Exploration Geophysics, $n^{0} 23$. P. 515 -519.

Ghorbani, A., Camerlynck, C., Florsch, N. 2009. CR1Dinv: A Matlab program to invert 1D spectral induced polarization data for the Cole - Cole model including electromagnetic effects. Computers \& Geosciences, vol. 35. P. 255-266.

Hoversten,G. M. \& Morrison, H. F. 1982. Transient fields of a current loop source above a layered earth. Geophysics, 47: 1068-1077. International Conference On Mineral Exploration, P. $489-496$.

Huang, H. \& Rudd, J. 2008. Conductivity-depth imaging of helicopter-borne TEM data based on a pseudolayer half-space model. Annual Meeting Selection. Geophysics,vol. 73, nº 3 May - June 2008; p. F115 - F120.

Huhn, S.R, Souza, C.I., Albuquerque, M.C., Leal, E.D., Brustolin, V. 1999. Descoberta Do Depósito $\mathrm{Cu}(\mathrm{Au})$ Cristalino: Geologia E Mineralização Associada Região Da Serra Do Rabo-Carajás - Pa. In: Simpósio de Geologia da Amazônia, Manaus, P. 140-143.

Ingeman-Nielsena, T. \& Baumgartner, F. 2006. CR1Dmod: A Matlab program to model 1D complex resistivity effects in electrical and electromagnetic surveys. Computers \& Geosciences, vol. 32. P. 1411-1419. 
Irving, J. \& Knight, R. 2006. Numerical modeling of ground-penetrating radar in 2-D using MATLAB, Computers \& Geosciences, vol. 32. P.1247-1258.

Kearey, P. Brooks, M., Hill, I. 2009, “Geofísica de Exploração”. Ed. Oficina de Textos, São Paulo.

Kelbert, A., Meqbel, N., Egbert, G.D. 2014. ModEM: A modular system for inversion of electromagnetic geophysical data. Computers \& Geosciences, vol. 66. P. $40-53$.

Kitanidis, P. 1997. Introduction to Geostatistics - Applications in Hydrogeology. Cambridge University Press, Cambridge.

Lobato, L.M., Rosière, C.A., Silva, R.C.F., Zucchetti, M., Baars, F.J., Sedane, J.C.S., Javier Rios, F., Pimentel, M., Mendes, G.E., Monteiro, A.M. 2006. A mineralização hidrotermal de ferro da Província Mineral de Carajás - controle estrutural e contexto na evolução metalogenética da província. In Marini O.J., Queiroz E.T., Ramos W.B. (Eds.) Caracterização de Depósitos Minerais em Distritos Mineiros da Amazônia. Brasília,DNPM, CT-Mineral / FINEP, ADIMB, 21-92.

Macnae, J. C. \& Lamontagne, Y. 1987. Imaging quasi-layered conductive structures by simple processing of transient electromagnetic data. Geophysics, 52: 545554.

Macnae, J. C., Smith, R., Polzer, B. D., Lamontagne, Y., Klinkerts, P. S. 1991. Conductivity-Depth Imaging of Airborne Electromagnetic Step-Response Data. Geophysics. Vol. 56, No. 1 (January 1991); P. 102-I 14.

Mahmoud, S. F., Botros, A. Z., Wait, J. R.1979. Transient Electromagnetic Fields of a Vertical Magnetic Dipole on A Two-Layer Earth. Proceeding of the IEEE. Vol. 67, No. 7. P. 1022 - 1029. 
McNeill, J. D. 1980a. Electrical Condutivity of Soils and Rocks. Geonics Limited. Technical Note TN -5 .

McNeill, J. D. 1980b. Electromagnetic Terrain Conductivity Meansurement at Low Induction Numbers. Geonics Limited. Technical Note TN - 6 .

McNeill, J. D. 1980c. Aplication of Transient Electromagnetic Techniques. Geonics Limited. Technical Note TN - 7.

Meirelles, M.R., Dardenne, M.A., 1991. Vulcanismo basáltico de afinidade shoshonítica em ambiente de arco Arqueano, Grupo Grão-Pará, Serra dos Carajás, Estado do Pará. In: Congresso Brasileiro Geologia, 33, Rio de Janeiro, 1991. Anais. Rio de Janeiro, SBG, v. 5: 2164-2174.

MathWorks, 2011, Disponível em: https://www.mathworks.com/matlabcentral/fileexchange/31055-kriging-and-inversedistance-interpolation-using-gstat?s tid=srchtitle. Acessado em 2 de julho de 2012.

Nabighian, M. N. 1972. The Analytic Signal of Two - Dimensional Magnetic Bodies with Polygonal Cross - Section: Its Properties and Use For Automated Anomaly Interpretation. Geophysics, vol. 37, No. 3 (June 1972), P. 507417.

Nabighian, M. N. 1979. Quasi-static transient response of a conductivity halfspace - an approximate representation. Geophysics, 44: $1700-1705$.

Nabighian, M.N. \& Macnae C.J. 1987a., Eletromagnetic Theory for geophysical applications. In Nabighian, M.N. Ed, Eletromagnetic methods in applied geophysics, v. 1, Theory, Investigations in geophysics, SEG, 203-252.- 1987b. Time domain eletromagnetic prospecting methods. In Nabighian, M.N. Ed, Eletromagnetic methods in applied geophysics, v. 1, Theory, Investigations in geophysics, SEG, 427-520.

Nekut, A. G. 1987. Direct inversin of time-domain eletromagnetic data. Geophysics, 52: 1432-1435. 
Newman, G. A., Anderson, W. L. \& Holmann, G. W. 1987. Interpretation of transient electromagnetic soundings over three-dimensional structures for the centralloop configuration. Geophys. J. R. astr. Soc. 89: 889-914.

Raab, P. V. \& Frischknecht, F. C. 1983. Desktop computer processing of coincident and central loop time-domain electromagnetic data . U.S. Geol. Surv. Open File Rep. 83-240.

Rao, K. P. \& Babu, G. A. 2009. Microsoft C\# .NET program and electromagnetic depth sounding for large loop source. Computers \& Geosciences, vol. 35. P. $1369-1378$.

Reynolds, J. M. 1977. An Introduction to Applied and Environmental Geophysics. Ed. Wiley, p. $553-680$.

Rijo, L., Pelton, W. H., Feitosa, E. C., Ward, S. H. 1977. Interpretation of Apparent Resistivity Data From Apodi Valley, Rio Grande do Norte, Brazil. Geophysics. Vol. 42, No. 4 (June 1977): P. 811-822.

Ryu, J., Morrison, F., Ward, S., 1970. Electromagnetic Fields About a Loop Source of Current. Geophysics, vol. 35, n ${ }^{\circ}$ 5. October, 1970. P. $862-896$.

Sandberg, S. K., 1988, Microcomputer software for the processing and forward modeling of transient electromagnetic data taken in the central loop sounding configuration: New Jersey Geological Survey Open-File Report 88-1.

Sandwell, D.T. 1987. Biharmonic Spline Interpolation of GEOS-3 and SEASAT Altimeter data. Geophysical Research Letters 2:139-142

Silva, M.G., Teixeira, J.B.G, Pimentel, M.M., Vasconcelos, P.M., Arielo, A., Rocha, W.J.S.F. 2006. Geologia e mineralização de Fe-Cu-Au do alvo GT46 (Igarapé Cinzento), Carajás. In Marini O.J., Queiroz E.T., Ramos W.B. (Eds.) Caracterização de 
Depósitos Minerais em Distritos Mineiros da Amazônia. Brasília, DNPM, CT-Mineral / FINEP, ADIMB, 93-151.

Spies, R.R. 1978. Interpretation of Transient Electromagnetic Measurements Using the Apparent Conductivity Concept. Department Of National Development. Bureau Of Mineral Resources, Geology And Geophysics.

Talwani, M. 1965. "Computation with the help of a digital computer of magnetic anomalies caused by bodies of arbitrary shape". Geophysics 30: 797-817.

Tassinari, C.C.G., Macambira, M. 2004. A evolução tectônica do Cráton Amazônico. In: Mantesso - Neto, V.; Bartorelli, A.; Carneiro, C.D.R.; Brito Neves, B.B. (Eds.), Geologia do Continente Sul Americano: Evolução da obra de Fernando Flávio Marques Almeida. São Paulo, p. 471-486.

Teixeira, J. B. G., Eggler, D. H. 1994. Petrology, geochemistry, and tectonic setting of Archean basaltic and dioritic rocks from the N4 iron deposit, Serra dos Carajás, Pará, Brazil. Acta Geologica Leopoldensia 17 (40), 71-114.

Telford, W.M., Geldart, L.P., Sheriff, R.E., “Applied Geophysics”, Cambridge University, 1990.

Travaglia Filho, U.J. 2012. Desenvolvimento e implementação de software para obtenção da resistividade pela profundidade de dados TDEM. Master Dissertation no. 28, Instituto de Geociências - Universidade de Brasília - UnB, 102 pp.

Von Huelsen, M. G. V., Moraes, R. A. V, Carvalho, T.. 2008. “CDI Versus inversão - aplicação a dados reais”. Rev. Bras. Geof., vol.26, n³, São Paulo.

Von Huelsen, M. G. V., Moraes, R. A. V. 2008. "Imageamento da subsuperfície baseado na condutividade: obtenção de CDIs para o Sistema Geotem”. Rev. Bras. Geof., vol.26, n³, São Paulo. 
Von Huelsen, M. G. V.. 2007. “Interpretação de Dados de Eletromagnetometria Aeroeletrotransportada (AEM) do Sistema GEOTEM (Domínio do Tempo)”. Tese de Doutorado n 080, Instituto de Geociências - Universidade de Brasília - UnB, 202 pp.

Wait, J. R. \& Hill, D. A. 1971. Transient Signals from a Buried Magnetic Dipole. Journal Of Applied Physics, vol. 42, nº10. P. 3866 - 3869.

Wait, J. R. \& Ott, R. H. 1971. On Calculating Transient Electromagnetic Fields of a Small Current - Carrying Loop Over a Homogeneous Earth. Institute for Telecommunication Sciences. Scientific Report n ${ }^{\circ} 53$.

Wait, J. R. 1951. A conducting sphere in a time varying magnetic field. Geophysics, 16, 666-672.

Wolfgram, P. 1995. Discussion on: Conductivity - Depth transformation of GEOTEM data. Exploration Geophysics, nº 26. P. 179-185.

Zhdanov, M. S., Traynin, P. N., Portniaguine, O. 1995. Resistivity Imaging by Time Domain Electromagnetic Migration (TDEMM). Exploration Geophysics, vol. 26. P. 186-194. 


\title{
Capítulo 4
}

\section{ImagEM - Programa de processamento e inversão de dados}

\section{eletromagnéticos utilizando as componentes longitudinais e}

\author{
verticais. \\ Umberto José Travaglia Filho ${ }^{1}$, Mônica G. Von Huelsen ${ }^{1}$ \\ 1 - Universidade de Brasília - UnB, Instituto de Geociências - IG
}

\section{1 - Resumo}

As pesquisas geofísicas em Métodos Eletromagnéticos (EM) que utilizam as três componentes do campo secundário se tornaram muito frequentes após os anos 80 , contudo o processamento utilizando as três componentes ainda é pouco utilizado, sendo usual o processamento apenas com a componente vertical. O ImagEM Programa de Modelagem 2D Eletromagnética no Domínio do Tempo trás dentre as suas sub-rotinas o Energy Envelope. Esta função é capaz de processar dados eletromagnéticos (nas componentes $z, x$ e y) de forma interativa, apresentando graficamente o comportamento do campo eletromagnético secundário, o envelope de energia calculado por meio da transformada de Hilbert, a profundidade, o mergulho e a direção do alvo. Com o objetivo de realizar um teste do software desenvolvido, foram utilizados os dados obtidos pela Geoterrex, adquiridos na plataforma GEOTEM, na região sul do Arizona (USA), sobre a Bacia de San Pedro. Foram analisadas as linhas aéreas do levantamento EM que cortam a Bacia de San Pedro, em especial uma área de resposta condutiva referente ao aquífero local, onde foi modelada a condutividade do alvo, além da sua extensão e profundidade. 
Abstract

The geophysical research in electromagnetic methods (EM) using three components of the secondary field became common after the decade of 1980 , however processing routines using the three components are still not common, usually processing only the vertical component. The ImagEM computer program Electromagnetic Modeling 2D in Time Domain provides the Energy Envelope. This function is capable of processing electromagnetic data (components $z, x$ and $y$ ) in an interactive way, graphically presenting the secondary electromagnetic field behavior, the energy envelope calculated by the Hilbert transform, depth, dip and direction of the target. In order to test the developed software, the data used were obtained by Geoterrex acquired in GEOTEM platform in the southern region of Arizona (USA), on the Basin of San Pedro. Airlines lifting MS were analyzed cutting Basin of San Pedro, in particular a conductive response area related to the local aquifer, where modeling of the target conductivity was performed, as well as its length and depth. 


\section{2 - Introdução}

Nos anos 80 com o desenvolvimento eletrônico dos equipamentos, de modo geral, foi possível acrescentar múltiplos canais de registro em equipamentos geofísicos, como de posição, de altitude, da distância e das componentes (z, x e y) não somente para Métodos Eletromagnéticos Transientes (TDEM), como também Magnetotelúrico (MT), tanto em levantamento do tipo borehole, como aerotransportados e terrestres. Em janeiro de 1991, a Crone Geophysics desenvolveu um sistema de três componentes, o Downhole ElectroMagnetics (DHEM), em cooperação com a Noranda Exploration Co. Ltd, com o objetivo específico de se obter melhor resolução de alvos condutores em poços. A pesquisa foi bem sucedida no depósito mineral de Noranda, em New Brunswick, Canadá (Macnae, 1984; Hogg, 1986; Newman et al., 1987; Annan, 1986; Annan \& Lockwood, 1991; Hodges et al., 1991; Cull, 1993). Em Novembro de 1991, este mesmo sistema foi utilizado no depósito mineral de Balcooma ao norte de Queensland para a Lachlan Resources, sendo este, o primeiro levantamento comercial com três componentes utilizando o DHEM na Austrália. Sistemas terrestres de multicomponentes também foram desenvolvidos como o MaxMin, o PROTEM da Geonics, o Zongue GDP -2, o SIROTEM, o UTEM da Lamontagne Geophysics Ltd. (Frischknecht et al., 1991; Palacky \& West, 1991; Spies \& Frischknecht, 1991; Nabighian \& Macnae, 2005 ).

Segundo Macnae (1984) as componentes horizontais, juntamente com a componente vertical, agregam uma maior quantidade de informações, além disso, a componente vertical pode ser uma componente menos sujeita aos ruídos esféricos. Este estudo foi bem complementado com o trabalho de Smith \& Keating (1996) o qual modela placas condutivas, variando o ângulo, mergulho, direção e profundidade. 
A aquisição de dados eletromagnéticos aerotransportados tornou-se uma prática muito comum devido à capacidade de obter informação eletromagnética de grandes áreas e gerar uma quantidade significativa de dados em curto tempo. Podem-se destacar as pesquisas feitas pela Fugro Airbone Surveys, utilizando o GEOTEM, tais como a área mineralizada na propriedade Black Bay em Ontário, Canadá, contratada pela empresa Avalon Ventures Limited em outubro de 2002, com foco na investigação em Níquel (Ni), Cobre $(\mathrm{Cu})$ e Elementos do Grupo de Platina (PGE), ou os levantamentos mais recentes ao norte de Edmonton-Calgary Corridor (ECC), no estado de Alberta, Canadá realizado em 2015 para a Alberta Geological Survey (AGS) em parceria com a Environment and Sustainable Resource Development (ESRD), com o objetivo de investigar novos aquíferos devido ao crescimento populacional e a necessidade do abastecimento de água. O uso de múltiplas componentes nestes levantamentos tem ajudado no processamento e na interpretação geológica das áreas pesquisadas (Hogg \& Associates, 2003; Slattery \& Andriashek, 2012).

Neste trabalho foi descrito uma forma de processamento dos dados Eletromagnéticos no Domínio do Tempo (Time Domain Electromagnetic - TDEM) utilizando a função Envelope de Energia implementada no programa ImagEM. Este programa tem como objetivo auxiliar no processamento e interpretação de dados eletromagnéticos terrestres ou aéreos, no domínio do tempo, que foram adquiridos com as três componentes (x, y e $\mathrm{z}$ ). Para a demonstração do programa foram utilizados os dados obtidos pelo GEOTEM da Geoterrex sobre o Vale de San Pedro, ao sul do Arizona, Estados Unidos da América.

As funções utilizadas no processamento dos dados foram: a) GeoTEM process, que realizou a inversão dos dados utilizando o método da secante, para obter a resistividade e profundidade aparente; b) "Resistivity Depth Imagem” (RDI) que é capaz 
de gerar perfis da tensão medida, uma seção da imagem da resistividade pela profundidade e um mapa de contorno com esta resistividade; c) O Energy Envelope que utiliza as três componentes, a transformada de Hilbert e o Envelope de Energia (EE) para calcular o mergulho e a profundidade das regiões condutivas. Assim será apresentada a teoria do EE, e posteriormente a aplicação a dados reais.

\section{3 - Método do Envelope de Energia - Fundamento Teórico}

\subsection{1 - Comportamento do Campo Secundário em Camadas.}

O estudo de multi-componentes começa na análise individual de cada uma delas. A componente vertical do campo magnético secundário $B z$ apresenta uma intensidade maior em relação às outras duas componentes, principalmente nos últimos canais "late times", e a maior parte da curva do campo secundário $B z$ fica acima da curva do ruído ambiental de 30 ppm (Fig. 4.1). Por possuir esta característica em relação à componente $B x$, a componente $B z$ é a principal referência no comportamento do sinal com relação ao envelope de energia (Morrison et al., 1969; Fraser, 1972; Macnae, 1984; McCracken et al., 1986; Macnae et al., 1991). 


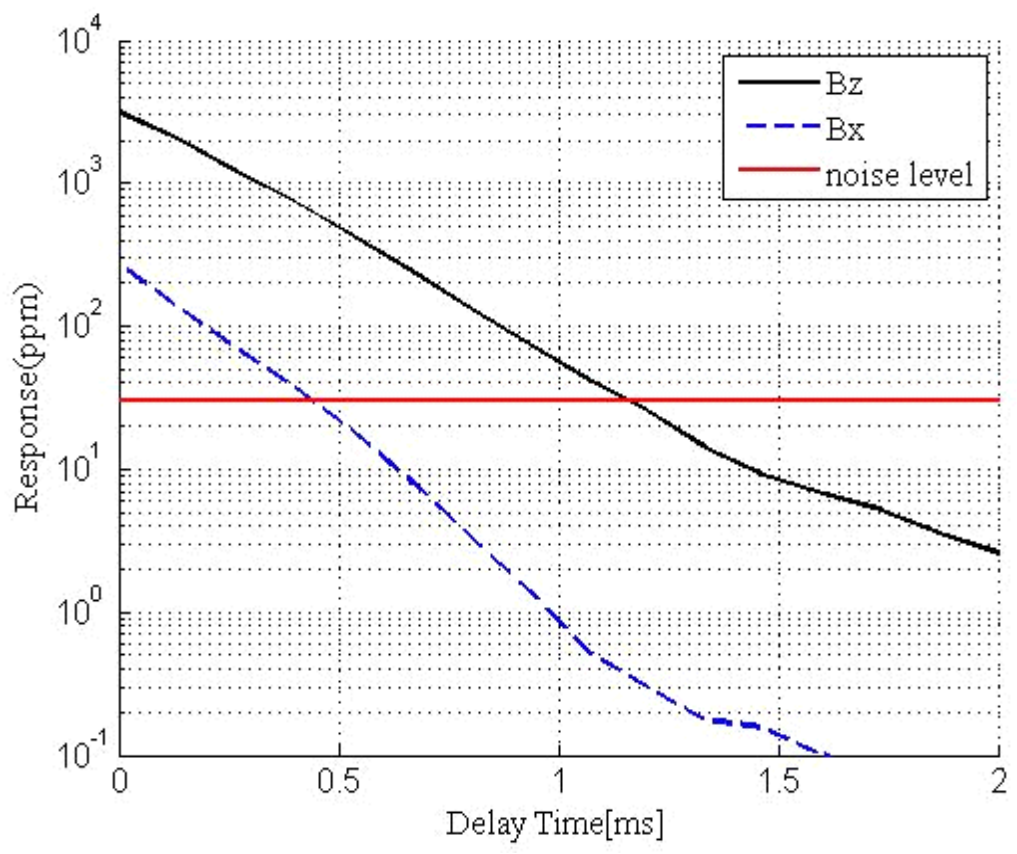

Figura 4.1 - As curvas de resposta de Bz (linha preta) e Bx (linha azul tracejada) do canal 10 registrados pelo levantamento utilizando o GEOTEM. O nível de ruído de 30 ppm é considerado um valor típico em ambas as componentes. (adaptado de Smith \& Keating, 1996).

Utilizando os dados oriundos do SPECTREM, Macnae et al. (1991) mediu a magnitude do campo e observou que a componente $B y$ é zero considerando um modelo de camadas homogêneas e sem heterogeneidade lateral e diferente de zero quando há heterogeneidade lateral.

\subsection{2 - Modelagem de condutores discretos.}

Os modelos de condutores discretos aplicados ao programa Energy Envelope se assemelham aos modelos de placas descritos por Dyck \& West (1984), ou seja, modelos de placas condutivas em perspectiva que representam a geometria e indução do campo magnético sobre o corpo alvo. Contudo, a resposta individual de cada componente (x, y 
e z) para estes modelos de placas, não deixa claro o comportamento do alvo, dificultando a interpretação geológica.

Uma forma de tratamento dos dados para uma melhor interpretação é retirar a tendência proveniente do equipamento durante o voo (Fig. 4.2). Aplicando os testes nos dados utilizados nesta pesquisa, foi gerado um perfil da amplitude do campo vertical $B z$, a linha azul representa os dados do canal 10 registrados pelo GEOTEM, a linha vermelha representa os mesmos dados após a retirada da tendência. Abaixo do sinal está representada a possível posição da placa condutiva. A tendência dos dados causada pelo acoplamento entre o transmissor e receptor, foi removida utilizando a função detrend do MATLAB, esta função subtrai o valor médio de cada dado de tempo, ou dados de sinal da série temporal. Após a retirada da tendência os dados foram submetidos à transformada de Hilbert nas três componentes do campo secundário expressa por:

$$
\bar{B}(\hat{z})=\frac{1}{\pi} \int_{-\infty}^{+\infty} \frac{B(z)}{z-\hat{z}} d z
$$

onde $B(z)$ é a componente no eixo z e $\hat{z}$ é a componente complexa do sinal do campo secundário. Aplicando a mesma equação para as outras duas componentes foi possível descrever o Envelope de Energia ( $E E)$ dado por:

$$
E E=\sqrt{B_{x}^{2}+\bar{B}_{x}^{2}+B_{y}^{2}+\bar{B}_{y}^{2}+B_{z}^{2}+\bar{B}_{z}^{2}}
$$

Como descrito no item 4.3.1, a componente By pode ser zero. Na condição em que a aeronave sobrevoe um condutor em posição transversal à linha de voo (homogeneidade lateral) a componente $B y$ deverá ser próxima de zero, simplificando assim a equação 4.2. O EE reduz o efeito da assimetria entre o sistema EM e o condutor. Normalizando as componentes $B z$ e $B x$ pelo $E E$ é possível melhorar a simetria dos perfis fazendo com que o envelope atinja valor máximo no topo do corpo. 


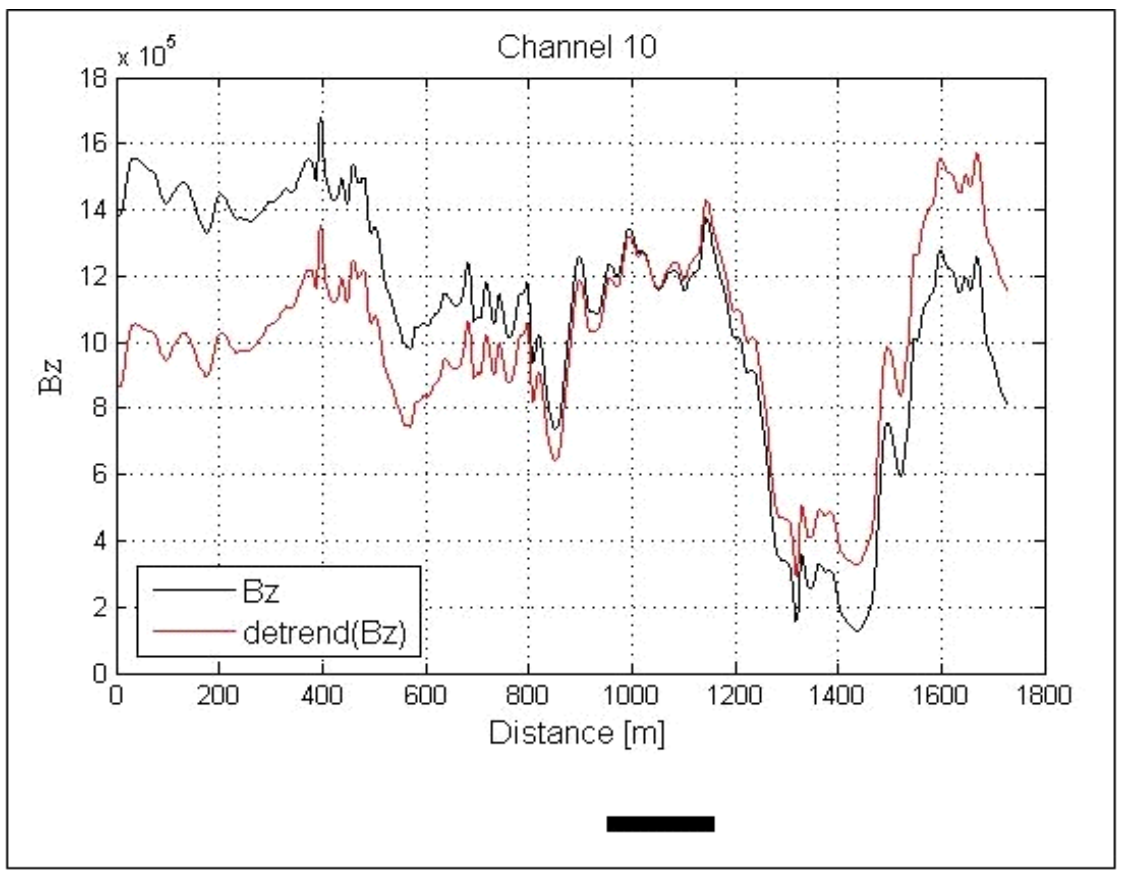

Figura 4. 2- Sinal do canal 10 registrado pelo GEOTEM. A componente $B z$ (preto) representa os dados coletados, A componente detrend $(B z)$ (vermelho) representa o mesmo dado com a retirada da tendência.

\subsection{3 - Cálculo do mergulho do alvo.}

Como citado anteriormente à normalização do sinal é feita pela razão entre a componente do campo secundário e o EE. Posteriormente o mergulho é calculado com base na razão $(R)$ entre dois picos de energia consecutivos deste sinal normalizado (eq. 4.3). Contudo para mergulhos rasos, os picos de energia da razão $B x / E E$ não costumam ser evidentes e por isso frequentemente adota-se a razão Bz/EE (Fig. 4.3). Este mergulho se comporta semelhante a relação trigonométrica:

$$
\theta=2 \tan ^{-1}(R)
$$

Sendo $R$ a razão entre dois picos de energia (Smith \& Keating, 1996). 


\subsection{4 - Cálculo da Profundidade do alvo.}

À medida que a profundidade do corpo aumenta, a amplitude dos picos de energia diminui devido à perda de energia do sinal. Além da diminuição da amplitude do sinal ocorre um aumento na distância entre os dois picos positivos no perfil $B z / E E$. A profundidade do topo do alvo é obtida pela distância entre os picos (Fig. 4.3, eq. 4.4). Este comportamento segue uma regressão aproximadamente linear e é dada por:

$$
\text { depth }=(\mid \text { Apeaks } \mid-125) \cdot 0,88
$$

Onde $\mid \Delta$ peaks $\mid$ é a distância positiva entre os picos de $B z / E E$. O erro estimado da profundidade “depth" é de \pm 25 m (Palacky \& West, 1973).

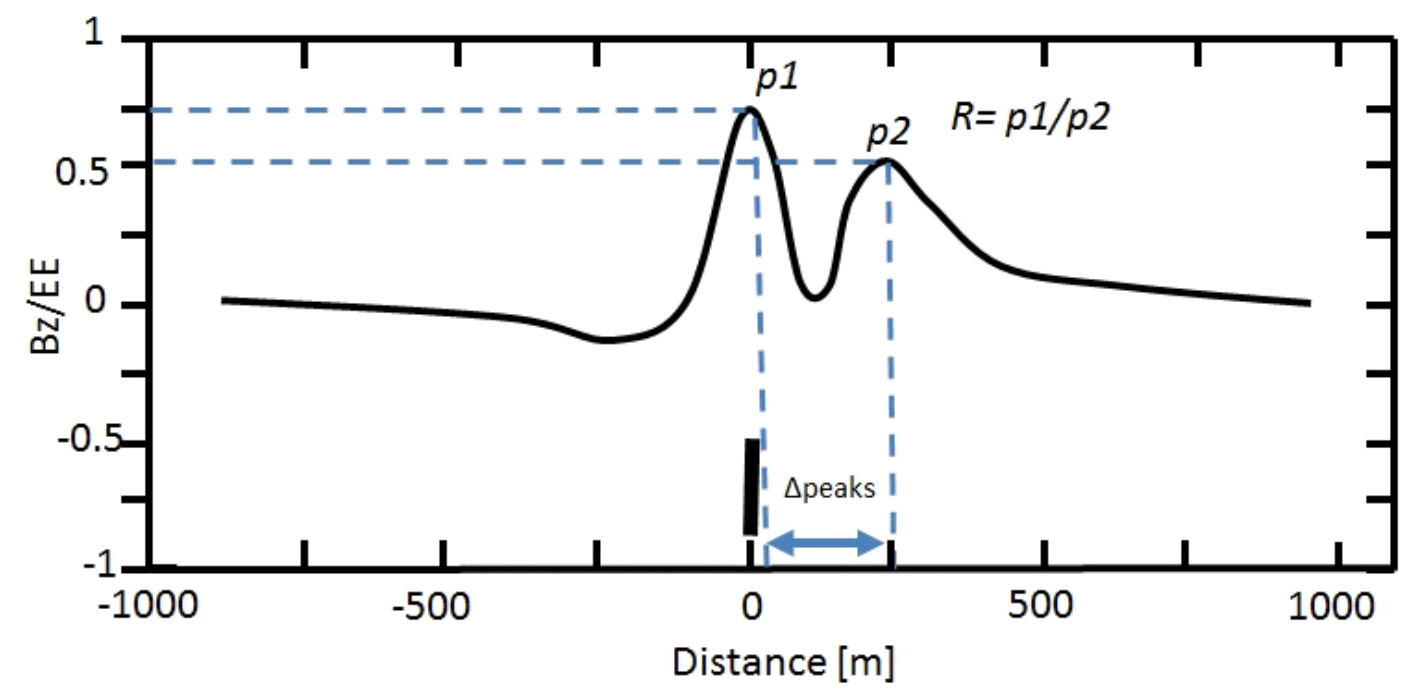

Figura 4. 3 - Gráfico da amplitude do campo na componente vertical normalizado pelo $E E$. Obtendo-se a Razão (R) e a distância $\mid$ Apeaks $\mid$ entre os picos de energia é possível calcular o mergulho e a profundidade do corpo alvo utilizando as equações 4.3 e 4.4 respectivamente (modificado de Smith \& Keating, 1996).

\subsection{5 - Determinação da distância (Off Set) e da direção (Strike).}

O Off Set é a distância entre duas linhas de voo, onde uma delas encontra-se sobre o alvo e a outra fora do alvo em questão (Fig. 4.4). A direção, ou Strike é o ângulo 
entre a placa condutiva e o eixo x, tomado na direção contrária a linha de voo, como indicado na Figura 4.5. Neste caso a componente $B y$ pode ser aproximada por composição vetorial de $B x$ e $B z$ dado por:

$$
B y=C_{\text {Strike }} \cdot B x+C_{O f f S e t} \cdot B z
$$

Onde $C_{\text {Strike }}=B y / B x$ e $C_{\text {OffSet }}=B y / B z$.

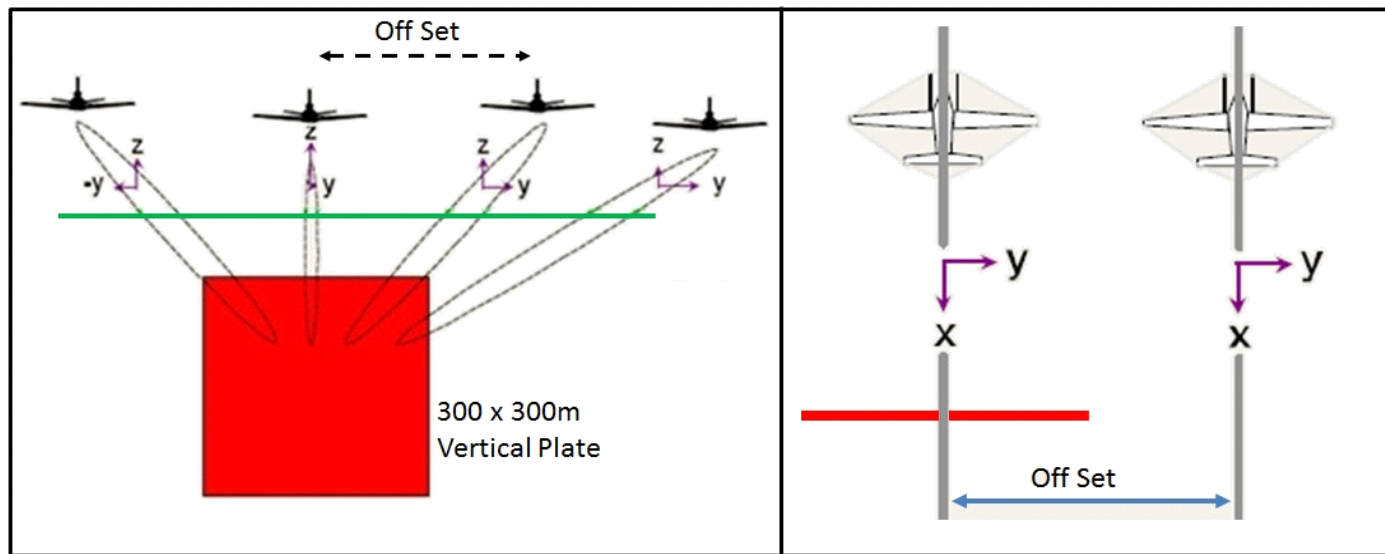

Figura 4. 4 - À esquerda o diagrama esquemático de uma placa condutora em plano vertical e o fluxo magnético do campo secundário. À medida que a aeronave se afasta da placa o campo magnético na componente By torna-se mais intenso (Smith \& Keating, 1996). À direita vista de cima da linha de voo e da placa condutora.

Palacky \& West (1973), estabeleceram que a relação de arco tangente para $C_{\text {OffSet }}$ é o ângulo entre o plano de voo na direção $x$ e o centro do corpo para a direção fixa em $90^{\circ}$ variando somente em deslocamento (Off set) e esta relação é dada por $\phi=\tan ^{-1}($ $\left.C_{\text {OffSet }}\right)$.

A distância estimada entre a componente vertical $x$ e o topo do condutor $(D)$ é obtida utilizando o método descrito por Palacky e West (1973):

$$
D=\sqrt{d O f f^{2}+d e p t h^{2}}
$$

Onde depth é a profundidade dada pela equação 4.4, e dOff é distância dado por:

$$
d O f f=\text { depth } \cdot \tan (\phi)=\text { depth } \cdot C_{\text {OffSet }} .
$$


O ângulo de Strike pode ser apresentado como a variação do ângulo sobre a placa condutiva quando não há deslocamento (Off set igual a zero) (Fig. 4.5). Utilizando o sistema DIGital de processamento de dados com Helicóptero Eletro-Magnetic (DIGHEM), Fraser (1972) constatou que os valores de $C_{\text {strike }}$ se assemelham ao comportamento trigonométrico dado por:

$$
\varphi=90-\operatorname{tang}^{-1}\left(C_{\text {strike }}\right)
$$

Onde $\varphi$ é a variação do ângulo de Strike.

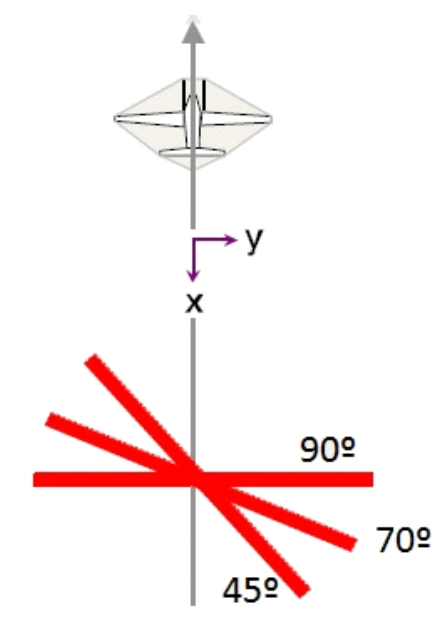

Figura 4. 5 - Diagrama esquemático mostrado a variação do ângulo de Strike $\varphi\left(45^{\circ}, 70^{\circ}\right.$ e $90^{\circ}$ ) em relação à linha do voo tomando a direção do eixo "x" como referencial.

\subsection{6 - Detecção Lateral}

Wait (1982) mostrou que o fluxo do campo magnético secundário By torna-se mais intenso à medida que se afasta do centro do alvo para campos magnéticos em bobinas grandes e Smith \& Keating (1996) chegaram a resultados semelhantes utilizando o áudio magnetotelúrico.

Para um deslocamento ( Off set) superior a $80 \mathrm{~m}$, a componente By terá um sinal maior que a $B z$ e consequentemente maior que o nível de ruído, aumentando a probabilidade de detectar o alvo quando a linha de voo não passar diretamente sobre o 
condutor (Fig. 4.4), ficando acima do nível de ruído como descrito no item 4.3.1. A componente $B y$ terá uma resposta maior que a $B z$ e consequentemente maior que o nível de ruído, aumentando a probabilidade de detectar o alvo quando a linha de voo não passar diretamente sobre o condutor (Smith \& Keating, 1996).

\section{4 - Aplicação da metodologia aos dados reais.}

\subsection{1 - Área de estudo.}

Os dados utilizados neste trabalho foram cedidos pela United States Geological Survey - USGS no ano de 1977. A área coberta pelo levantamento Aeroeletromagnético (AEM) foi de $400 \mathrm{~km}^{2}$, e localiza-se na parte superior do Rio San Pedro a sudeste do Arizona (EUA), entre o Forte Huachuca e o Rio San Pedro (Fig. 4.6). A plataforma utilizada foi o GEOTEM, com bobina transmissora tendo seis espiras entorno do avião com uma área total de $232 \mathrm{~m}^{2}$ e a corrente injetada nesta bobina foi de 935A. O receptor adquiriu os dados nas três componentes (x, y e z) a uma altura aproximada de $120 \mathrm{~m}$ em relação ao solo. As linhas de voo tiveram aproximadamente $20 \mathrm{~km}$ de extensão e espaçamento entre elas de aproximadamente 400m. O transmissor foi configurado com frequência de $30 \mathrm{~Hz}$ em 20 canais, sendo os primeiros quatro canais ligados (on time) e os 16 últimos canais desligados (off time) registrando a tensão em $p V / m$.

O sistema Basin-Range (bacias e montanhas) é constituído por cadeias de montanhas alinhadas, limitadas por falhas e bacias sedimentares, que começaram a se formar a cerca de 17 Ma (Gettings \& Houser, 1995). Topograficamente, a bacia superior San Pedro, de direção N-NW, tem a aparência de um amplo vale aluvial interrompido pelo embasamento das montanhas Tombstone. Esta bacia também é constituída por três sub-bacias principais. A primeira ao sul de Sierra Vista, entre as montanhas Huachuca e 
o Rio San Pedro (sub bacia Palominas). Ao norte da cidade de Sierra Vista encontramos a segunda sub bacia denominada sub Bacias Huachuca (mais a oeste), e a terceira sub - bacia conhecida como sub Bacia de Tombstone (leste) (Von Huelsen, 2007).

As montanhas Huachuca e Whetstone, no lado oeste do vale, são compostas por rochas ígneas, metamórficas, vulcânicas e sedimentares e variam em idade do PréCambriano ao Mioceno (Gettings \& Houser, 1995).

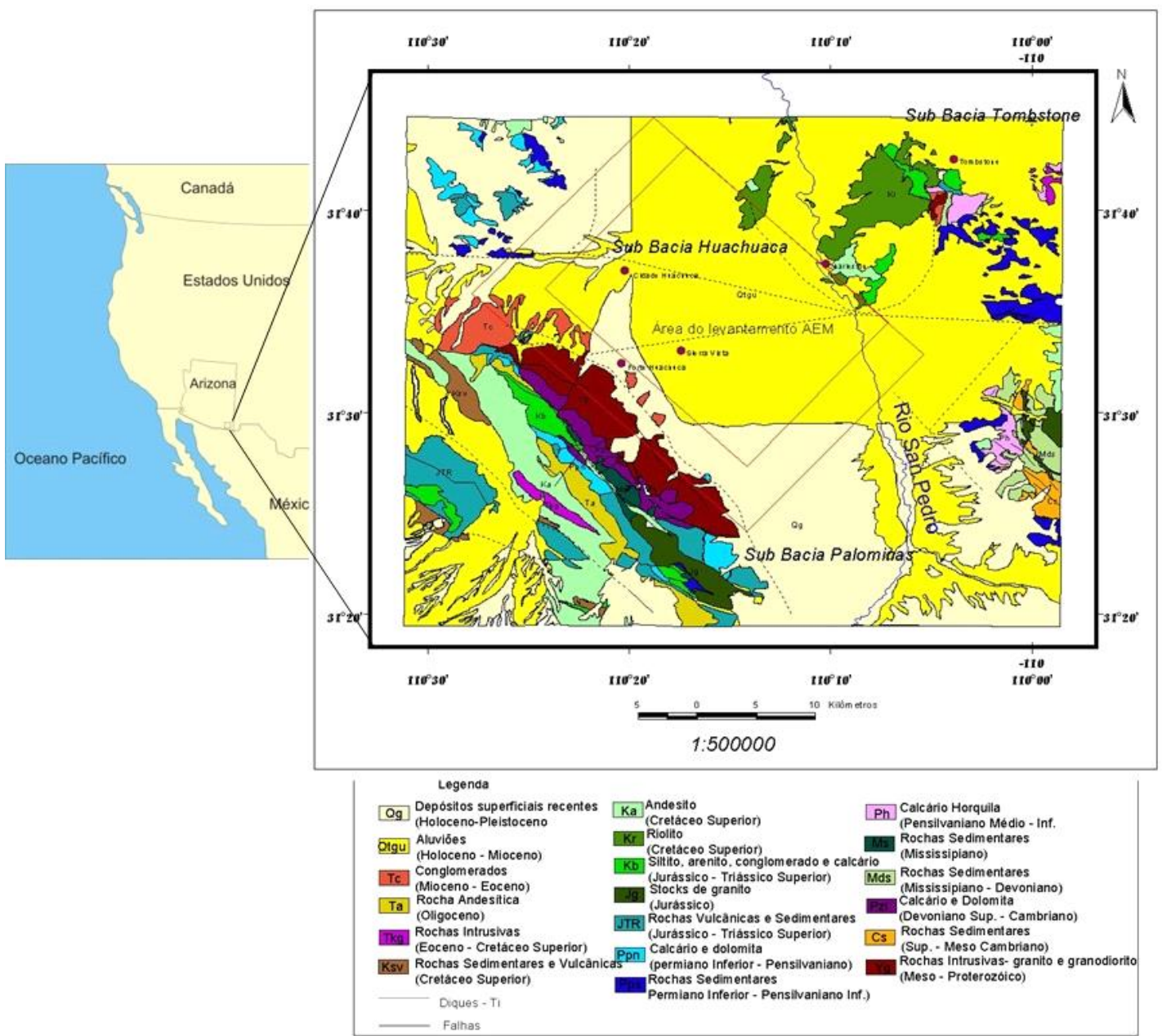

Figura 4. 6 - Localização da área. O retângulo vermelho delimita a área do levantamento aeroeletromagnético (Von Huelsen, 2007).

Os sedimentos das bacias podem ser divididos em dois períodos. As camadas mais antigas podem ser de levemente a moderadamente deformadas, sendo mais consolidados e mais densos que as camadas mais novas. A densidade dos sedimentos 
mais antigos resulta dos processos diagenéticos que alteram a mineralogia dos sedimentos e preenchem os poros. Devido a esta redução dos poros e da permeabilidade, os sedimentos mais antigos tornam os aquíferos pobres em relação aos mais novos (Gettings \& Houser, 1995). A Figura 4.7 apresenta um modelo esperado do formato da Bacia como base nos estudos geológicos.

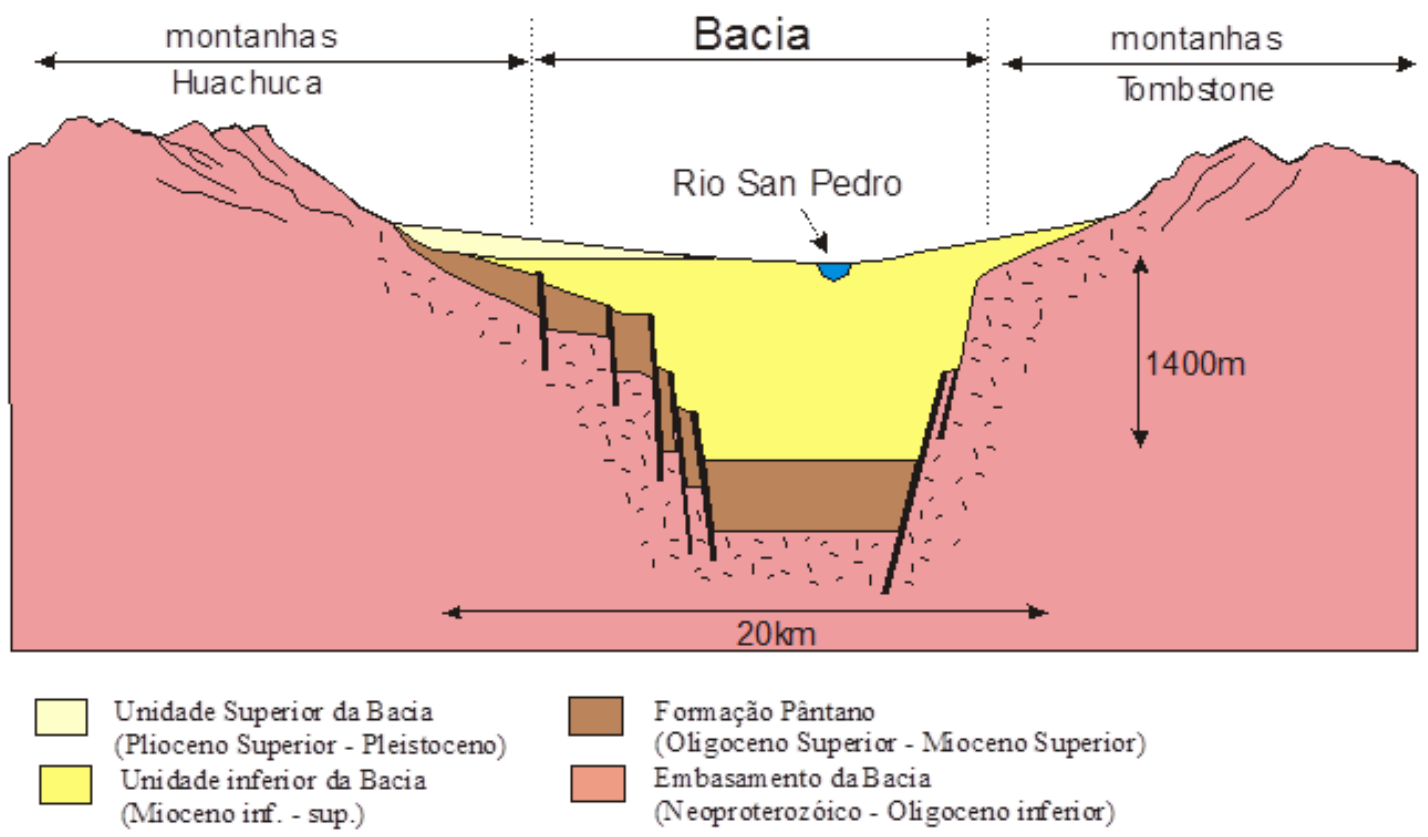

Figura 4. 7- Formação esperada da Bacia de San Pedro (Von Huelsen, 2007).

As rochas sedimentares no Vale San Pedro são do Mioceno ao Holoceno, principalmente areia e cascalho aluvionais de depósitos em leque aluvional, terraços e canais. Estas rochas foram separadas em três unidades de sedimentos; Oligoceno Superior a Mioceno Inferior, Mioceno Superior a Plioceno Inferior e Plioceno Superior a Pleistoceno Superior (Gettins \& Houser, 1995).

Esta área foi escolhida para testar o software desenvolvido, por se tratar de uma área com estudos, já realizados, qualitativos e pelo registro das três componentes (x, y e z) do campo eletromagnético. Neste trabalho se propõe estudar parte do alvo condutivo da Bacia San Pedro de forma quantitativa, obtendo sua profundidade, sua extensão e 
mergulho do alvo, utilizando as funções GeoTEM process, RDI e Energy Envelope do programa ImagEM. Dentre as linhas registradas (Fig. 4.8), destacam-se as linhas L40112901，L4013001，L4013101，L4013201，L4013301，L4013401 e L4013501 apresentada aqui nos mapas das Figuras 4.9, 4.10 e 4.11.

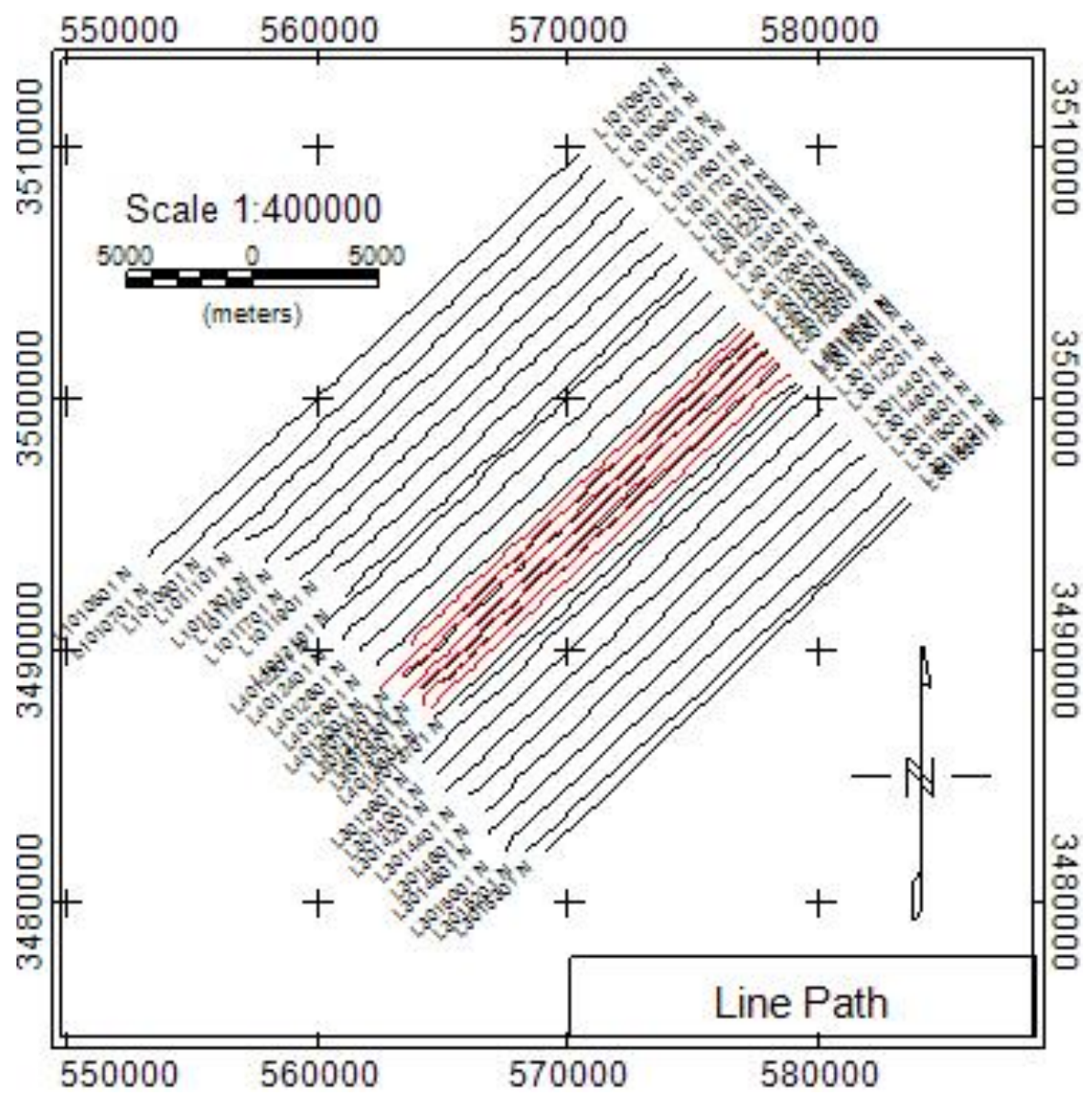

Figura 4. 8- Linhas de voo do levantamento aéreo realizado pelo GEOTEM, com destaque para as linhas L40112901, L4013001, L4013101, L4013201, L4013301, L4013401 e L4013501.

Utilizando o programa Oasis Montaj ${ }^{T M}$ foram obtidas as imagens do campo magnético secundário para o canal 12 (off time) nas componentes Z, X e Y (Figs. 4.9, 4.10 e 4.11). O método de interpolação utilizado foi a Krigagem e a célula de interpolação foi de 50m. É possível constatar que as componentes "X e Z" apresentam melhor relação sinal/ruído em relação a componente "Y". 


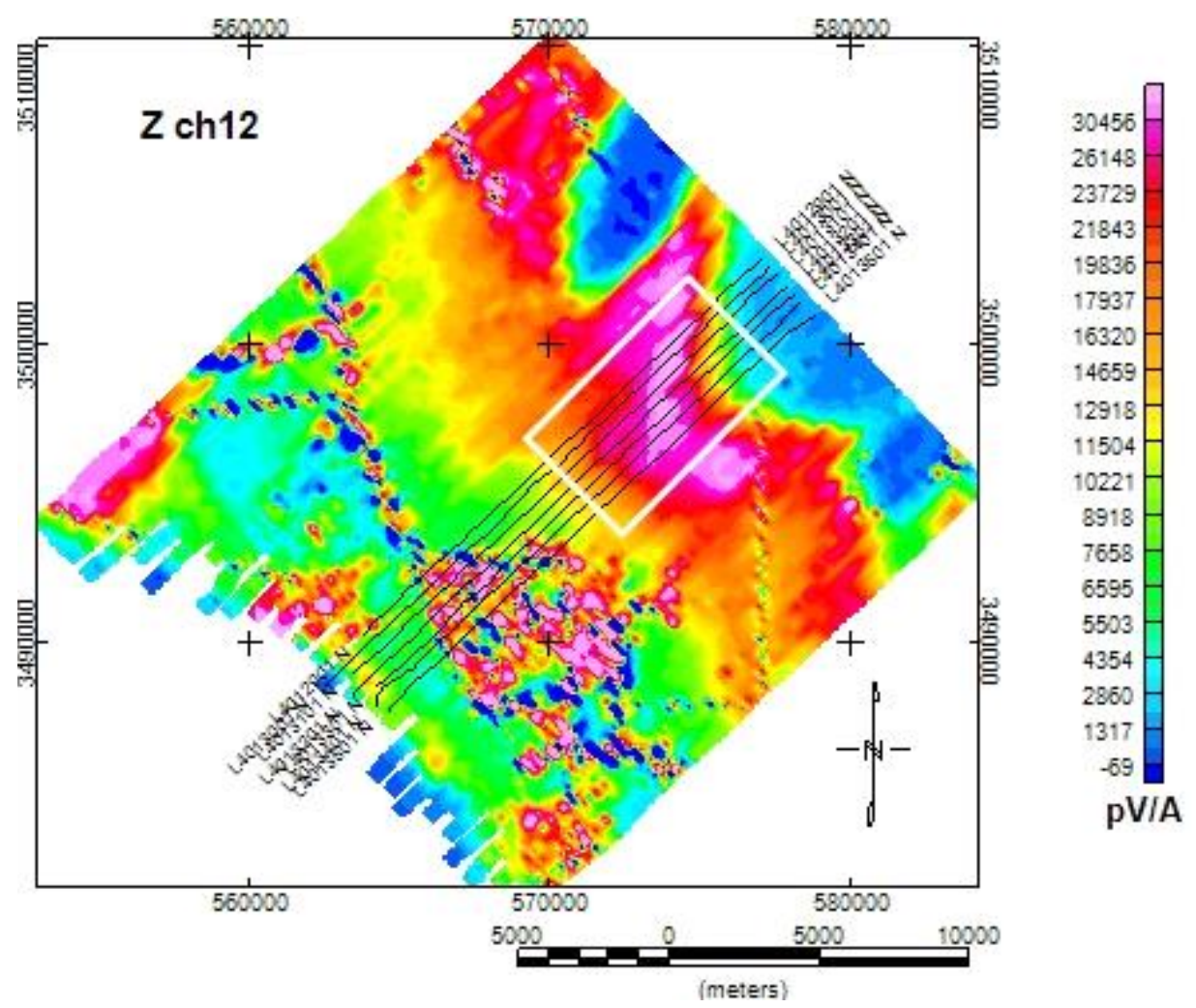

Figura 4. 9 - Mapa da componente $Z$ do campo secundário do canal 12, no quadrado em branco está a região condutiva cortada pelas linhas L4012901, L4013001, L4013101, L4013201, L4013301, L4013401 e L4013501 dentro da Bacia de San Pedro.

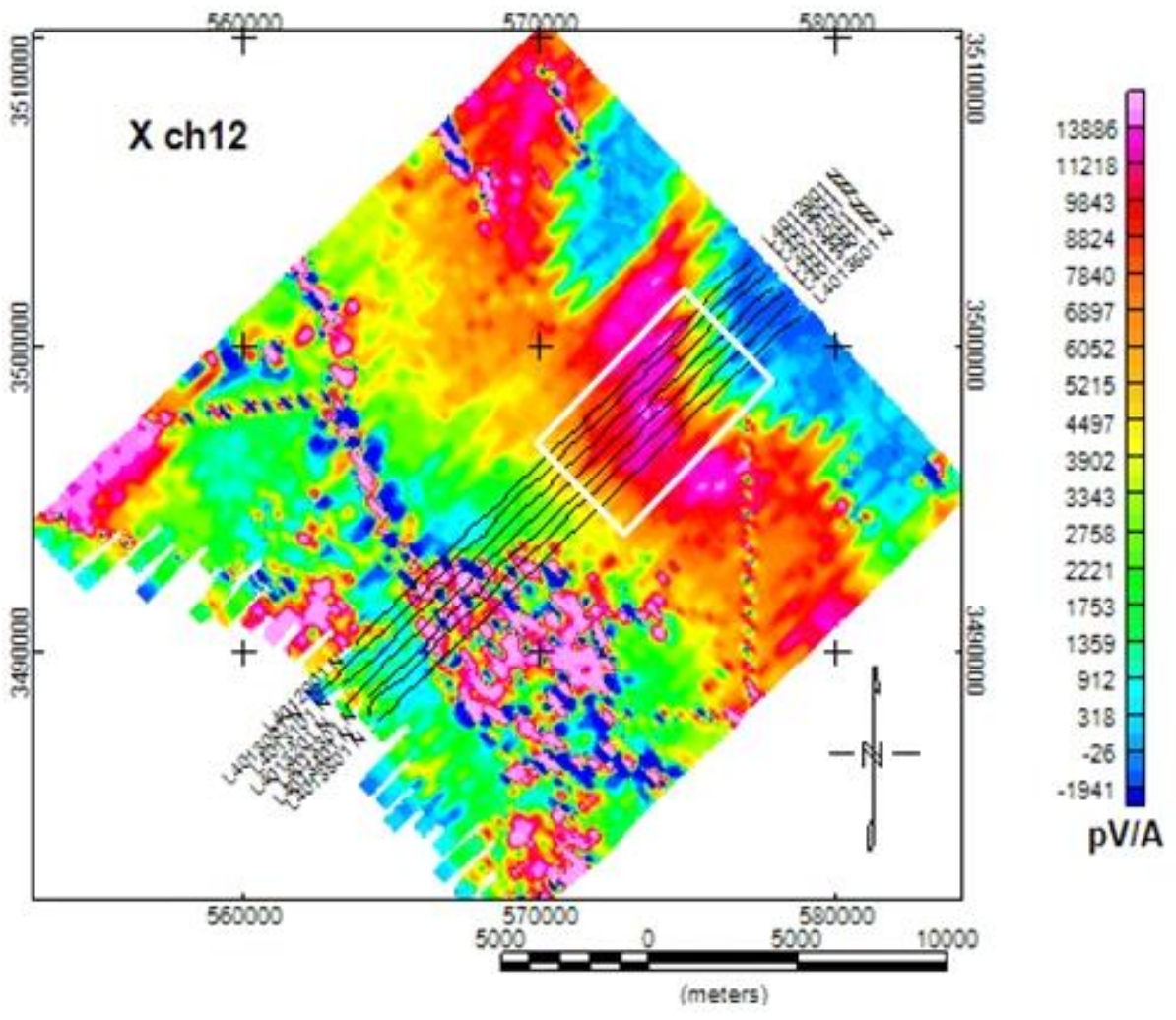


Figura 4. 10 - Mapa da componente X do campo secundário do canal 12, no quadrado em branco está a região condutiva cortada pelas linhas L4012901, L4013001, L4013101, L4013201, L4013301, L4013401 e L4013501 dentro da Bacia de San Pedro

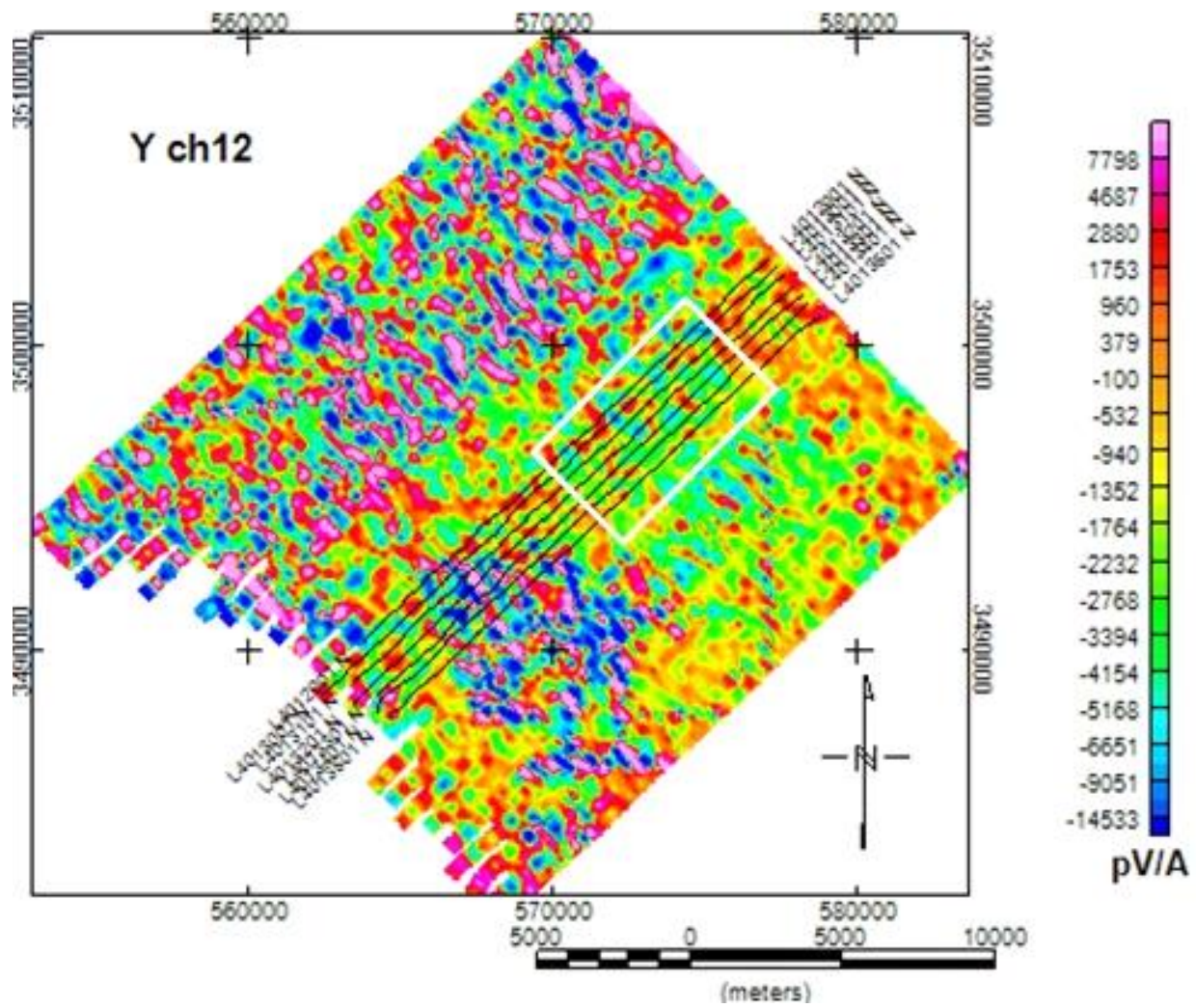

Figura 4. 11 - Mapa da componente Y do campo secundário do canal 12, no quadrado em branco está a região condutiva cortada pelas linhas L4012901, L4013001, L4013101, L4013201, L4013301, L4013401 e L4013501 dentro da Bacia de San Pedro

\subsection{2 - Inversão}

Para realizar a inversão dos dados do GEOTEM utilizamos a função GeoTEM process para a componente vertical (z). Este programa é uma adaptação do TDEM process, que foi desenvolvido para processar dados terrestres. Esta função é capaz de retornar os valores de resistividade pela profundidade de forma qualitativa aplicando uma inversão simplificada pelo método da secante, mais informações podem ser 
encontradas em Von Huelsen, (2007) e Travaglia Filho, (2012). A partir destes dados é possível gerar seções do levantamento como demonstrado no item 4.4.3.

\subsection{3 - Seção da resistividade pela profundidade (RDI)}

Após processar os dados por meio da sub-rotina GeoTEM process, foi utilizada a função RDI (Fig. 4.12) para a modelagem da resistividade pela profundidade aparente. Utilizando esta função foi possível gerar os perfis das tensões medidas no receptor, a linha de contorno da resistividade e uma seção da imagem da resistividade pela profundidade (Resistivity Depth Image - RDI). Os produtos da função RDI irão auxiliar na obtenção dos resultados da função Energy Envelope, nas interpretações e na modelagem da subsuperfície.

A seção da RDI foi gerada utilizando o método de interpolação Inverso da Distância Ponderada “Inverse Distance Weighted" (IDW, Figura 4.12), com a célula de interpolação de 25 metros. Informações complementares sobre interpolação por IDW podem ser encontradas no anexo A. Para ilustrar os resultados da função RDI foi selecionada a linha L401340. A Figura 4.13 apresenta os resultados dos perfis do campo secundário, a RDI e as linhas de contorno da resistividade. 


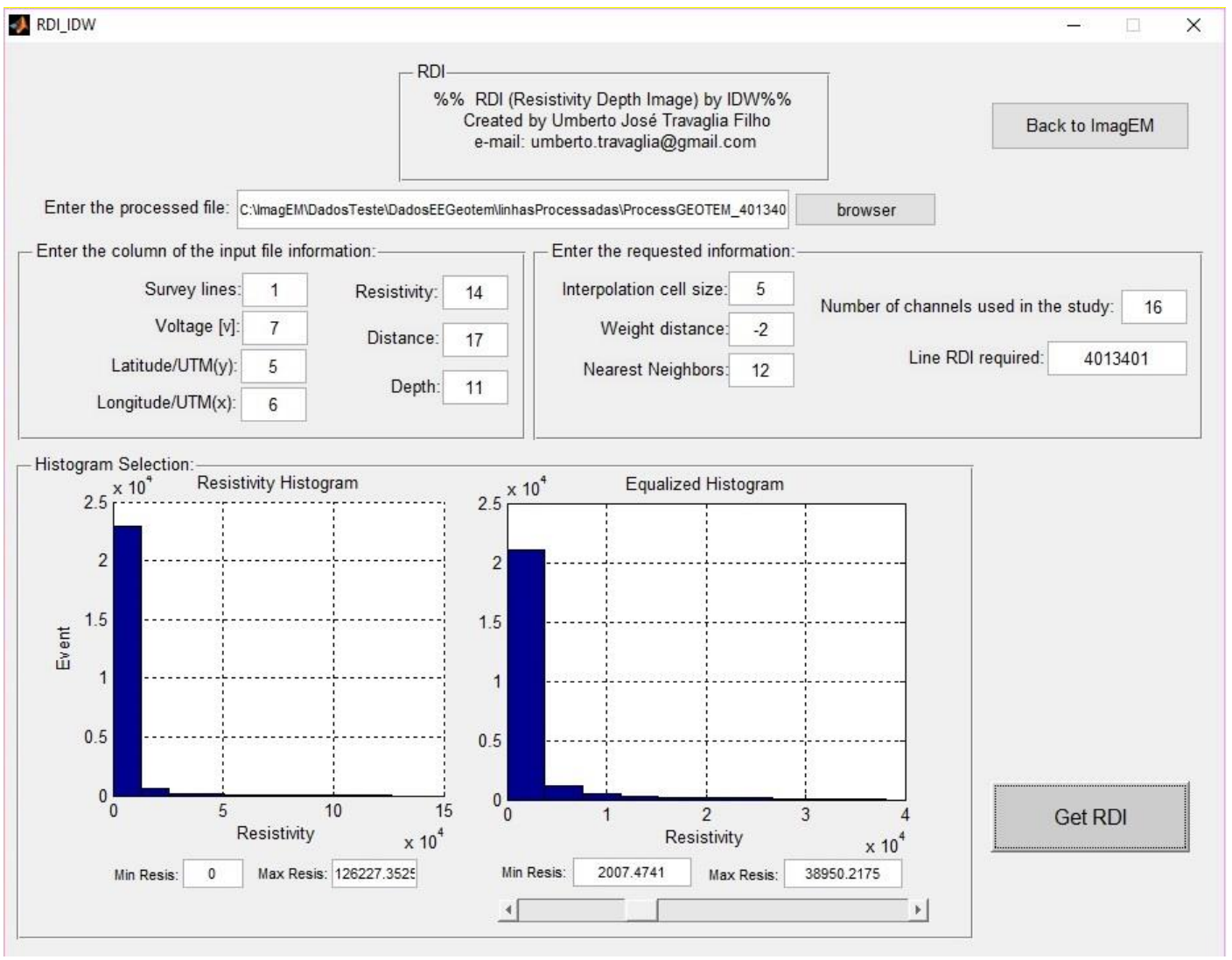

Figura 4. 12 - Interface da função $R D I$ aplicando o interpolador $I D W$, acima os parâmetros de entrada e abaixo os histogramas bruto à esquerda e equalizado à direita. 


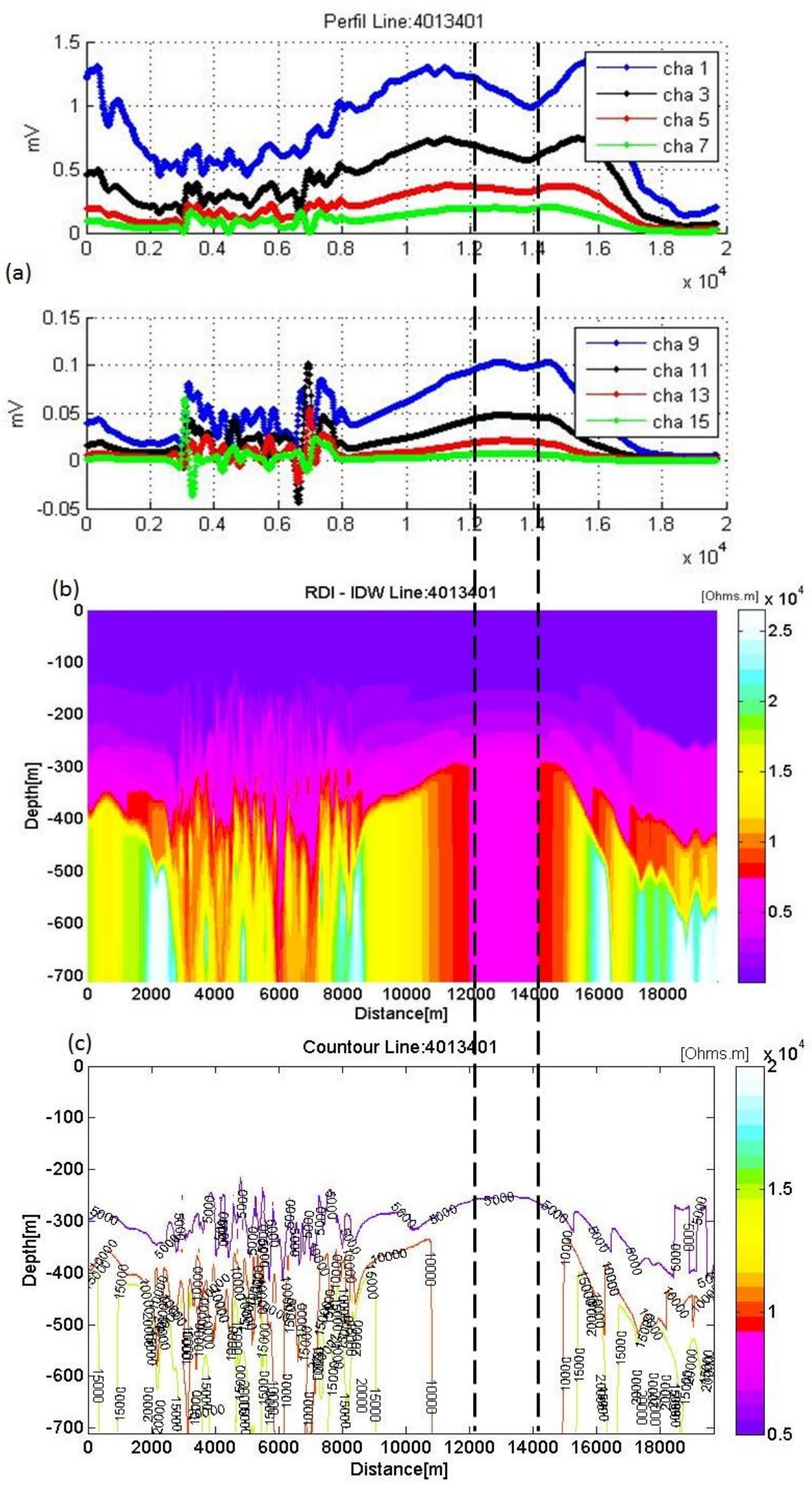

Figura 4. 13 - Resultados da Linha L4013401, (13a) perfis dos canais de 1 a 15 dados em $m V$. (13b) Seção da $R D I$ interpolada pelo método $I D W$ com célula de $25 \mathrm{~m}$. (13c) Superfície com as linhas de contorno de resistividade aparente. 
Os perfis dos canais 1 a 7 (Fig. 4.13a) apresentam uma tensão entre 0,2 e 1,3 mV dentro da região condutiva entre 12 e $14 \mathrm{~km}$ (linhas pretas tracejadas). Para os perfis dos canais $9,11,13$ e 15 a tensão variou entre 0,01 e $0,11 m V$ (Fig. 4.13a) nesta mesma região. As Figuras 4.13b e 4.13c apresentam uma camada condutiva que se estende por toda a linha e atinge em média uma profundidade de $300 \mathrm{~m}$. A resistividade nesta região varia entre 0,2 e $0,6 \cdot 10^{4} \Omega \cdot m$.

\section{5 - Desenvolvimento computacional}

A teoria descrita neste trabalho (item 4.3) foi implementada ao programa ImagEM (Fig. 4.14) na plataforma $M A T L A B^{\circledR}$, neste artigo destacamos a função do Envelope de Energia - "Energy Envelope" (Fig. 4.15). Para processar os dados são necessárias as três componentes $B x$, $B y$ e $B z$ dos campos secundários captados pelo equipamento de cada linha individualmente. A interface do Energy Envelope apresenta as curvas de decaimento das 20 primeiras sondagens da linha L4013401 para os 16 canais desligados (Fig. 4.15). Desta forma é possível analisar o comportamento das curvas de decaimento e avaliar a qualidade dos dados antes de gerar o EE. O item 4.5.1 tratará do cálculo do mergulho, direção e profundidade do alvo apenas para o canal 12 da linha L4013401, posteriormente foram calculados os mesmos parâmetros para outros canais da mesma linha e assim obter a modelagem do alvo. 


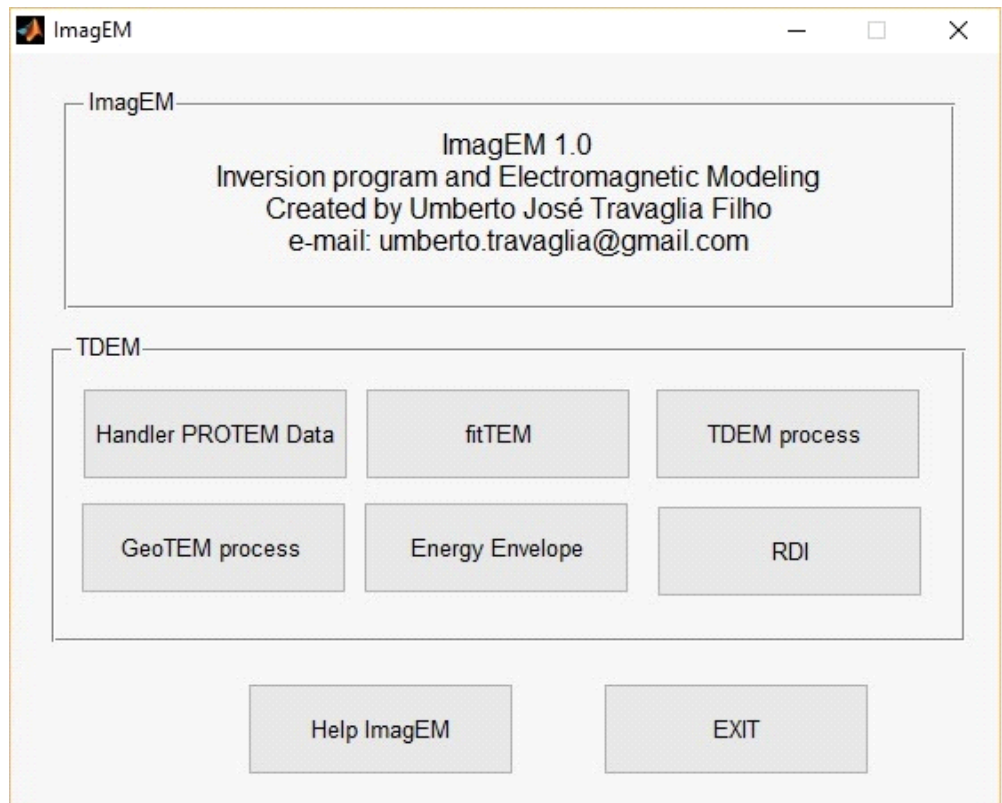

Figura 4. 14- Interface do ImagEM. O painel TDEM, refere-se ao processamento no domínio do tempo. O Envelope de Energia é uma das funções deste método.

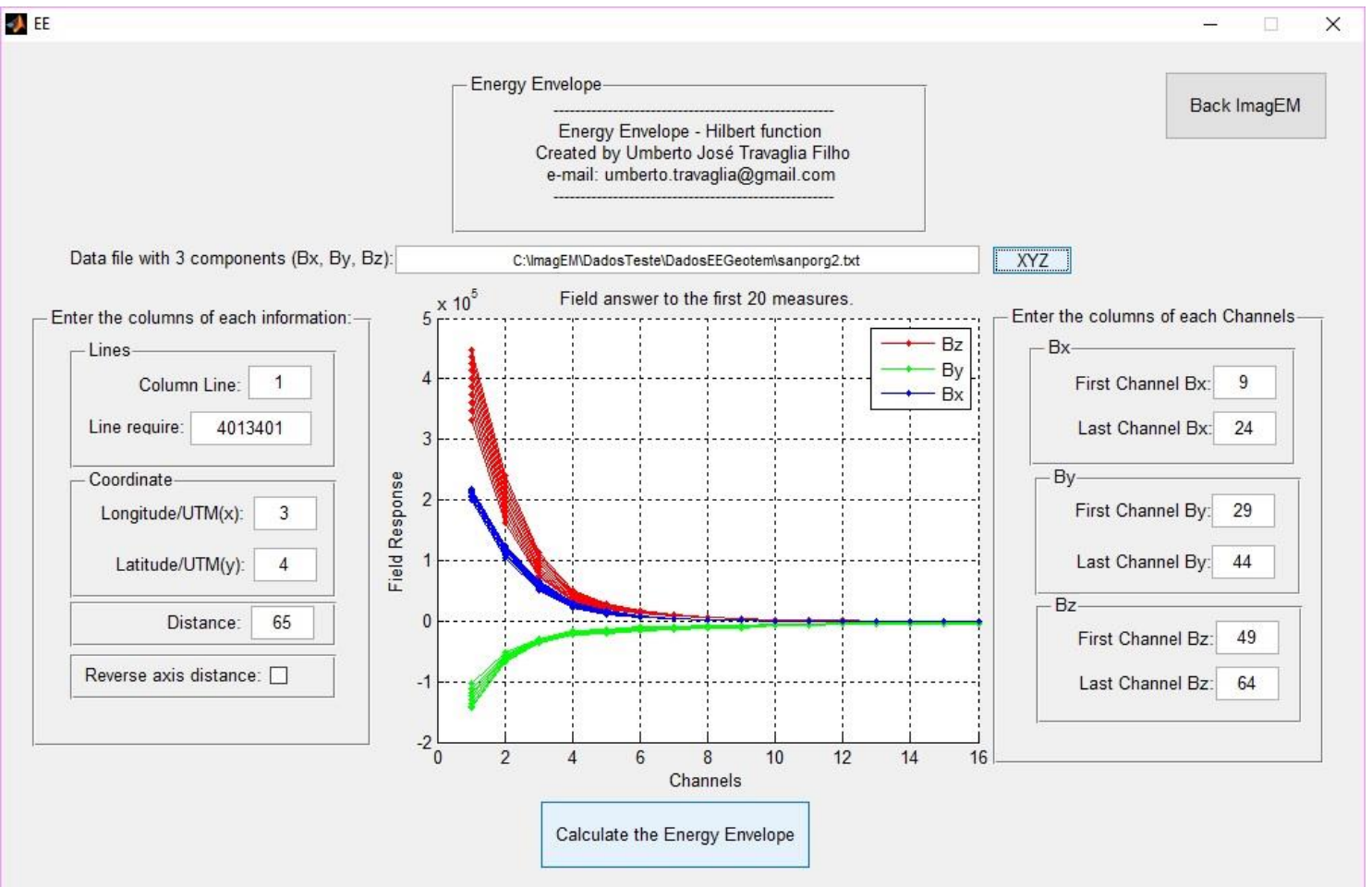

Figura 4. 15- Interface do Energy Envelope. Considerando o banco de dados de entrada, o usuário coloca os números das colunas que constam: o número da linha do levantamento, a distância, as coordenadas ( $\mathrm{x}$ e y) e as componentes dos campos magnéticos medidos $(B x, B y$ e $B z)$. 


\subsection{1 - Aplicação do Envelope de Energia aos dados do GEOTEM, para o canal 12 da linha L4013401.}

Para a demonstração da função Energy Envelope foram selecionadas as três componentes dos canais desligados da linha L4013401. O primeiro gráfico apresentado pela sub-rotina são as três componentes separadamente (Fig. 4.16), sendo possível analisar o comportamento de cada componente individualmente.

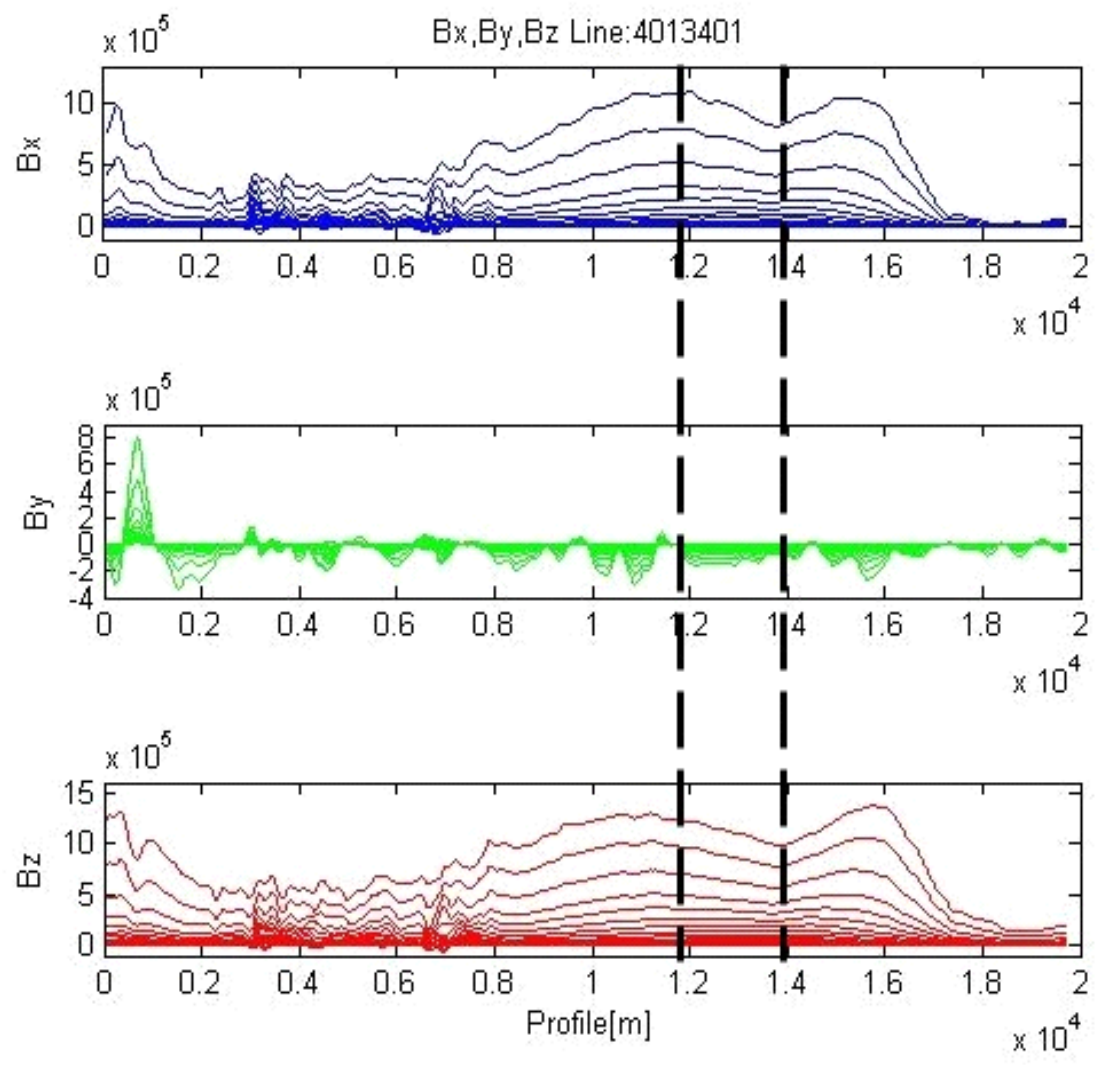

Figura 4. 16 - Campo secundário $B x$, $B y$ e $B z$, de cima para baixo respectivamente, pela distância em metros.

Aplicando a transformada de Hilbert (eq. 4.1) em cada componente individualmente, foi possível mensurar o Envelope de Energia (eq. 4.2). A Figura 4.17 apresenta os perfis do EE. 


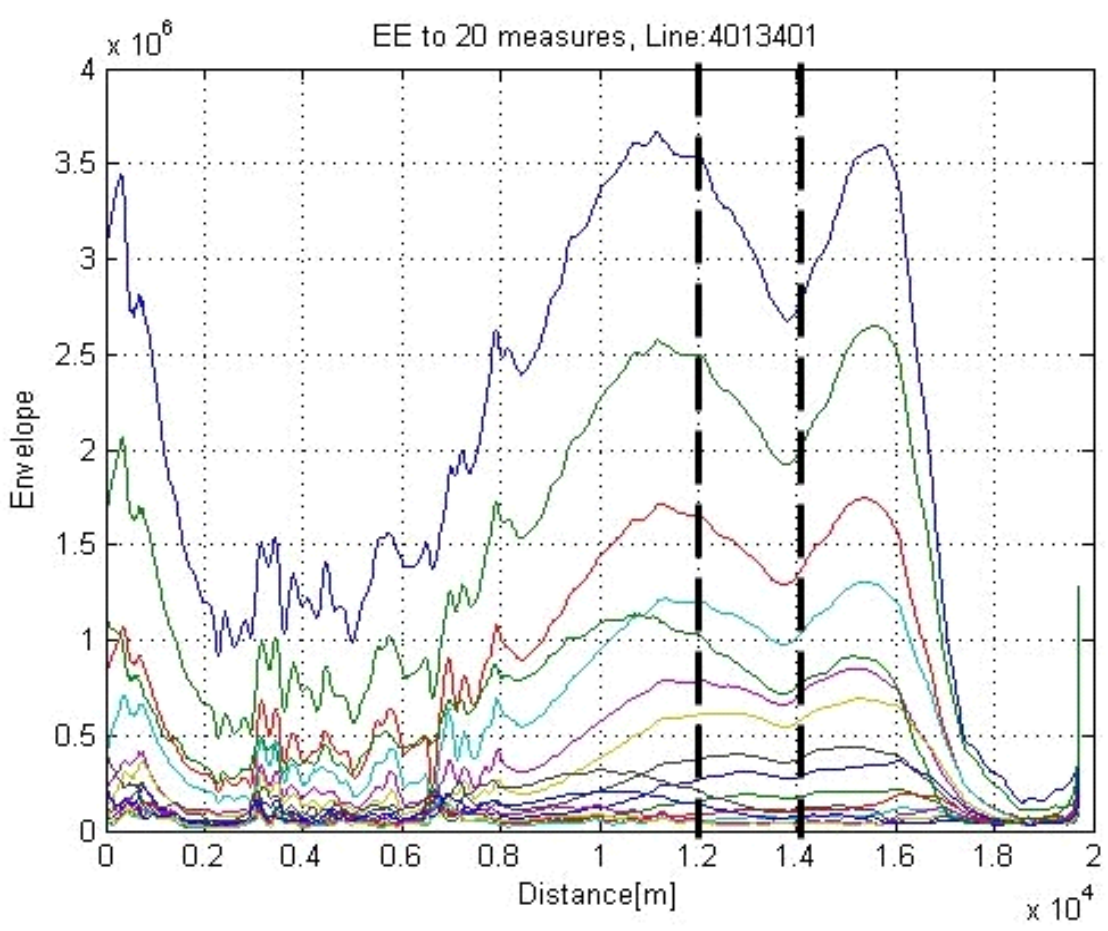

Figura 4. 17- Perfis do Envelope de Energia (EE) para a linha L4013401.

Como descrito anteriormente no item 4.3.5, a análise da resposta é realizada pela normalização de $B z / E E$ (Fig. 4.18a). As curvas $B z / E E$ e $B x / E E$ representam a resposta obtida na linha de voo. A Figura 4.18 b apresenta as componentes $B x, B y, B z$ e o $E E$.

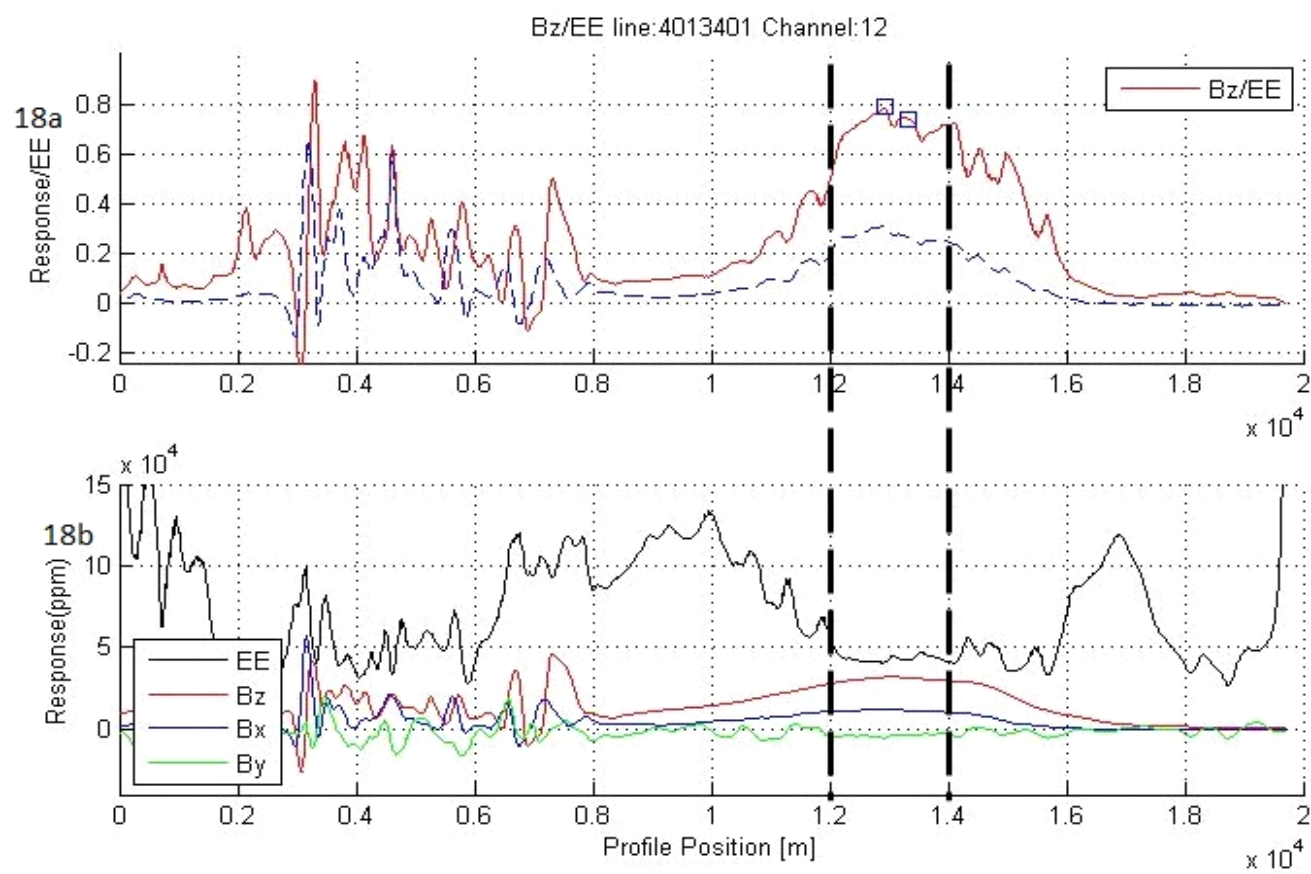

Figura 4. 18 - (18a) Perfis $B z / E E$ (Vermelho em linha sólida) e $B x / E E$ (Azul em linha tracejada), os quadrados em azul demonstram a marcação dos picos de energia. 
Tomando como base a marcação destes picos de energia foi possível calcular o mergulho e profundidade. (18b) $B x, B y, B z$ e o EE do canal 12 da linha L4013401.

Neste ponto do processamento, o programa deixa a critério da experiência do pesquisador marcar os dois picos de energia (quadrados em azul na Fig. 4.18), sobre o perfil da razão $B z / E E$ (Fig. 4.18a) que melhor representam a resposta do corpo. A partir das marcações destes pontos foi realizado o cálculo do mergulho e profundidade de forma automática com descrito anteriormente pelas equações 4.3 e 4.4 respectivamente. A Figura 4.19 mostra a curva teórica bem como o resultado do mergulho de $93^{\circ}$ (círculo azul sobre a curva teórica) para os picos marcados. A Figura 4.20 mostra a curva teórica e o resultado da profundidade do topo do corpo encontrado naquela área (445 m; círculo vermelho).

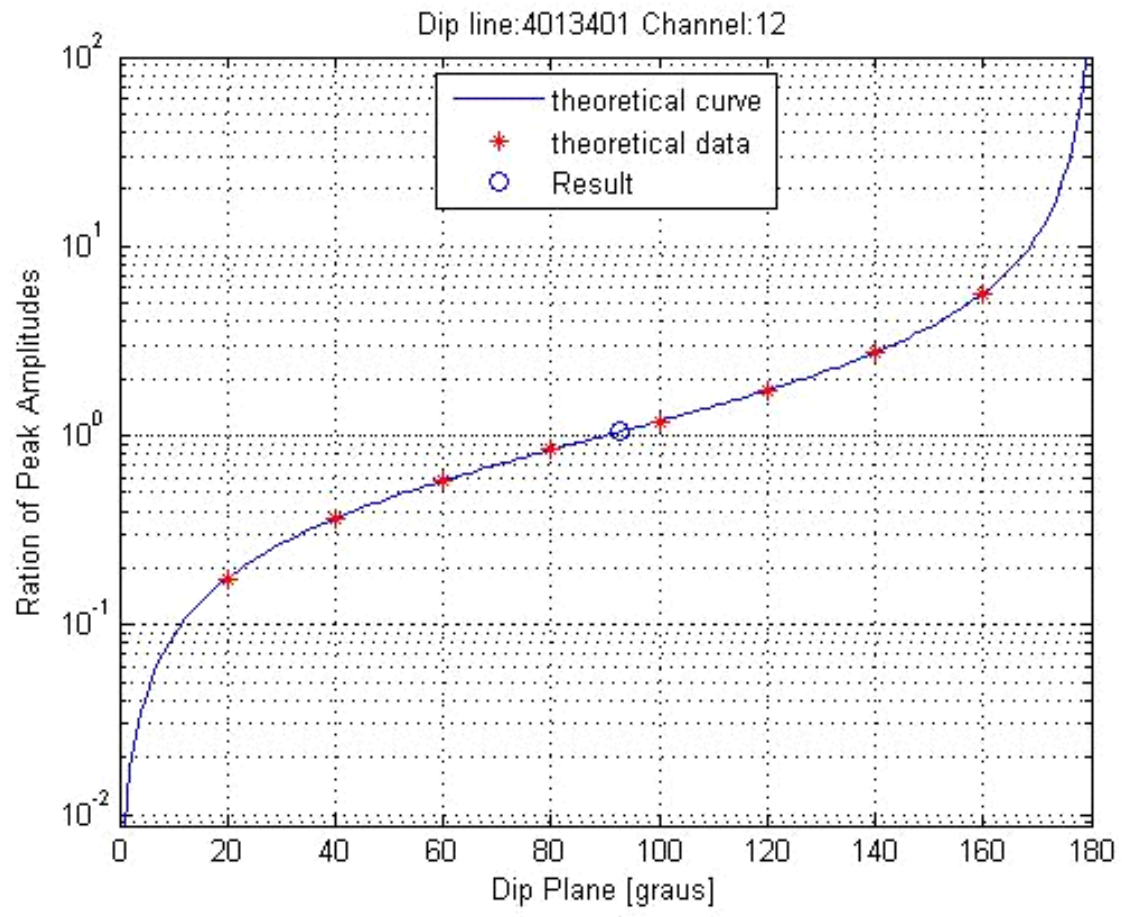

Figura 4. 19 - Gráfico da razão dos picos das amplitudes pelo ângulo de mergulho calculado para o canal 12, linha L4013401. 


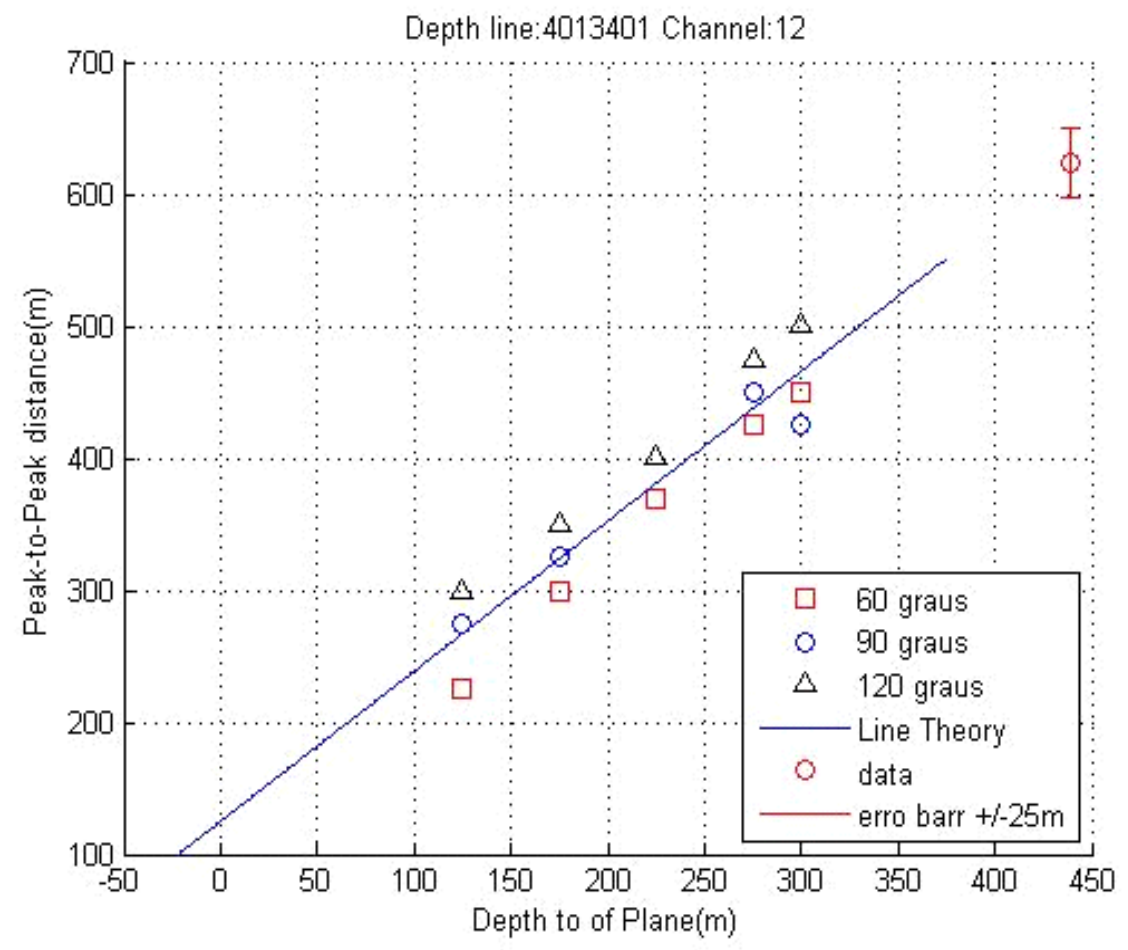

Figura 4. 20 - Gráfico da distância entre os picos das amplitudes pela profundidade do topo do corpo para o canal 12, linha L4013401.

Utilizando as componentes $B x$ e $B y$, (eq. 4.5) foi possível recompor o sinal $B y \sim$ (Fig. 4.21a, em vermelho) e compará-lo com By (Fig. 4.21a, em azul) da linha L4013401. Quanto maior a proximidade entre as duas curvas, melhor a relação sinal ruído e melhor o acoplamento entre as bobinas. A Figura 4.21b apresenta o comportamento do ângulo de Strike descrito pela equação 4.8 , com o valor de $98^{\circ}$ para o alvo considerado. 

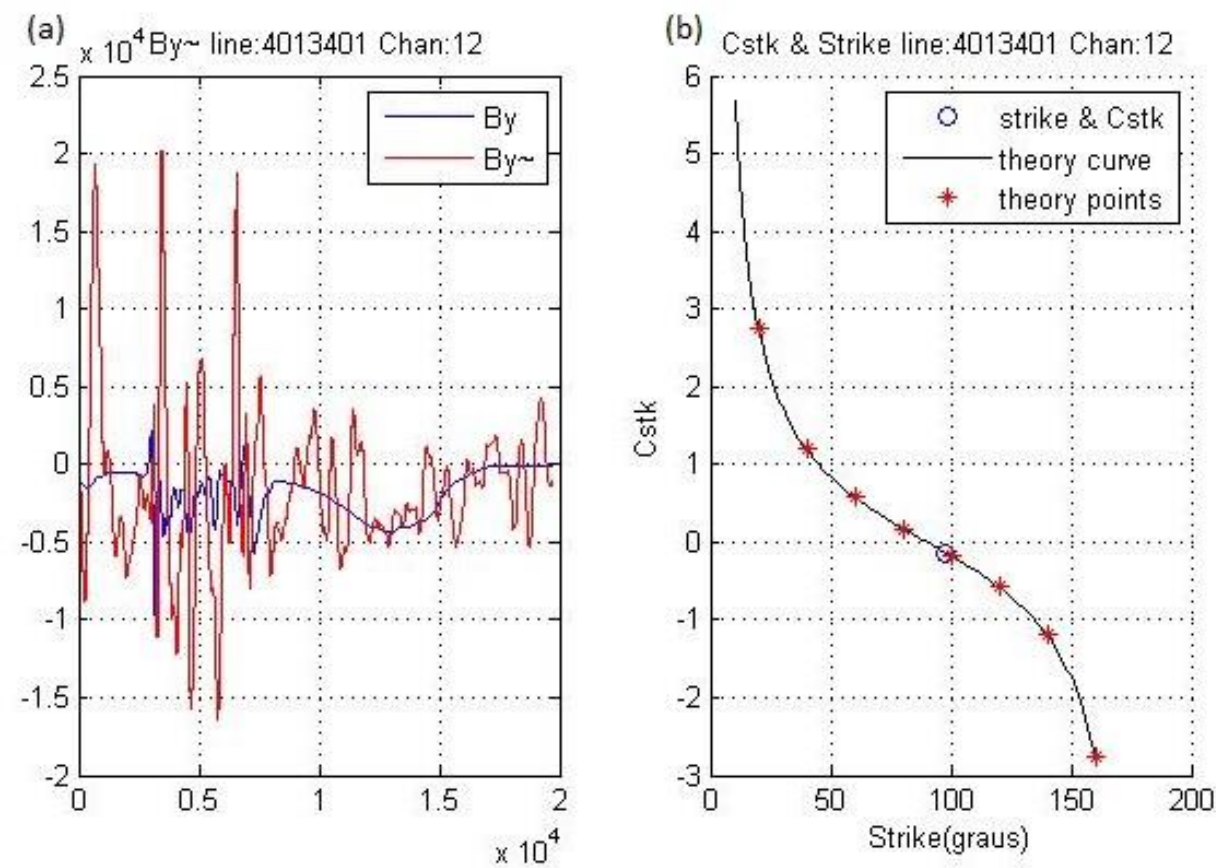

Figura 4. 21 - (21a) Perfil do campo secundário By e By pela distância; em azul os dados reais e em vermelho os valores calculados (eq. 4.5). (21b) Curva representativa da função trigonométrica da equação 4.8. O eixo das ordenadas é o ângulo da direção do alvo (Strike) e o círculo azul é o strike calculado para o canal 12.

\subsection{2 - Aplicação do Energy Envelope: uma modelagem com os canais} selecionados.

Os picos de energia apresentados no item 4.3.5 foram examinados em todos os canais desligados da linha L4013401, contudo somente nos canais 9, 10 11, 12 e 13 foram utilizados por apresentarem melhor resposta sobre a área condutiva. As respostas destes canais estão dispostas na Tabela 4.1 e na Figura 4.22. Os resultados da Tabela 4.1 serviram de base para estimar o eixo principal da região condutiva e modelar uma placa condutiva com base no mergulho, na profundidade e no deslocamento em relação à linha de voo.

A profundidade alcançada entre os canais 9 e 13 variou entre 320 e 464 metros. A placa condutiva apresentou uma pequena variação no mergulho, entre $91^{\circ}$ e $96^{\circ}$, 
tomando como base o ângulo de $90^{\circ}$ no sentido horário do circulo trigonométrico, a partir da horizontal. O deslocamento da placa condutiva também é percebido na variação da posição dos picos de energia marcados na Figura 4.22.

Os valores obtidos para a direção do alvo focaram entre $98^{\circ}$ e $99^{\circ}$ (Tabela 4.1). O strike retornou pequena variação de ângulo, entre $98^{\circ}$ e $99^{\circ}$ (Tabela 4.1; Figura 4.23), o que é esperado devido os canais analisados se tratarem da mesma linha do levantamento (L4013401).

\begin{tabular}{|c|c|c|c|}
\hline Canal & $\begin{array}{c}\text { Profundidade } \\
\text { (metros) }\end{array}$ & $\begin{array}{c}\text { Mergulho } \\
\text { (graus) }\end{array}$ & $\begin{array}{c}\text { Direção } \\
\text { (graus) }\end{array}$ \\
\hline $\mathbf{0 9}$ & 320 & 91 & 99 \\
\hline $\mathbf{1 0}$ & 372 & 94 & 99 \\
\hline $\mathbf{1 1}$ & 407 & 92 & 98 \\
\hline $\mathbf{1 2}$ & 445 & 93 & 99 \\
\hline $\mathbf{1 3}$ & 464 & 96 & 99 \\
\hline
\end{tabular}

Tabela 4.1 - Resposta de profundidade, mergulho e direção entre os canais 9 e 13 da linha L4013401 obtidos pela função Energy Envelope do programa ImagEM. 

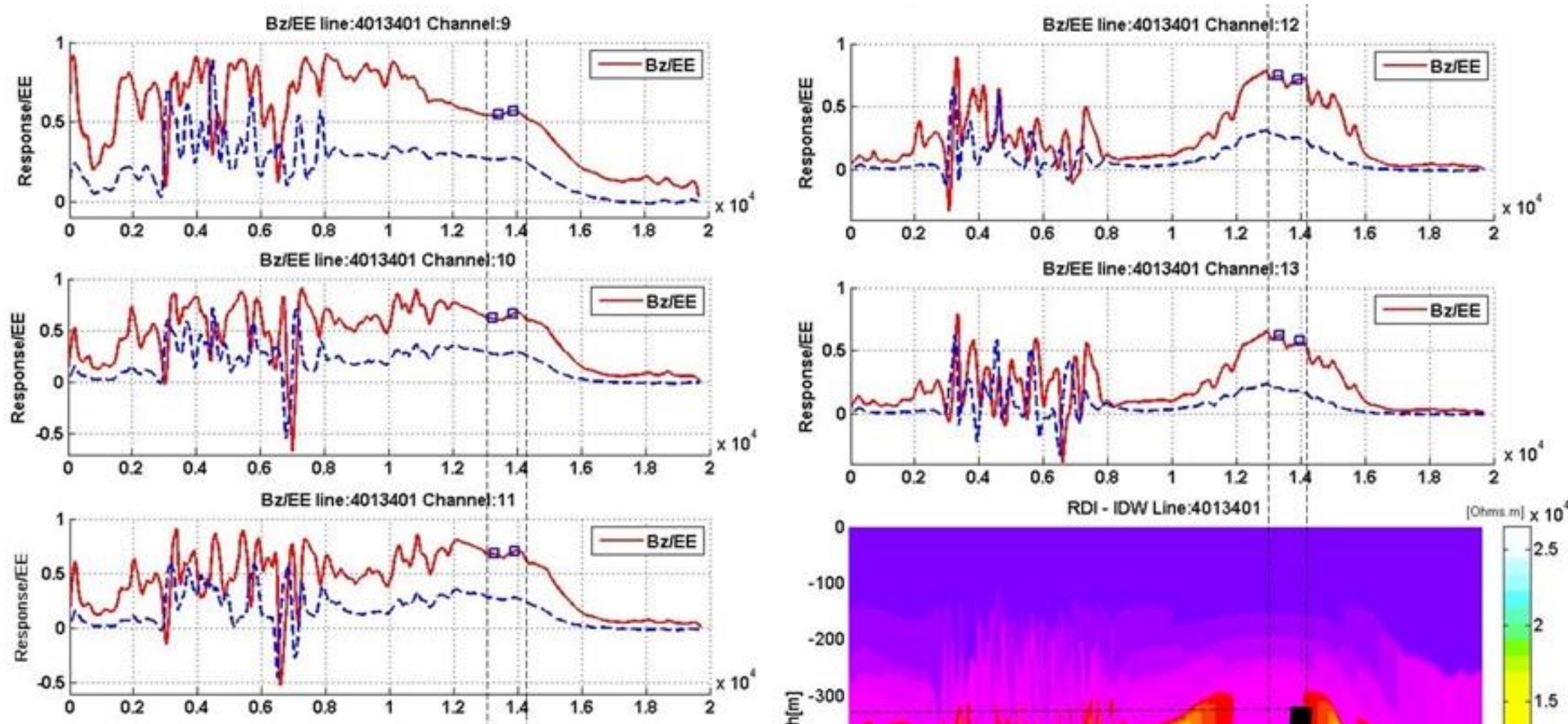

Figura 4. 22 - Marcação dos picos de energia entre os canais 9 e 13, a $R D I$ da linha L4013401 e resultado da modelagem (preto). Nos quadrados azuis foram selecionados os picos de energia dentro da região condutiva.

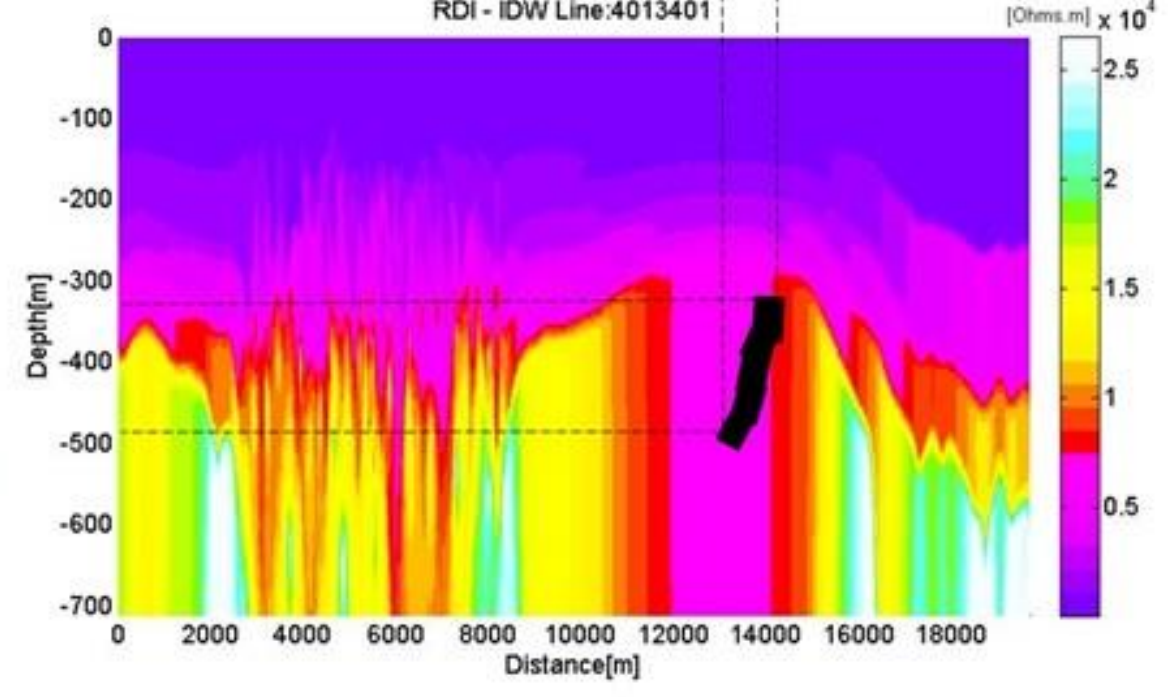




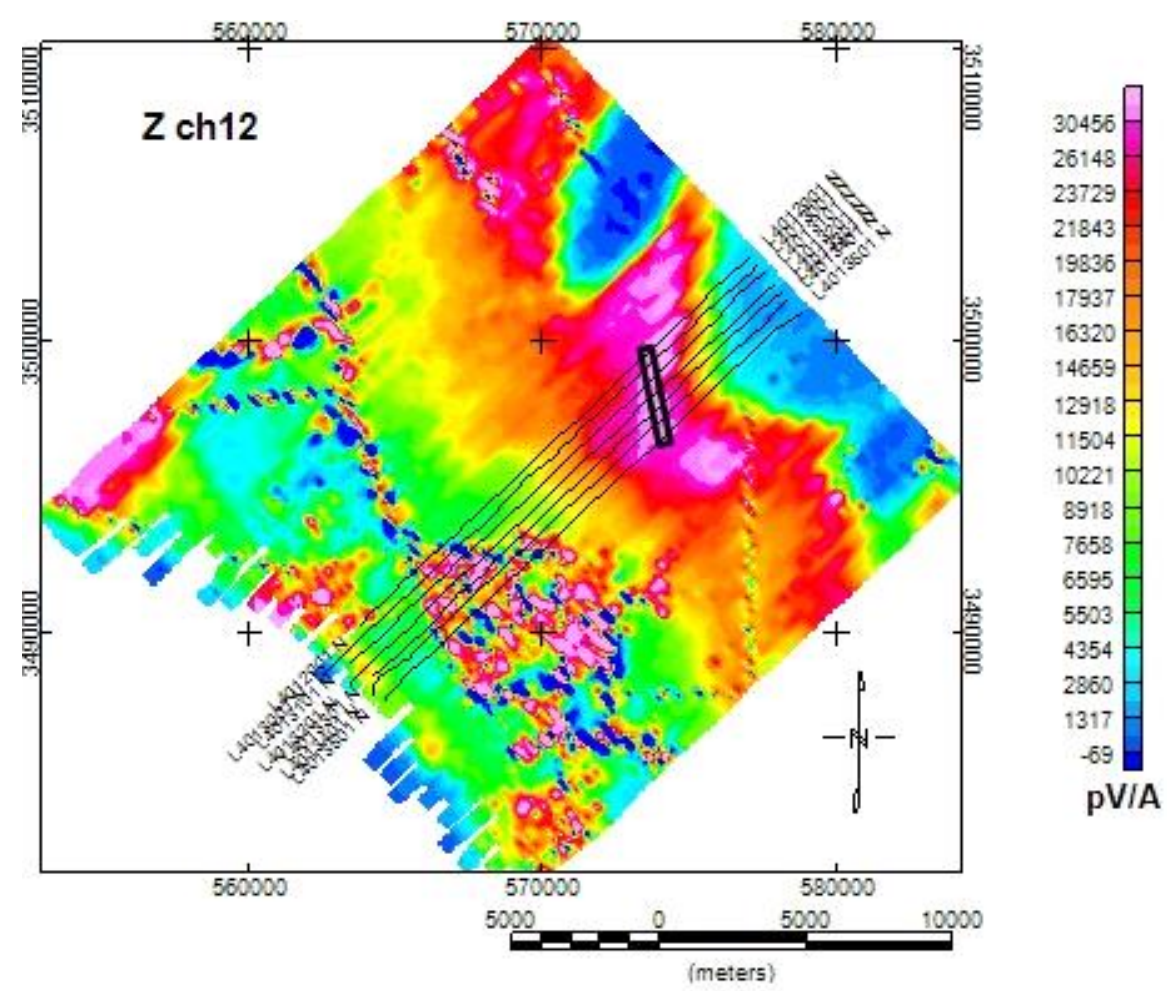

Figura 4.23 - Representação do corpo condutivo sobre o canal 12 da componente Z. O ângulo entre as linhas de voo e a placa condutiva representam a direção do corpo.

\section{6 - Análise dos resultados}

A região condutiva descrita na linha L4013401 (Fig. 4.9 e Fig. 4.22) é compatível com o a localização do aquífero pertencente à bacia de San Pedro. A linha do levantamento encontra-se quase integralmente dentro da bacia sedimentar e é composta por depósitos superficiais recentes e aluviões.

A direção, mergulho e profundidade calculados pela função Energy Envelope apresentam valores estimados para um corpo condutivo (Fig. 4.22). A direção do alvo praticamente foi N-S, considerando as linhas contíguas àquela analisada (L4013401). O mergulho do corpo teve uma variação de 5 graus, mostrando um alvo subvertical. A profundidade variou entre 320 e $464 \mathrm{~m}$ com erro estimado de $25 \mathrm{~m}$. 
A sub-rotina GeoTEMprocess calculou a resistividade, utilizando uma inversão simplificada, a qual encontra-se dentro dos valores esperados para o vale de San Pedro, e obteve-se a RDI de acordo com o campo secundário (dado bruto).

Os resultados das funções GeoTEM process, RDI e Energy Envelope do ImagEM são compatíveis com os resultados obtidos sobre esta mesma área apresentados por Von Huelsen, 2007, onde foi utilizado um método de inversão mais robusto e demorado.

\section{7 - Conclusão}

Pode-se concluir que a sub-rotina Energy Envelope bem como as outras subrotinas do programa ImagEM podem contribuir na interpretação dos dados TDEM. A normalização do campo secundário $B z$ pelo envelope de energia utilizando a transformada de Hilbert é um importante recurso para destacar os picos de energia, necessários para a o cálculo da direção, do mergulho e da profundidade do alvo.

Os resultados obtidos pelo Energy Envelope complementam as seções geradas pela função RDI provenientes da inversão realizada pelo GeoTEMprocess trazendo assim mais informações sobre a região em questão.

Analisando apenas a RDI conclui-se que o corpo condutivo é vertical, já os resultados obtidos utilizando-se o método do envelope de energia fornece detalhes do alvo e uma modelagem mais adequada mostrando que o corpo condutivo mergulha para SW conforme aumenta a sua profundidade.

Assim este trabalho, disponibiliza um software que fora desenvolvido na plataforma MATLAB, e que contribui para a modelagem eletromagnetométrica em subsuperfície, para equipamentos EM terrestres ou aéreos e que trabalham no domínio do tempo. 


\section{8 - Agradecimentos}

Os autores agradecem ao Instituo de Geociências da Universidade de Brasília, ao Observatório Sismológico de Brasília e seus pesquisadores pela liberação do uso da licença do MatLab ${ }^{\mathrm{TM}}$ e instalações, a CAPES pelo concessão do uso da bolsa de pesquisa. Aos amigos do programa de pós-graduação e graduação.

\section{Apêndice A - Interpolação por IDW}

O interpolador Inverso das Distâncias Ponderada (Inverse Distance Weighting IDW) é um procedimento para estimação, ou interpolação determinista (por oposição a um processo estocástico) em recurso a um conjunto de dados separados, geralmente no espaço. As localizações de valor desconhecido são calculadas em recurso a uma média ponderada pelo inverso das distâncias ponderada desta mesma localização à localização de valores conhecidos (regra geral os dados reais). É habitualmente utilizado em sistemas de informação geográfica e geoestatística e por este motivo comparado com outros dos métodos de interpolação utilizados nesta área como é o caso da krigagem ou interpolação por vizinho mais próximo (também chamado, por vezes, método dos polígonos de influência). A sua formulação habitual é utilizando a potência de 2 , sendo neste caso denominado inverso da distância ponderada.

O modelo baseia-se na dependência espacial, isto é, supõe que quanto mais próximo estiver um ponto do outro, maior deverá ser a correlação entre seus valores. Desta forma atribui maior peso para as amostras mais próximas do que para as amostras mais distantes do ponto à ser interpolado. Assim o modelo consiste em se multiplicar os valores das amostras pelo inverso das suas respectivas distâncias ao ponto de referência para a interpolação dos valores. 


$$
z=\frac{\sum_{i=1}^{n} \frac{1}{d_{i}} z_{i}}{\sum_{i=1}^{n} \frac{1}{d_{i}}}
$$

em que, $\mathrm{z}=$ valores estimados;

$\mathrm{n}=$ número de amostras;

$\mathrm{Z}_{\mathrm{i}}=$ valores conhecidos;

$\mathrm{d}_{\mathrm{i}}=$ distâncias entre os valores conhecidos e estimados $\left(\mathrm{z}_{\mathrm{i}} \mathrm{e} \mathrm{z}\right)$.

A equação 1a pode ser adaptada para incluir uma potência para as distâncias, com isso pode-se atribuir pesos diferentes para a estimativa do valor de uma amostra para uma mesma distância.

$$
z=\frac{\sum_{i=1}^{n} \frac{1}{d_{i}^{P}} z_{i}}{\sum_{i=1}^{n} \frac{1}{d_{i}^{P}}}
$$

Observando-se a equação 2a verifica-se que foi adicionado uma potência "p" ao inverso das distâncias " $1 / \mathrm{d}_{\mathrm{i}}^{\mathrm{p}}$ ".

Com esta modificação na equação pode-se atribuir diferentes valores a potência "p", sendo que quanto maior for o valor desta potência maior será a influência do vizinho mais próximo na estimativa dos valores.

De acordo com a equação $2 \mathrm{a}$, quanto maior o valor de "p" maior será a influência dos pontos mais próximos, e com isso terão maior influência no resultado da interpolação. Quando se ajusta a opção Nearest Neighbors o software busca os vizinhos mais próximos, independente da distância, contudo nesta opção o valor de Interpolation cell size também tem influência no resultado da interpolação. 


\section{9 - Referências Bibliográficas}

Annan, A. P., 1986. Development of the PROSPECT I airborne electromagnetic system, in Palacky. G. J., Ed., Airborne resistivity mapping: Geol. Surv. Can. Paper 86-22, 63-70.

Annan, A. P., and Lockwood, R., 1991, An application of airborne GEOTEM in Australian conditions: Expl. Geophys., 22, 5-12.

Cull, J. P., 1993. Downhole three component TEM probes: Expl. Geophys., 24, $437-442$.

Dyck, A. V., and West, G. F., 1984, The role of simple computer models in interpretations of wide-band, drill-hole electromagnetic surveys in mineral exploration: Geophysics, 49, 957-980.

Fraser, D. C., 1972. A new multicoil aerial electromagnetic prospecting system: Geophysics, 37, 518-537.

Frischknecht, F. C., Labson, V. F., Spies, B. R., and Anderson, W. L., 1991, Profiling methods using small sources, in Nabighian M. N., Ed., Electromagnetic methods in applied geophysics, Vol. 2, Applications: Soc. Expl. Geophys. Investigations in geophysics, no. 3, 105-270.

Gettings, M. E. \& Houser, B. B. 1995. Preliminary results of modeling the gravity anomaly field in the upper San Pedro basin, southeast Arizona. U. S. Geological Survey Open-File Report 95-76, 9p.

Hodges, D. G., Crone, J. D., and Pemberton, R., 1991. A new multiple component downhole pulse EM probe for directional interpretation: Proc. 4th Int. MGLS/KEGS Sym. on Borehole Geophys. for Min. Geotech. and Groundwater Appl.

Hogg, R. L. S., 1986. The Aerodat multigeometry, broadband transient helicopter electromagnetic system, in Palacky. G. J., Ed., Airborne resistivity mapping: Geol. Surv. Can. Paper 86-22, 79-89. 
Hogg, S. \& Associates LTD, 2003, October. Technical Report, Airborne Magnetic and Electromagnetic Survey McFauld's Lake - Northestern Ontario Compilation and Interpretation Report.

Macnae, J. C., 1984, Survey design for multicomponent electromagnetic systems: Geophysics, 49, 265-273.

Macnae, J. C., Smith, R. S., Polzer, B. D., Lamontagne, Y., and Klinkert, P. S., 1991, Conductivity-depth imaging of airborne electromagnetic step-response data: Geophysics, 56, 102-114.

McCracken, K. G., Oristaglio, M. L., and Hohmann, G. W., 1986, Minimization of noise in electromagnetic exploration systems: Geophysics, 51, 819832.

Morrison, H. F., Phillips, R. J., and O’Brien, D. P., 1969, Quantitative interpretation of transient electromagnetic fields over a layered earth: Geophys. Prosp., 17, 82-101.

Nabighian M.N., Macnae J.M., 2005. Eletrical and EM methods 1980- 2005. SEG@75.

Newman, G. A., Anderson, W. L., Holmann, G. W., 1987. Interpretation of transient electromagnetic soundings over three-dimensional structures for the centralloop configuration. Geophys. J. R. astr. Soc 89, 889-914.

Palacky, G. J. \& West, G. F., 1973, Quantitative measurements of Input AEM measurements: Geophysics, 38, 1145-1158.

Palacky, G. J., \& West, G. F., 1991, Airborne electromagnetic methods, in Nabighian M. N., Ed., Electromagnetic methods in applied geophysics, Vol. 2, Applications: Soc. Expl. Geophys. Investigations in geophysics, no. 3, 811-879. 
Smith, R. S., Keating, P. B., 1996, The usefulness of multicomponent Time Domain Airbone Electromagnetic Measurements, Geophsics, VOL. 61, Nº 1 (January February 1996); P. 74-81, 17 FIGS. Sons, New York.

Spies, B. R., and Frischknecht, F. C., 1991, Electromagnetic sounding, in Nabighian M. N., Ed., Electromagnetic methods in applied geophysics, Vol. 2, Applications: Soc. Expl. Geophys. Investigations in geophysics, no. 3, 285-425.

Slattery, S.R. \& Andriashek, L.D., 2012, June. Technical Report - Overview of Airborne-Electromagnetic and - Magnetic Geophysical Data Collection Using the GEOTEM $^{\circledR}$ Survey near Drayton Valley, Central Alberta

Von Huelsen, M. G., 2007. Interpretação de Dados de Eletromagnetometria Aeroeletrotransportada (AEM) do Sistema GEOTEM (Domínio do Tempo). Tese de Doutorado n 080, Instituto de Geociências - Universidade de Brasília - UnB, 202 pp.

Wait, J. R., 1982, Geo-electromagnetism: Academic Press Inc. Zonge K. L., and Hughes, L. J., 1991, Controlled-source audiomagnetotellurics, in Nabighian M. N., Ed., Electromagnetic methods in applied geophysics, Vol. 2, Applications: Soc. Expl. Geophys. Investigations in geophysics, no 3. 713-809.

Travaglia Filho, 2012. Desenvolvimento e Implementação de Software para obtenção da Resistividade pela profundidade de dados TDEM. Universidade de Brasília - Instituto de Geociências . Dissertação de mestrado n ${ }^{0} 28$. 


\section{Conclusão da Tese}

Pode-se concluir no decorrer deste trabalho que o desenvolvimento de rotinas computacionais para o processamento de dados geofísicos é viável e de baixo custo, quando comparado ao custo das licenças de outros softwares que necessitam ser renovadas anualmente e possuem um número limite de unidades disponíveis, mesmo se tratando de uma versão acadêmica, além de promover o desenvolvimento da pesquisa acadêmica.

Logicamente não está em questão a robustez da capacidade de processamento, ou gráfica de programas conhecidos, contudo, coloca-se em questão a oportunidade de se desenvolver um produto nacional de qualidade que possa ser utilizado entre os estudantes, professores e pesquisadores com uma menor restrição.

A tese como um todo contempla o objetivo de apresentar uma contribuição, ao conhecimento em geociências por entregar uma ferramenta computacional endereçada ao Método Eletromagnético no Domínio do Tempo com algumas rotinas computacionais específicas e aplicar estas rotinas a dados sintéticos e reais, tanto para levantamentos terrestres e/ou aéreos.

Os resultados obtidos a partir dos dados sintéticos apresentados no capítulo 2 demonstram a capacidade do programa em retornar ao pesquisador uma resposta satisfatória na composição de modelagem 2D. A função RDI utilizando o interpolador por krigagem representa de forma nítida a divisão dos modelos de duas e três camadas, principalmente nas condições onde a primeira camada é predominantemente resistiva. Esta função apresenta de forma rápida e eficiente uma representação do alvo condutivo e seu posicionamento horizontal.

A região condutiva apresentada nas $R D I s$, nos perfis e nas seções das linhas de contorno da resistividade obtidos da região de Carajás (Capítulo 3, artigo2), mostram 
uma modelagem geofísica compatível com os estudos geológicos e com outros modelos obtidos na região. As duas linhas processadas e interpretadas pelo ImagEM apontam consonância com o dados brutos do campo eletromagnético secundário. Na linha -300 o ImagEM apresenta uma área rasa condutiva que representa a cobertura sedimentar condutiva bem como o minério disseminado mais profundo; e a modelagem da linha 1700 indica um pequeno alvo condutivo e profundo.

A transformada de Hilbert e o Envelope de Energia aplicado ao levantamento aerotransportado de múltiplas componentes, apresentados no último capítulo, são ferramentas úteis no auxílio da interpretação geológica e geofísica. Com a normalização do campo secundário foi possível estimar a profundidade e o mergulho do corpo alvo tomando como referência a região condutiva da seção confeccionada pela função $R D I$ utilizando a interpolação por $I D W$. A $R D I$ apresenta um corpo totalmente verticalizado, contudo a utilização do envelope e das componentes mostra uma pequena variação do ângulo de mergulho do corpo. Esta função se destaca por utilizar as três componentes e fornecer maior detalhe para a modelagem do alvo.

Pretende-se, em trabalhos futuros, desenvolver novas ferramentas computacionais que serão incrementadas ao ImagEM, como o interpolador 3D para dados terrestres e aéreos, a modelagem 3D com os parâmetros de saída da função Energy Envelope, dentre outras. 